\title{
Clave ilustrada para la identificación de los estomatópodos (Crustacea: Hoplocarida) del Pacífico oriental
}

\author{
An illustrated key to the identification of eastern Pacific stomatopods (Crustacea: \\ Hoplocarida)
}

\author{
José Salgado-Barragán* y Michel E. Hendrickx \\ Unidad Académica Mazatlán, Instituto de Ciencias del Mar y Limnología, Universidad Nacional Autónoma de México. Apartado postal 811 , 82000 \\ Mazatlán, Sinaloa, México. \\ *Correspondencia: salgado@ola.icmyl.unam.mx
}

\begin{abstract}
Resumen. Las 53 especies y subespecies de estomatópodos del Pacífico oriental conocidas hasta la fecha pertenecen a 5 superfamilias, 11 familias y 22 géneros. Varias de estas especies solamente se conocen a partir de un ejemplar o una pequeña serie de ejemplares que sirvieron para la descripción original. En estos casos, la falta de material adicional para completar el estudio de las especies, así como la ausencia de muestras procedentes de otras localidades que permitirían tener una visión global de la distribución del grupo a lo largo del Pacífico americano han complicado considerablemente su estudio; consecuentemente, no siempre se logran identificaciones correctas de las especies. Con la finalidad de facilitar su identificación y coadyuvar a incrementar su conocimiento en todos los aspectos posibles, se presenta una clave taxonómica ilustrada de las superfamilias, familias, géneros y especies de estomatópodos registrados en aguas del Pacífico americano.
\end{abstract}

Palabras clave: clave ilustrada, estomatópodos, Pacífico oriental.

\begin{abstract}
The 53 species and subspecies of stomatopods known to date for the eastern Pacific belong to 5 superfamilies, 11 families and 22 genera. Several species are known only from the original description, including only one or a few specimens. In these cases, the lack of voucher specimens to complete the study of other species and the absence of samples from throughout the range of each species, which will allow to have a general idea of their distribution along the Pacific, have made their study complicated. Consequently, correct identifications of specimens are not always achieved. An illustrated key to superfamilies, families, genera and species of all species recorded for the American Pacific is presented, with the objective of facilitating species identification to increase the amount of reliable information available on the group in the region.
\end{abstract}

Key words: illustrated key, stomatopods, eastern Pacific.

\section{Introducción}

Los estomatópodos (orden Stomatopoda) forman un grupo relativamente pequeño dentro de la clase Crustacea. Constituyen el único orden viviente dentro del superorden Hoplocarida, con aproximadamente 450 especies de hábitos depredadores activos que se distribuyen en ambientes marinos, y en ocasiones estuarinos, de las regiones tropicales, subtropicales y templadas, a profundidades que van desde la zona intermareal hasta los $1000 \mathrm{~m}$, lo que los convierte en un componente importante dentro de los ecosistemas bentónicos marinos (Manning, 1995).

Entre las características que permiten separar los estomatópodos del resto de los malacostracos destacan

Recibido: 04 febrero 2010; aceptado: 21 junio 2010 la presencia de ojos con omatidias especializadas para la percepción de las formas, los colores y el movimiento, un par de anténulas trirrámeas terminadas en 3 flagelos cortos, cuerpo deprimido dorsoventralmente con un caparazón corto, de forma semicóncava que no alcanza a cubrir toda el área anterior ni todos los segmentos torácicos, por lo que los segmentos $5^{\circ}$ al $8^{\circ}$ pueden verse dorsalmente; abdomen bien desarrollado; los primeros 5 segmentos cuentan con pleópodos birrámeos, aplanados y equipados con branquias en el exopodio, el sexto somito abdominal lleva los uropoditos y un telson aplanado, en muchas ocasiones ornamentado con carinas o espinas (Fig. 1). Las estructuras corporales de los estomatópodos suelen tener características únicas que reflejan las afinidades filogenéticas entre los organismos, lo que permite identificarlos de manera relativamente sencilla y conlleva a la elaboración de claves taxonómicas "naturales" a 


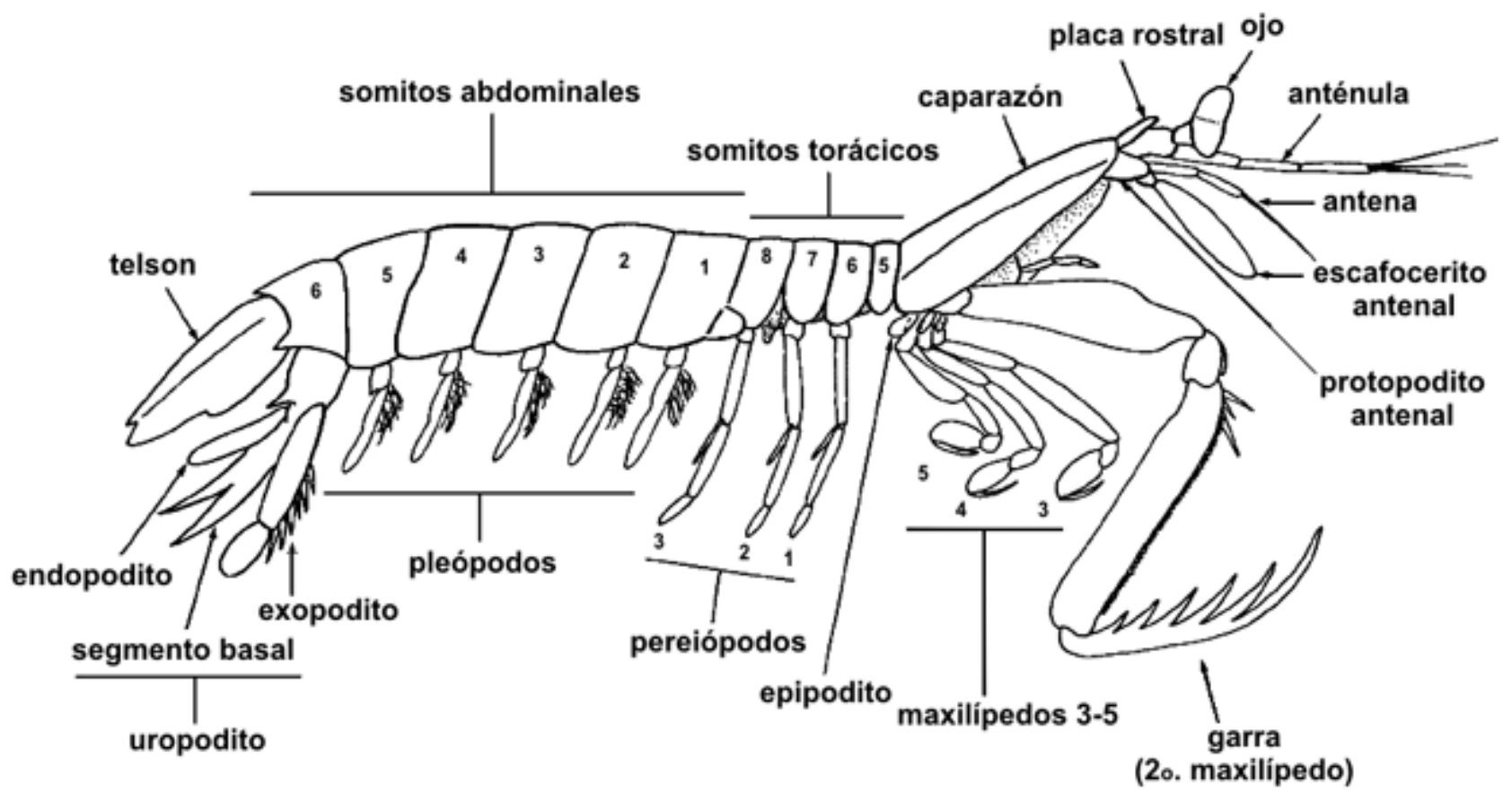

Figura 1. Morfología externa de un estomatópodo.

nivel de familia y, en no pocas ocasiones, hasta género y especie (Fig. 1).

Tal vez lo que mejor distingue a estos organismos es la forma de sus apéndices torácicos, denominados maxilípedos, que le sirven para la depredación y para sujetar la presa durante la alimentación. Tienen una forma subquelada, sin exopodios y están ubicados alrededor de la boca, de ahí el nombre del grupo (gr. stomatos = boca; poda $=$ pies). De estos maxilípedos, el segundo sobresale en tamaño, desarrollo y capacidad de movimiento. Comunmente se denominan "garras"; el segundo par está mucho más desarrollado que el resto y es la principal arma con que cuentan los estomatópodos para capturar a sus presas. Se considera que la musculatura abdominal les permite desarrollar altas velocidades de proyección de este apéndice, de tal modo, que en una fracción de segundo pueden atrapar o golpear a su presa sin darle tiempo de reaccionar.

Aunque con variantes, las garras de los estomatópodos tienen 2 formas básicas que determinan la selección de las presas y la estrategia de ataque; la de tipo "arponeador" y la de tipo "triturador". En el tipo arponeador, el propodio generalmente tiene un margen interno aserrado con pequeños dientecillos de tamaño uniforme (pectinado) o con espinas erectas y un dactilo con dientes largos, muchas veces aserrados en su superficie y apreciables bajo el microscopio, los que le permiten perforar el cuerpo de sus presas, generalmente blando, y sujetarlas firmemente. Se ha observado que en ocasiones el movimiento de proyección y retraimiento de la garra es tan rápido que ésta funciona como una guillotina que corta la presa (Fig. 2).

La garra tipo triturador por lo general es una garra fuerte, no pectinada o con escasos dientecillos en el propodio, mientras que el dactilo suele ser engrosado en su parte proximal y en la mayoría de los casos consta de un sólo diente terminal (Fig. 3). Con este tipo de garra, el estomatópodo proyecta el propodio hacia adelante con el dactilo plegado, para golpear el cuerpo de sus presas, generalmente duro o protegido con conchas, como cangrejos o moluscos, hasta destrozarlas o inmovilizarlas para después consumirlas. Este tipo de garra también puede ser utilizado a manera de puñal; en esta forma, el organismo proyecta la garra hacia adelante y perfora el cuerpo de la presa con el dactilo, como si usara una daga o espada (Caldwell y Dingle, 1976).

La fauna del Pacífico oriental. El conocimiento de las especies de estomatópodos de la región del Pacífico americano se remonta a mediados y fines del siglo XIX, con la descripción de algunas especies; sin embargo, fue hasta 1894 cuando Bigelow presentó el primer estudio de estomatópodos recolectados entre 1885 y 1891 en ambas costas del continente a bordo del vapor "Albatross" . Incluía 9 especies obtenidas en la porción occidental (Bigelow, 1894). 


\section{Garra de tipo "arponeador"}

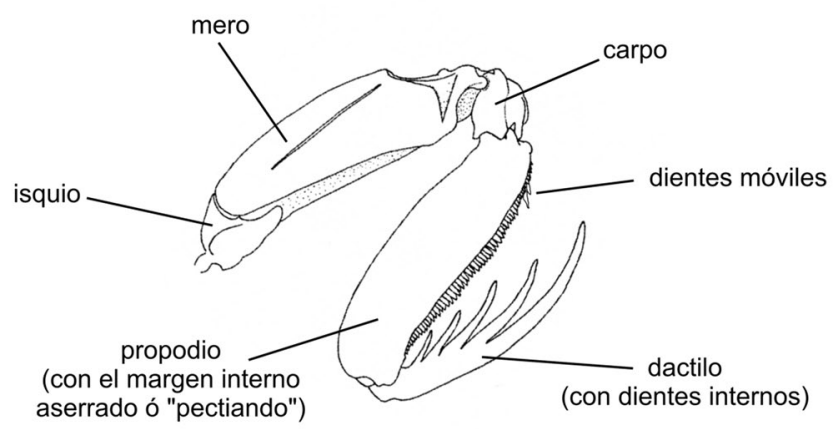

\section{captura de una presa}
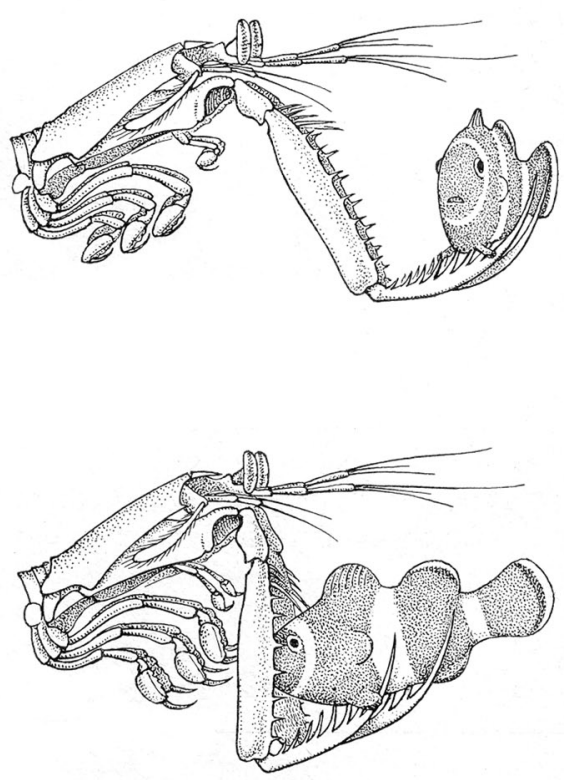

movimiento para golpear

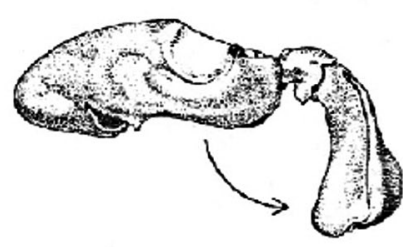

movimiento para perforar

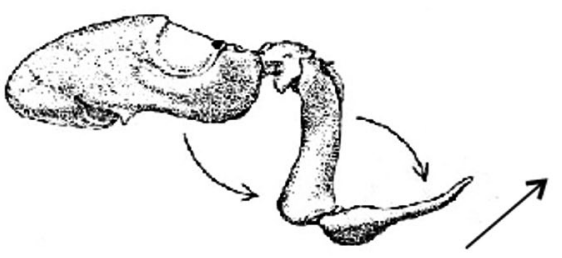

Figura 3. Garra tipo triturador.

Para 1940, a través de las expediciones de la Allan Hancock Foundation en el Pacífico (1933-1938), la cifra llegó a 29 especies y subespecies, agrupadas en 6 géneros (Schmitt, 1940). Posteriormente, y debido a una serie de trabajos de descripción y redescripción de nuevas especies, la cifra fue en aumento a la vez que la taxonomía del grupo se modificó.

En 1980, Reaka y Manning publicaron un análisis sobre la ecología de la distribución y de las relaciones geográficas de las 20 especies conocidas para la costa del Pacífico de Costa Rica. Incluía un listado de 18 géneros con 50 especies y subespecies distribuidas a lo largo del Pacífico americano (Reaka y Manning, 1980).

La monografía de los estomatópodos del Pacífico mexicano, elaborada por Hendrickx y Salgado-Barragán 
(1991), retomaba los avances realizados en la sistemática del grupo hasta finales de los años 80 con la inclusión de una nueva especie en las costas del golfo de California. Desde entonces se han propuesto muchos cambios en la secuencia taxonómica del grupo, particularmente por Manning (1995) y Ahyong y Harling (2000), por lo que actualmente se reconocen 7 superfamilias y 19 familias distribuidas en aguas tropicales, subtropicales y templadas alrededor del mundo. A partir de esta información, Hendrickx y SalgadoBarragán (2002) presentaron un documento sobre fauna de estomatópodos en aguas mexicanas, tanto del Pacífico como del Atlántico y Caribe, que también considera los trabajos publicados después de 1989 sobre la fauna del Pacífico americano. De acuerdo con este trabajo, se reconocían 5 superfamilias, 10 familias, 17 géneros y 52 especies con representantes en aguas del Pacífico americano a lo que se agrega el descubrimiento de 1 ejemplar de Odontodactylus hawaiiensis Manning, 1967 (Odontodactylidae) en la isla Salas y Gómez, Chile (Retamal, 2002); así, a la fecha se ha identificado un total de 5 superfamilias, 11 familias y 53 especies de estomatópodos en aguas del Pacífico de América.

Según Hendrickx y Salgado-Barragán (2002), entre 1991 y 2000 se publicaron 26 trabajos sobre la fauna de estomatópodos del Pacífico mexicano y para Latinoamérica se han hecho importantes contribuciones con listados faunísticos más amplios que incluyen decápodos y estomatópodos. Sin embargo, se conoce muy poco material publicado exclusivamente sobre este grupo; se pueden destacar los trabajos de Guzmán (2002) en las costas de Chile, de Murillo-Bohórquez y Álvarez-León (2004) para el Pacífico colombiano y Vargas (2009) en aguas de Costa Rica.

La presente contribución tiene como propósito ayudar al estudiante o investigador a la correcta identificación de las especies de estomatópodos del Pacífico americano mediante una clave ilustrada. Más allá de las consideraciones ecológicas, fisiológicas o filogenéticas del grupo, en esta guía se pretende apoyar al investigador en el reconocimiento de la morfología de los estomatópodos de la región del Pacífico oriental, haciendo énfasis en aquellas características que permitan reconocer fácilmente las especies.

Con la idea de que este documento debe ser accesible a cualquierinteresado y no sóloa especialistas en carcinología, ha sido ampliamente ilustrado con dibujos originales o con el apoyo de imágenes que pueden encontrarse en la literatura especializada en el tema. Además de las figuras generales que se presentan en esta introducción, el lector podrá encontrar una serie de imágenes que indican la ubicación y la forma de las estructuras que se mencionan a lo largo de la guía.
Como resultado de la adaptación de los términos en latín o por la adopción de vocablos en inglés o anglicismos, la nomenclatura de las diferentes secciones del cuerpo de un crustáceo y la de sus apéndices y artejos no se ha presentado de manera uniforme en la literatura en español; por ejemplo, un apéndice localizado en el pleón ha sido denominado pleopodito, pleopodio o pleópodo, lo que ha provocado confusión entre los estudiantes de carcinología.

En este trabajo, para designar las estructuras de los estomatópodos se utilizará la nomenclatura empleada por Zariquiey-Álvarez (1968) para los decápodos ibéricos, y se adapta la terminología de Manning (1969) para nombrar las carinas y estructuras en segmentos y apéndices de los estomatópodos (Fig. 4).

Como información adicional, en cada especie se agregan datos sobre su intervalo de distribución geográfica o localidad de colecta única (de ser el caso), la longitud máxima registrada para la especie, su intervalo de distribución batimétrica y los substratos donde se ha recolectado. 

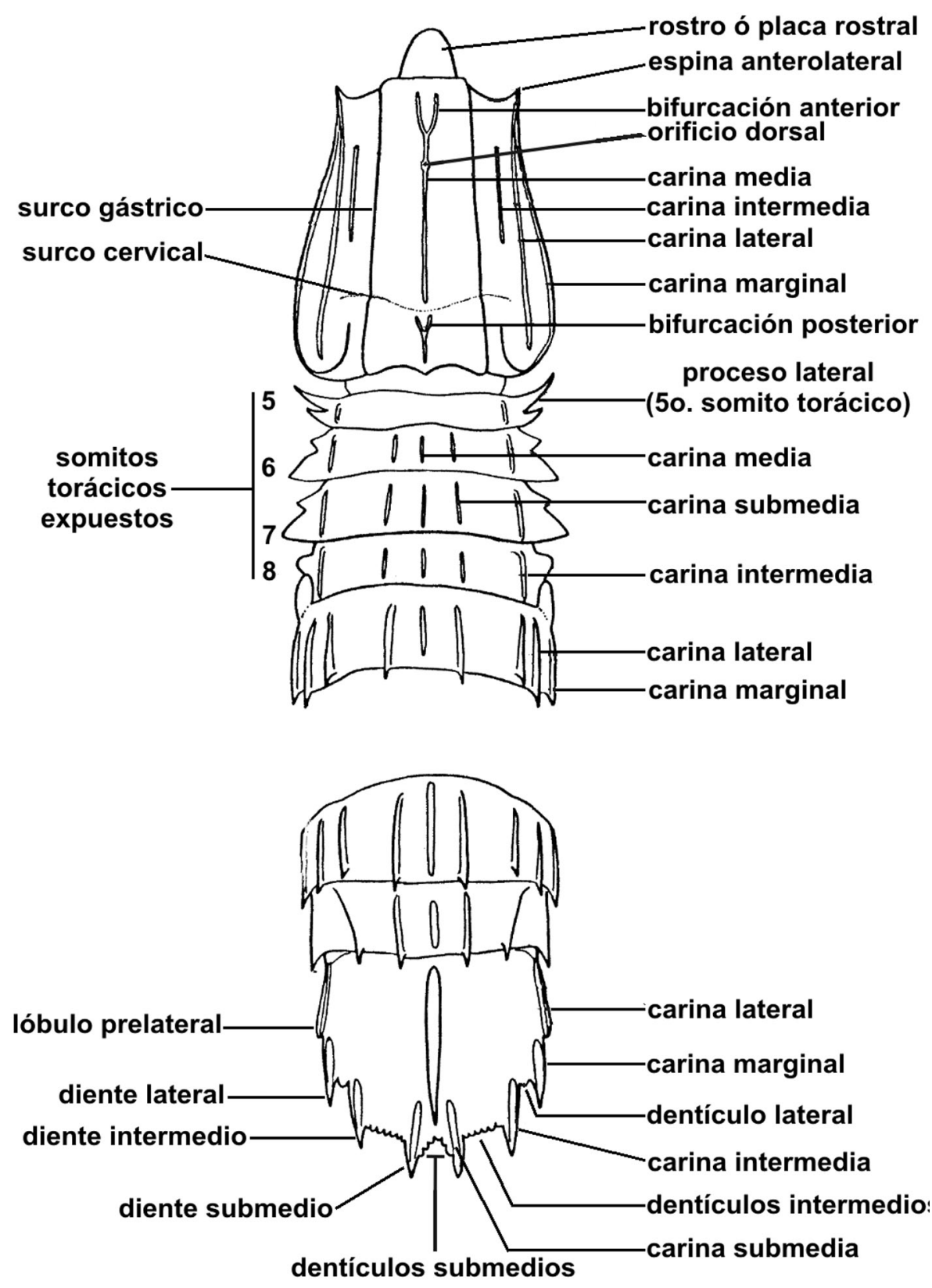

Figura 4. Nomeclatura de los segmentos, carinas y surcos dorsales del cuerpo de un estomatópodo.

Resultados

Clave de identificación de las superfamilias

1a. Propodio del $3^{\circ}$ y $4^{\circ}$ maxilípedos más ancho que largo, con pequeños glóbulos o costillas que lo adornan centralmente (Fig. 5) 
1b. Propodio del $3^{\circ}$ y $4^{\circ}$ maxilípedos alargado, sin pliegues o costillas ventrales (Fig. 6) . .3

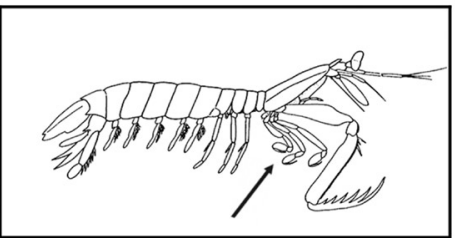

Fig. 5

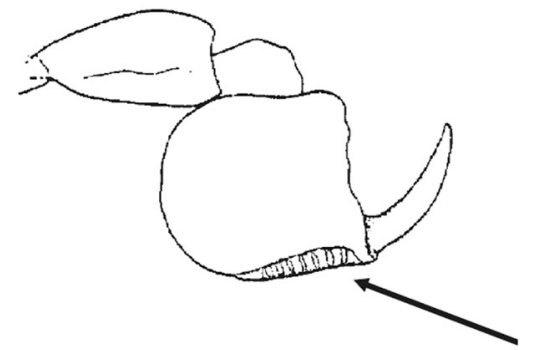

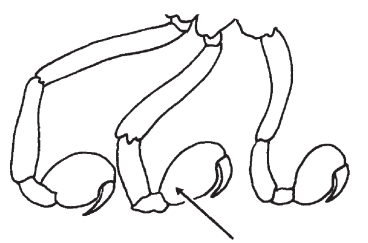

Fig. 6

2a. Telson sin carina media dorsal bien definida, cuando mucho presenta una elevación media más bien gruesa (Fig. 7). Lysiosquilloidea

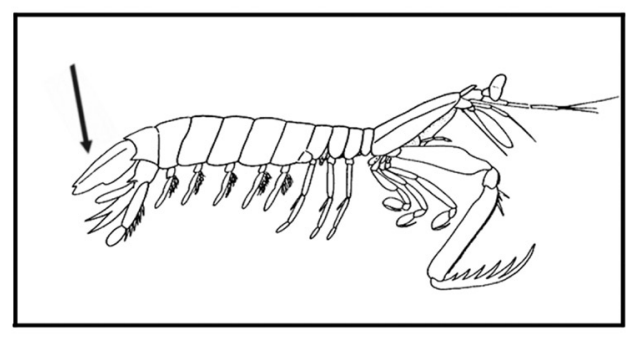

2b. Telson con carina media dorsal afilada (Fig. 8)

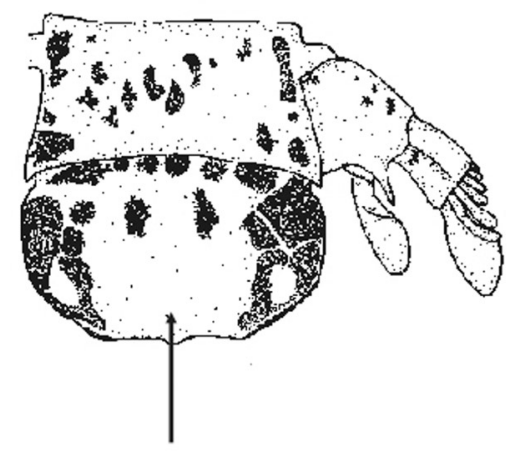

telson sin carina media dorsal

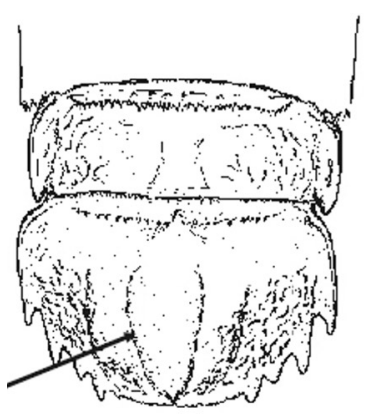

elevacion meaia aorsaı

.................... Erythrosquilloidea (no presente en el Pacífico oriental)

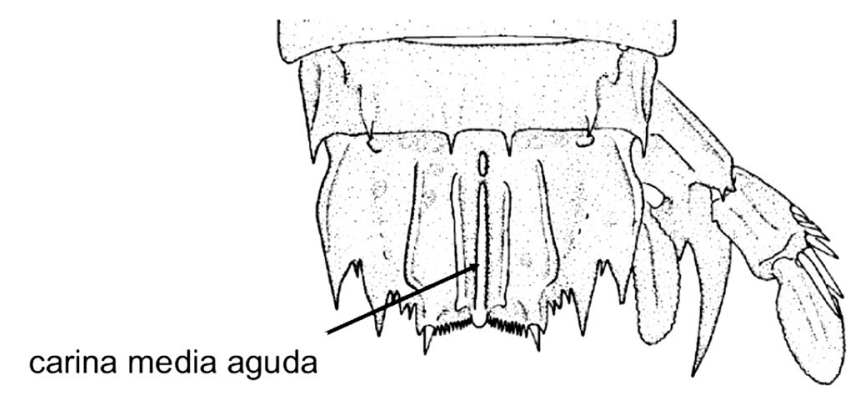

3a. Todos los dientes marginales del telson presentan ápices móviles

.Bathysquilloidea (no presente en el Pacífico oriental) (Fig. 9)

3b. Cuando mucho, los dientes submedios del telson presentan ápices móviles (Fig. 10) ...... 


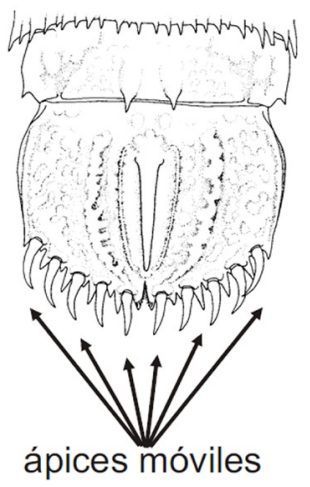

Fig. 9

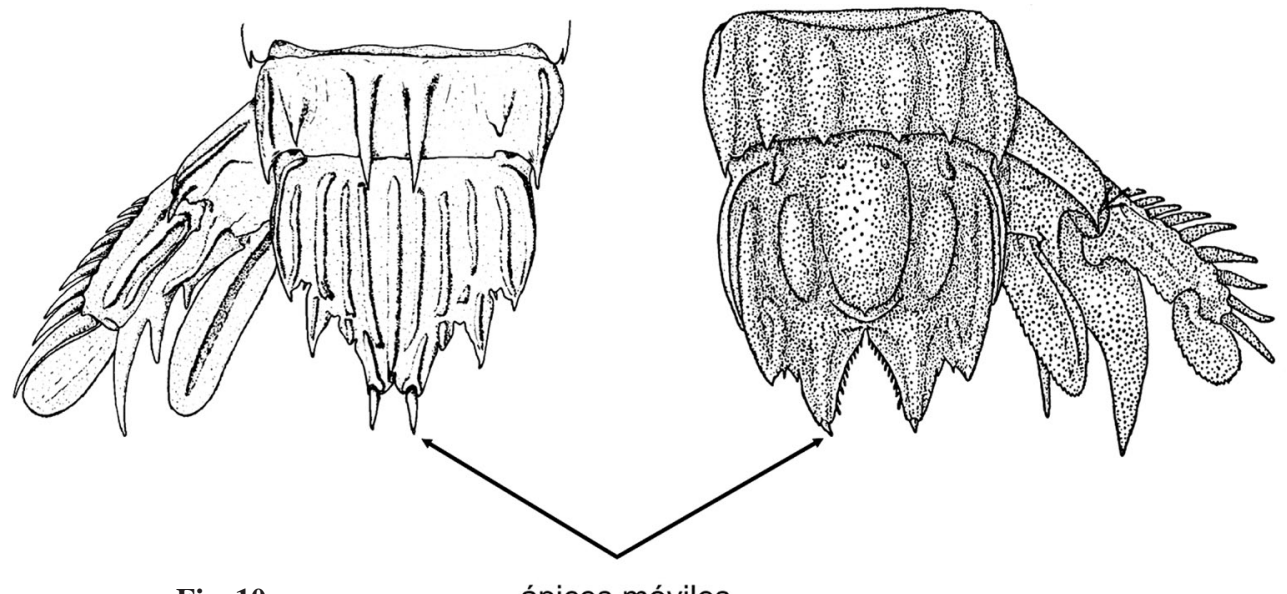

Fig. 10

ápices móviles

4a. Telson con 4 o más dentículos intermedios (Fig. 11) Squilloidea
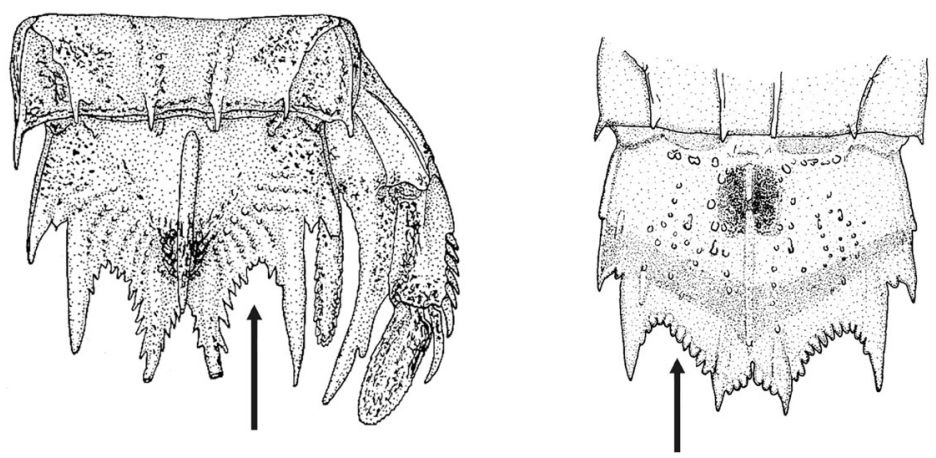

4b. No más de 3 dentículos, generalmente 2 intermedios en el telson (Fig. 12) 5
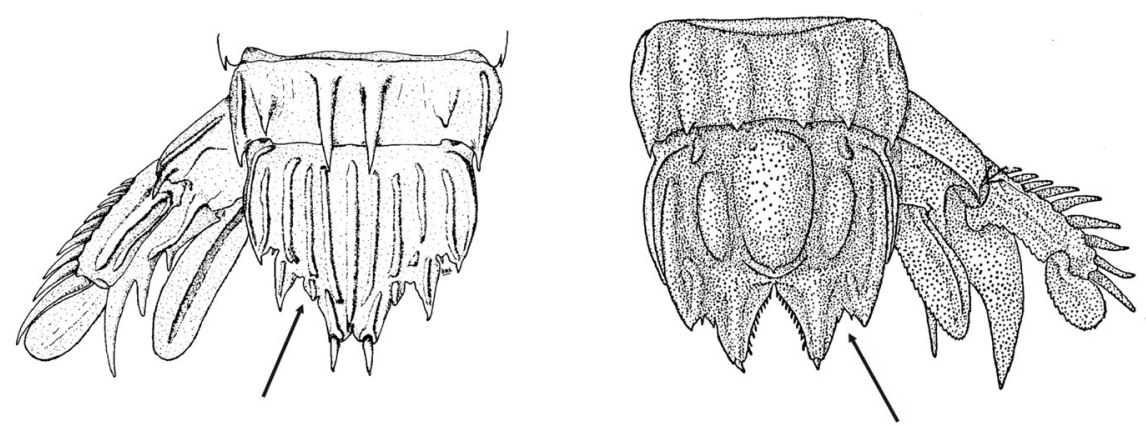

5a. Cuerpo deprimido, no compacto (Fig. 13A). Dactilo de la garra generalmente esbelto, con 4 o más dientes bien desarrollados (Fig. 13B) Eurysquilloidea
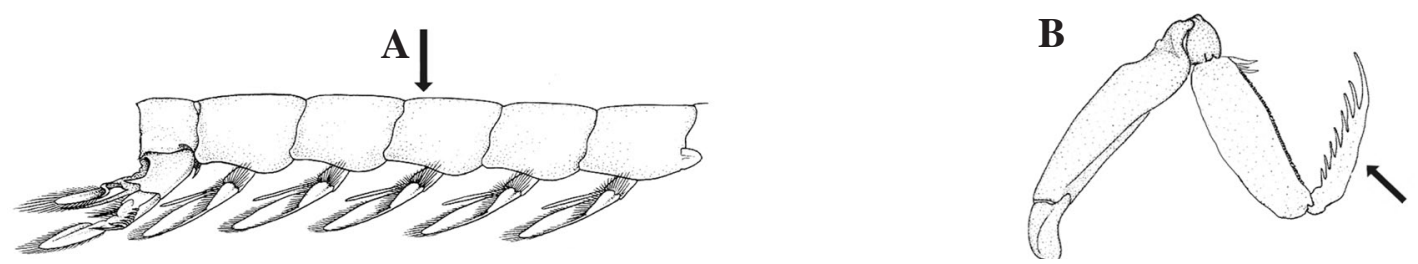
5b. Cuerpo compacto, subcilíndrico y fuertemente convexo (Fig. 14A). En muchas de las especies el dactilo de la garra aparece abultado en su base (Fig. 14B), como máximo con 3 dientes (Fig. 14C)
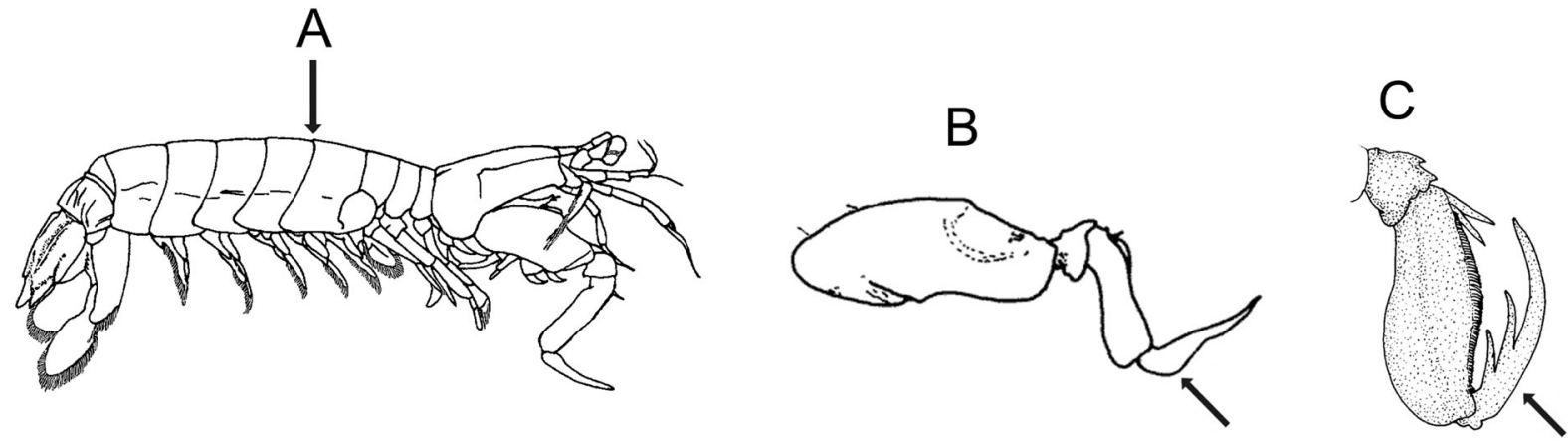

6a. Córnea del ojo bilobulada, pero asimétrica, con el lóbulo externo más grande que el interno (Fig. 15A). Protopodito antenal no tiene espina o placa dorsal (Fig. 15B). Prolongación basal del uropodito con 3 espinas primarias en el margen interno (Fig. 15C) Parasquilloidea

6b. Córnea del ojo subglobular o simétricamente bilobulada (Fig. 16A). Protopodito antenal con una espina o placa de forma variable en posición dorsal (Fig. 16B). Prolongación basal del uropodito con 1 o 2 espinas primarias en su margen interno (Fig. 16C)
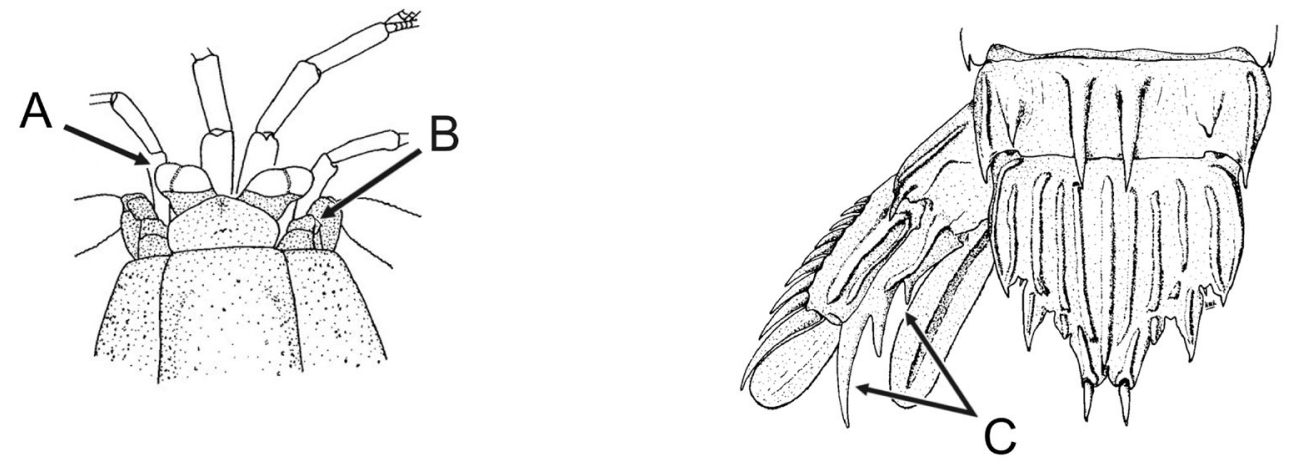

Gonodactyloidea
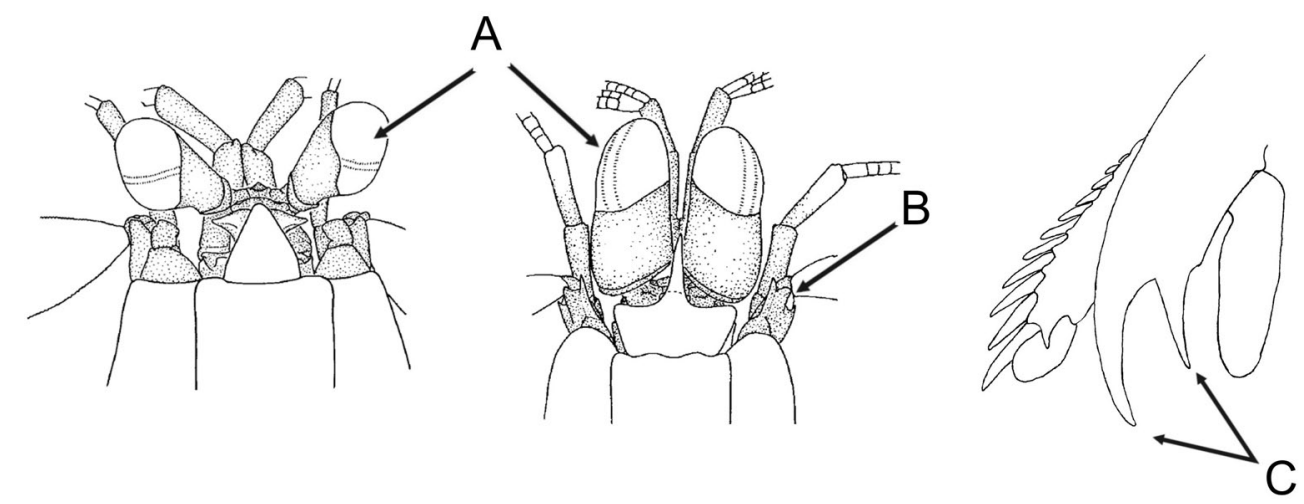
Superfamilia Eurysquilloidea Manning, 1977

La superfamilia Eurysquilloidea se asemeja a la superfamilia Gonodactyloidea porque sus especies presentan el propodio de los maxilípedos 3 y 4 ovalado, no hinchado ni adornado ventralmente (Fig. 17A), telson con una carina media dorsal evidente y hasta 2 dentículos intermedios en cada lado (Fig. 17B). Se diferencian de este grupo y de los Parasquilloidea porque el cuerpo es deprimido o aplanado y no subcilíndrico y porque los dentículos externos del telson, tanto los intermedios como los laterales, están por arriba de la superficie ventral (Fig. 17F). A su vez, difieren de los Gonodactyloidea por carecer de espina o placa dorsal articulada en el protopodito antenal (Fig. 17D) y por presentar omatidias hexagonales en la banda media de los ojos (Fig. 17E). Se distinguen de los Parasquilloidea por tener más de 3 dientes en el dactilo de la garra (Fig. 17C) y 2 en lugar de 3 espinas primarias terminales en la prolongación basal del uropodito. No confundir con las que pueden aparecer en el margen interno de esa estructura (Fig. 17G).
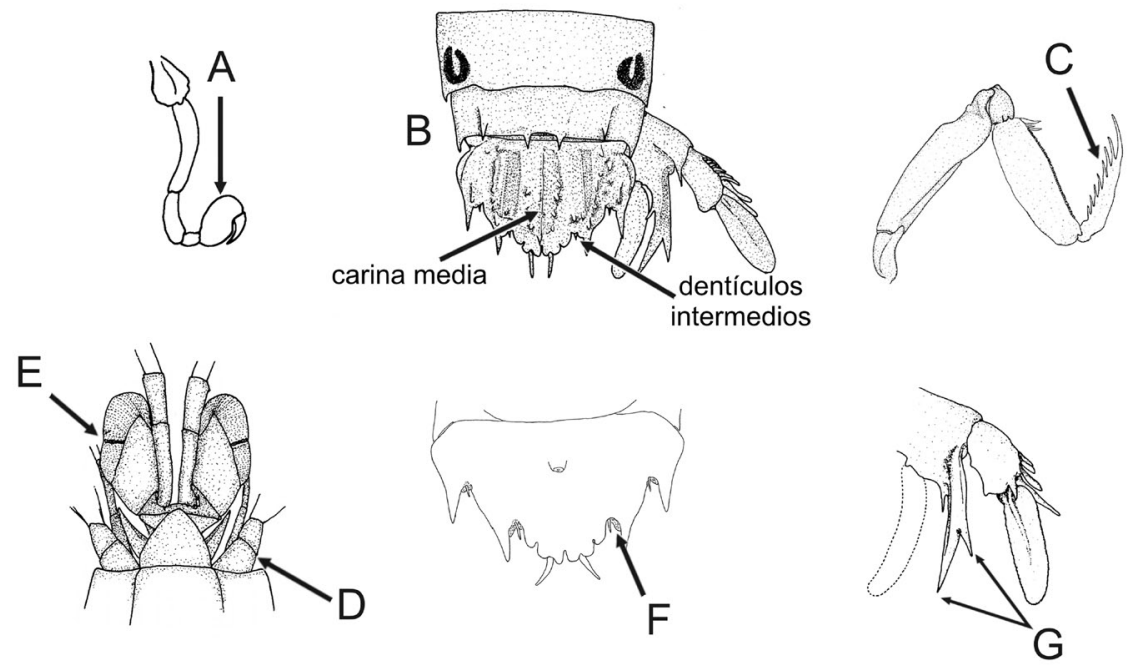

Especies de Eurysquilloidea del Pacifico oriental.

Eurysquilla pumae Hendrickx y Salgado-Barragán, 1987;

Eurysquilla solari Manning, 1970;

Eurysquilla veleronis (Schmitt, 1940).

Familia Eurysquillidae Manning, 1977

Las especies del género Eurysquilla son de talla mediana (50-100 mm). Se diferencian del resto de los géneros de Eurysquillidae por tener una placa rostral triangular o subtriangular, con la porción anterior incluso aguda, pero sin espina distal (Fig. 18A). Otras características que sí comparte con otros géneros de esta familia son: garra con el propodio pectinado a todo lo largo (Fig. 18B), el dactilo con 5 o más dientes (Fig. 18C), sexto somito abdominal con 6 o más espinas posteriores (Fig. 18D) y prolongación basal del uropodito con la espina interna más larga que la externa (Fig. 18E).
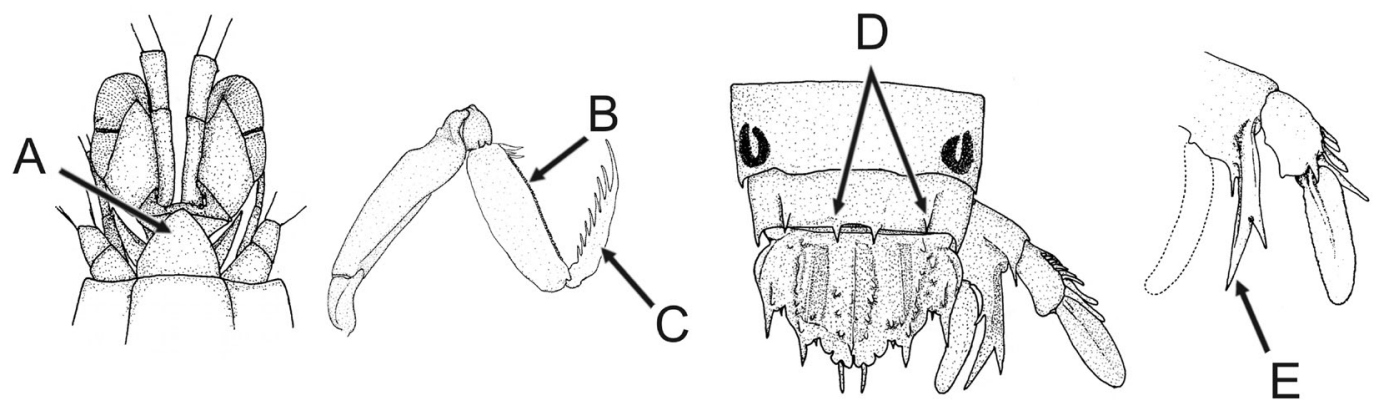
Clave para la identificación de las especies de Eurysquillidae

1a. Córnea de los ojos no bilobulada, oblicua con respecto al pedúnculo (Fig. 19A). Proceso antenular relativamente corto, alcanzando el margen anterior de las escamas oculares (Fig. 19B). Telson con un sólo par de carinas dorsales además de la carina media (Fig. 19C) Eurysquilla pumae (Sonora, golfo de California; $34 \mathrm{~mm}$; 34-37 m; arena).
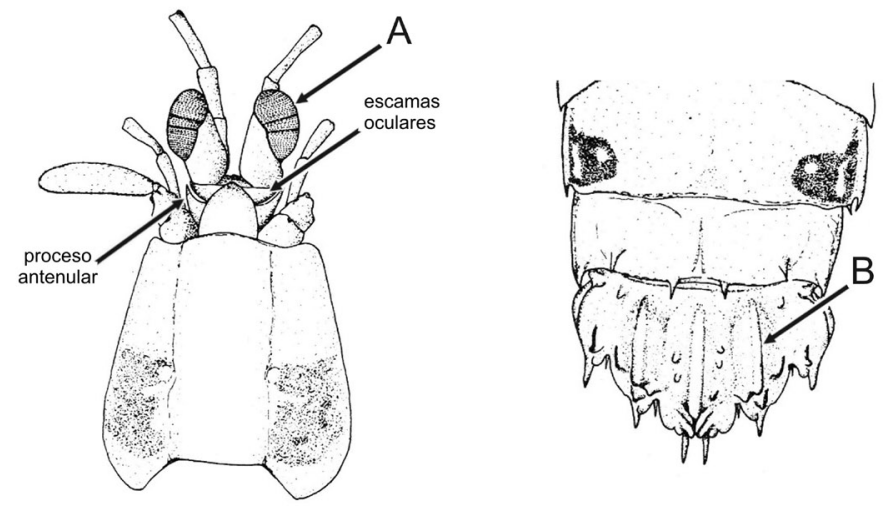

1b. Córnea de los ojos bilobulada, oblicua con respecto al pedúnculo (Fig. 20A). Punta del proceso antenular ubicada en posición anterior, a la altura de las escamas oculares. Telson con 2- 3 pares de carinas dorsales (Fig. 20B)
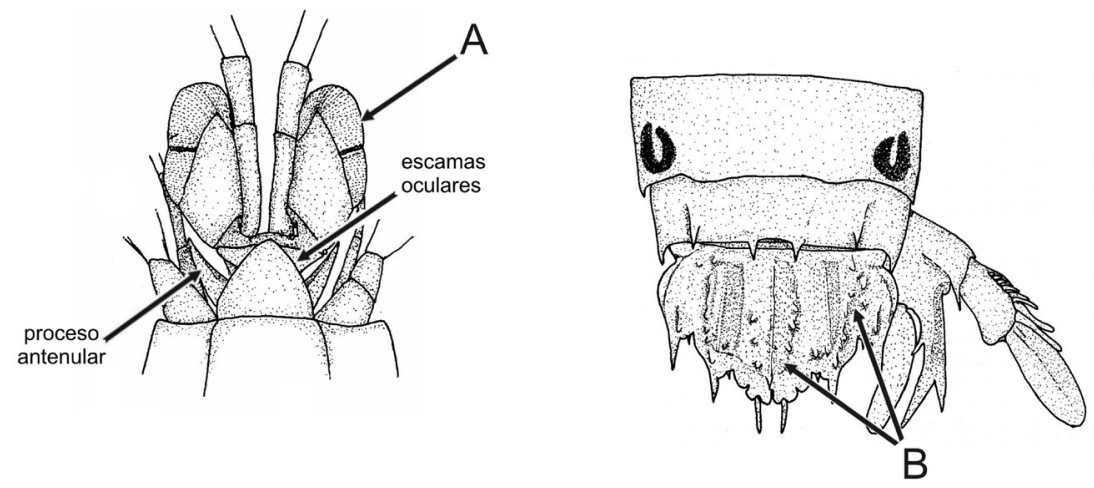

2a. Placa rostral triangular terminada en un ápice agudo, no en forma de espina (Fig. 21A). Prolongación basal del uropodito con sólo 2 espinas distales, porción ventral no armada (Fig. 21B)

Eurysquilla solari (Perú; $47 \mathrm{~mm} ; 160 \mathrm{~m}$; arena fina).
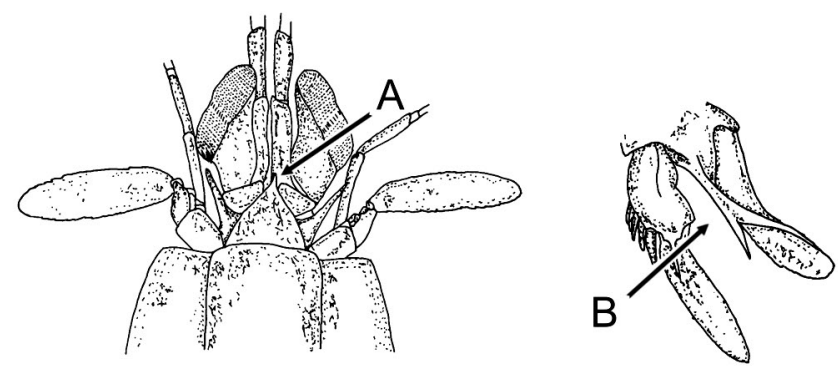
2b. Placa rostral triangular (Fig. 22A). Prolongación basal del uropodito con 2 espinas distales, una espina en la porción ventral (Fig. 22B) Eurysquilla veleronis (golfo de California - Colombia; 44 mm; 29-118 m; arena?).
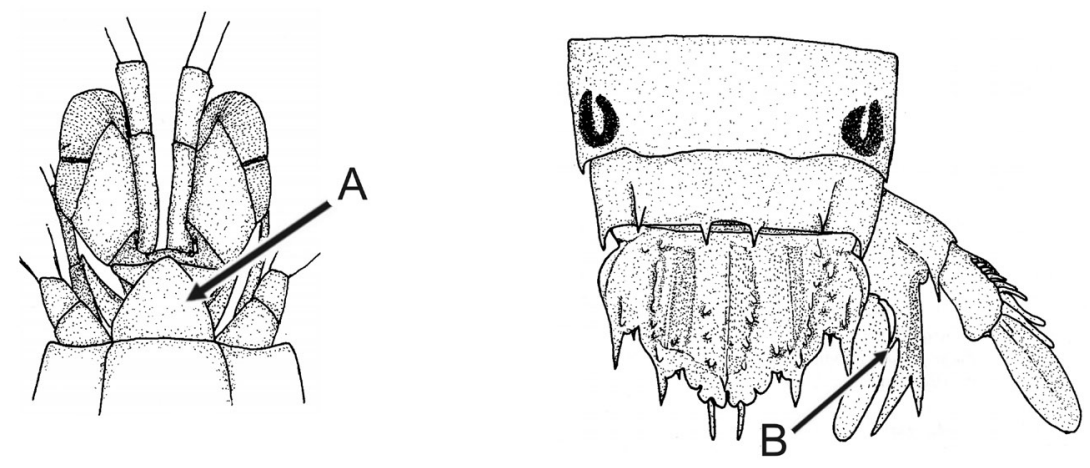

Superfamilia Parasquilloidea Manning, 1995

Familia Parasquillidae Manning, 1995

La superfamilia Parasquilloidea contiene únicamente la familia Parasquillidae con 3 géneros, Faughnia, Parasquilla y Pseudosquillopsis, de los cuales los 2 últimos contienen especies en el Pacífico oriental.

A diferencia de los Gonodactyloidea, los miembros de esta familia tienen la córnea bilobulada, el lóbulo externo más grande que el interno y 2 o 3 bandas de omatidias hexagonales en su parte central (Fig. 23A), el protopodito antenal desprovisto de placa o espina dorsal (Fig. 23B), las garras de tipo arponeador con una articulación isquiomeral terminal (Fig. 23C) y la prolongación basal del uropodito con 3 espinas primarias en lugar de 2 (Fig. 23D). Difieren de los Eurysquilloidea también porque la prolongación basal del uropodito tiene 3 espinas primarias en lugar de 2 (Fig. 23D), por presentar el cuerpo compacto y subcilíndrico y el dactilo de la garra con 3 dientes (Fig. 23E).

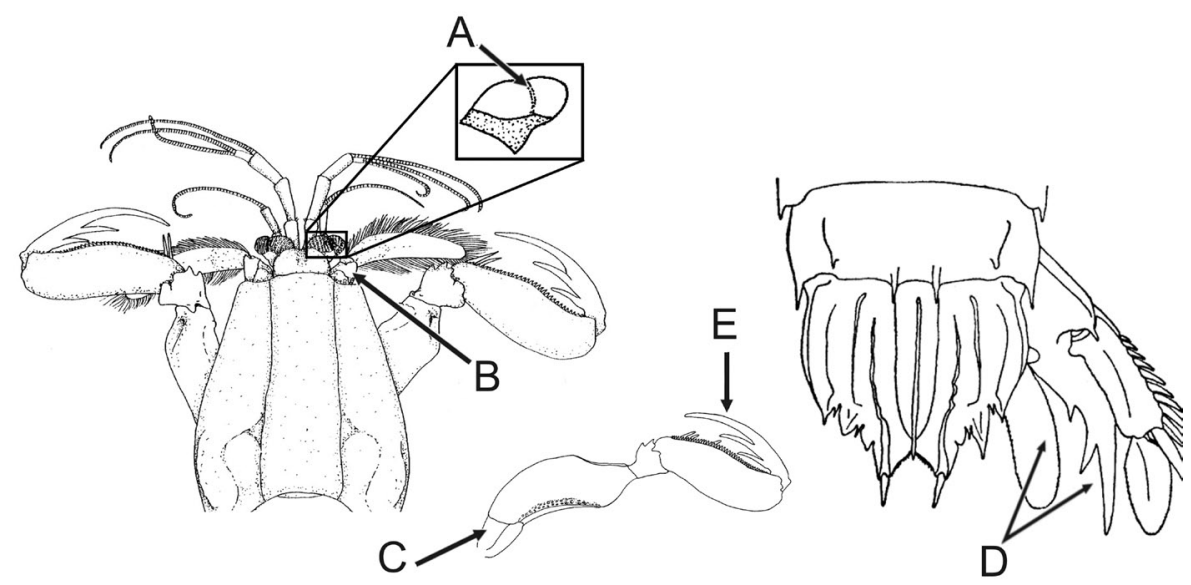

Especies de Parasquilloidea del Pacifico oriental.

Parasquilla similis Manning, 1970;

Pseudosquillopsis marmorata (Lockington, 1877);

Pseudosquillopsis lessonii (Guérin, 1830) 
Clave para la identificación de las especies de Parasquillidae

1a. Placa rostral más ancha que larga, un tanto deprimida longitudinalmente (Fig. 24A). Abdomen con carinas longitudinales, telson con dentículos submedios (Fig. 24B) y sin carinas longitudinales, excepto por la presencia de la carina media (Fig. 24C) (Parasquilla) Parasquilla similis (golfo de California - Perú; 160 mm; 73-125 m; lodo, arena limosa).
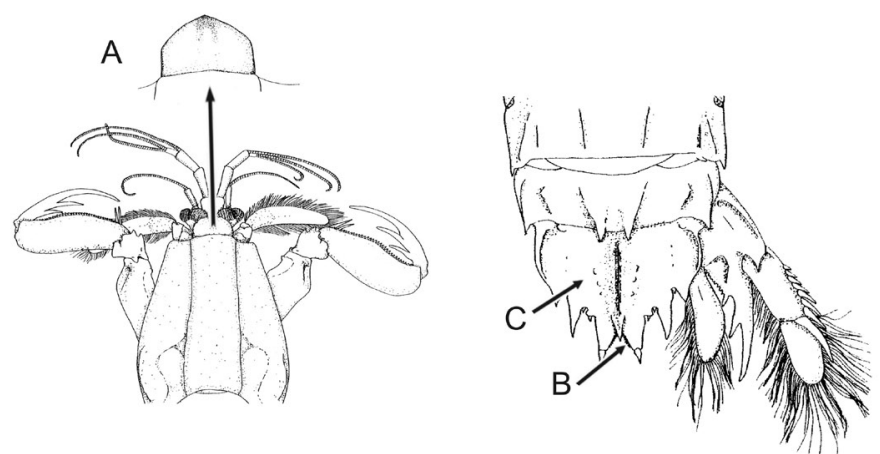

1b. Placa rostral más larga que ancha y terminada en 1 espina apical (Fig. 25A). Abdomen sin carinas longitudinales, excepto en el sexto somito, telson sin dentículos submedios (Fig. 25B) y con carinas longitudinales paralelas a la carina media (Fig. 25C) (Pseudosquillopsis)
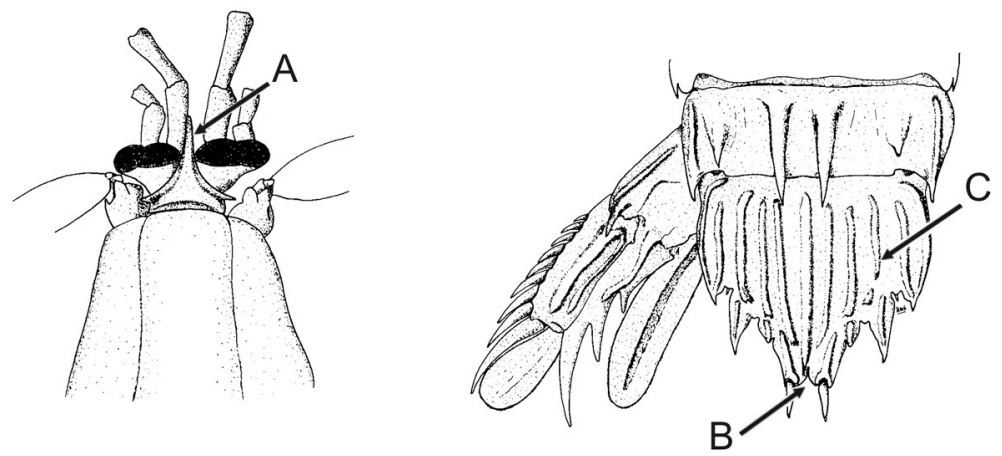

2a. Somitos torácicos 6 y 7 con 1 espina posterolateral (Fig. 26)

Pseudosquillopsis marmorata (California - golfo de California; $124 \mathrm{~mm}$; 0-99 m; lodo, arena, rocas). 


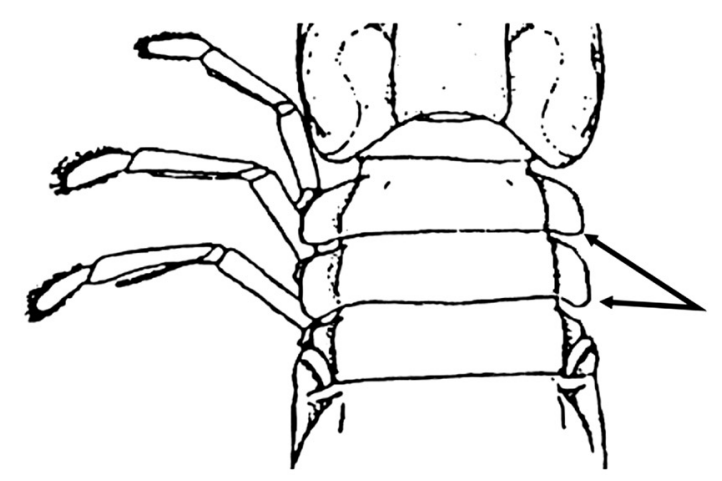

Superfamilia Gonodactyloidea Giesbrecht, 1910

Las especies de Gonodactyloidea en el Pacífico oriental está conformada por 4 familias: Gonodactylidae, Pseudosquillidae, Hemisquillidae y Odontodactylidae. Se caracterizan por tener la córnea con una banda media compuesta por 6 hileras de omatidias rectangulares (Fig. 28A), los maxilípedos 3 y 4 con el propodio ovalado, sin tubérculos o costillas ventrales (Fig. 28B), el cuerpo subcilíndrico con articulaciones compactas (Fig. 28C), la garra con la articulación isquiomeral (entre el isquium y el mero) terminal o subterminal (Fig. 28D) y el dactilo hinchado o esbelto en su base con 1-3 dientes, incluyendo el terminal (Fig. 28E). También poseen un telson con la carina media bien definida (Fig. 28F), los dientes submedios con ápices móviles y hasta 3 dentículos intermedios (Fig. 28G), los uropoditos con 1-2 espinas primarias en el protopodito (Fig. 28H) y la articulación de los exopodios terminal o subterminal (Fig. 28I).
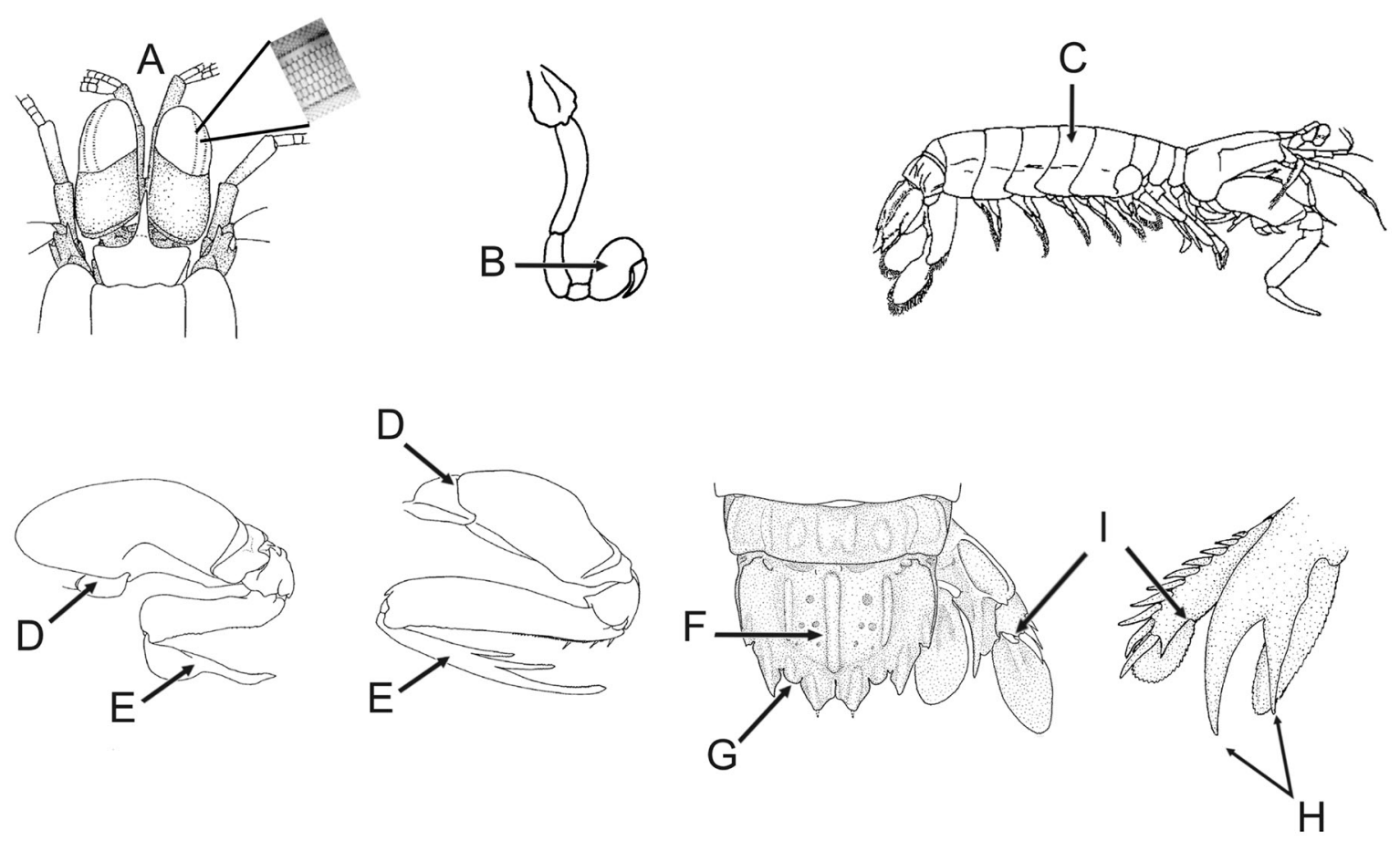
Clave para la identificación de las familias de Gonodactyloidea

1a. Articulación isquiomeral de la garra en posición subterminal, mero proyectándose más atrás del punto de articulación con el isquio (Fig. 29A). Base del dactilo de la garra con una hinchazón prominente (Fig. 29B) ...... 2

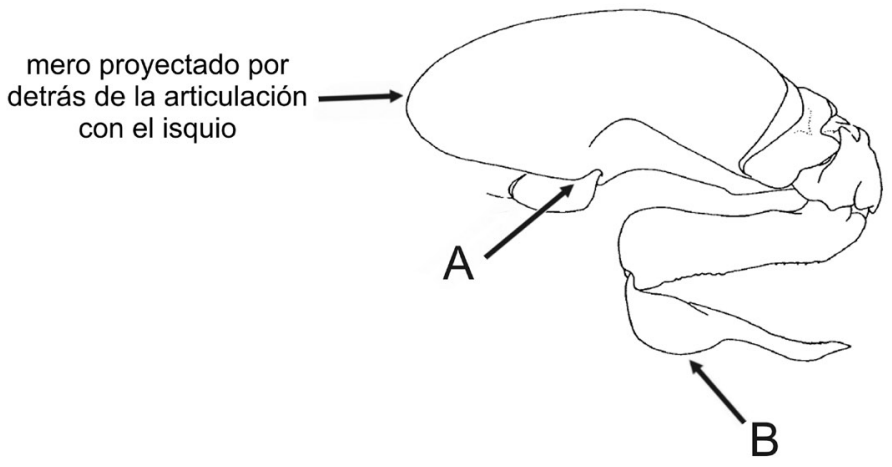

1b. Articulación isquiomeral de la garra en posición terminal, la porción proximal del mero articulándose con la porción distal del isquio (Fig. 30A). Base del dactilo de la garra no hinchada, puede estar un poco engrosada(Fig. 30B)

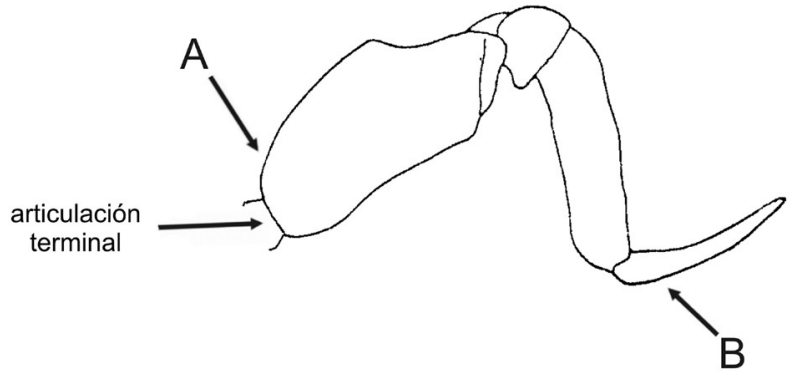

2a. Articulación de los segmentos del exopodio del uropodito terminal (Fig. 31A). Dactilo de la garra con dientes cortos en su margen interno (Fig. 31B) Odontodactylidae
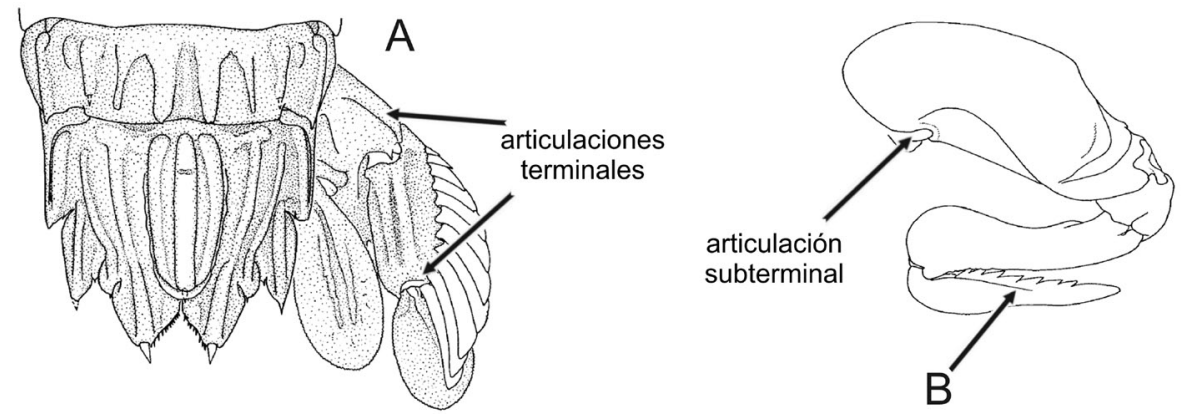
2b. Articulación de los segmentos de exopodio del uropodito subterminal (Fig. 32A). Dactilo de la garra sin dientes en su margen interno (Fig. 32B) Gonodactylidae

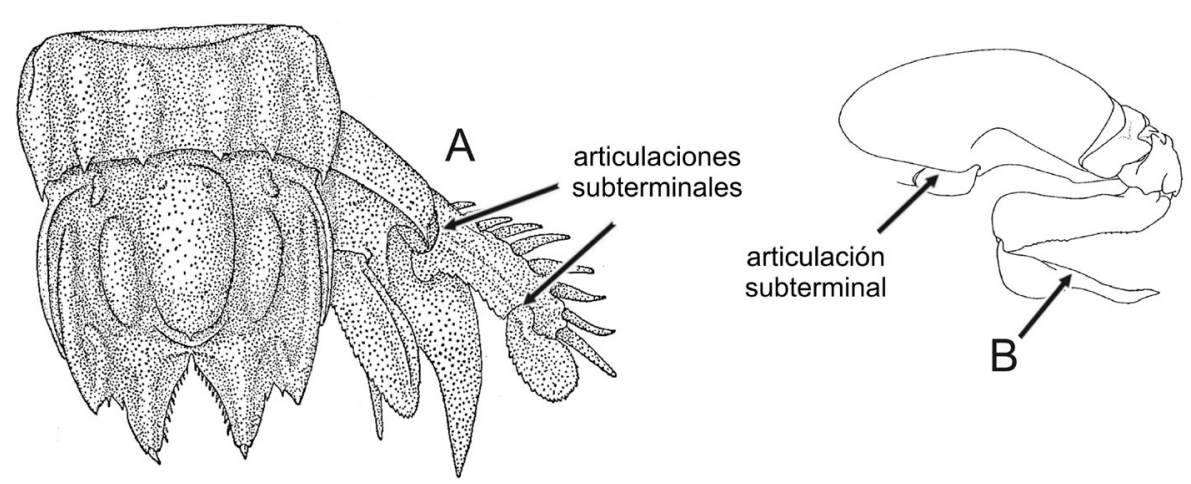

3a. Organismos de tamaño mediano $(51-100 \mathrm{~mm})$. Protopodito antenal con 1 escama o pequeña placa articulada dorsalmente, ésta con 1carina media ventral (Fig. 33A). Dactilo de la garra esbelto, con 3 dientes (Fig. 33B) ....

Pseudosquillidae

3b. Grandes a muy grandes en estado adulto (> $200 \mathrm{~mm})$. Porción dorsal del protopodito de la antena sin escamas dorsales (Fig. 34A). Dactilo de la garra sin dientes, con el margen externo ligeramente hinchado (Fig. 34B)

Hemisquillidae
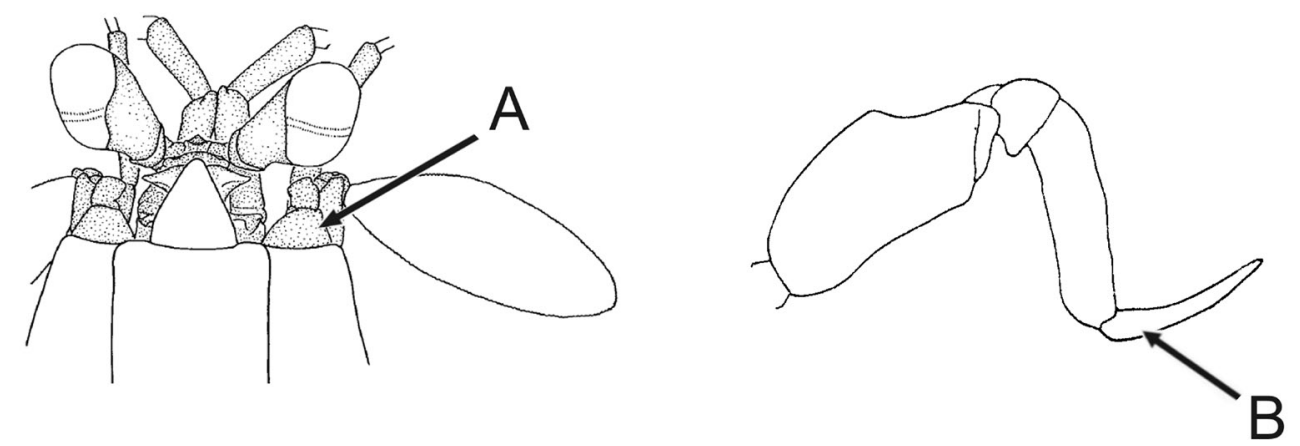
Familia Hemisquillidae Manning, 1980

Los Hemisquillidae son organismos grandes, de cuerpo robusto y colores intensos, especialmente en sus apéndices. Llegan a alcanzar tallas hasta de $250 \mathrm{~mm}$ o más y han sido capturados a profundidades mayores a $100 \mathrm{~m}$, sobre grava, arena o lodo. En el Pacífico oriental la familia está representada solamente por 2 especies muy parecidas entre sí. Aunque presentan diferencias morfológicas entre ellas, es muy complicado definir a qué especie pertenecen si no se conoce su color en fresco y su lugar de captura.

Especies de Hemisquillidae en el Pacifico oriental. Hemisquilla californiensis Stephenson, 1967; Hemisquilla ensigera (Owen, 1832).

\section{Clave para la identificación de las especies de Hemisquillidae}

1a. Dactilo de las garras y del endopodito uropodal de color amarillo intenso (Fig. 35).

Hemisquilla californiensis (California - Colombia; >250 mm; 30-114 m; lodo, arena, grava). 1b. Dactilo de las garras y del endopodito uropodal de color azul grisáceo (Fig. 35).

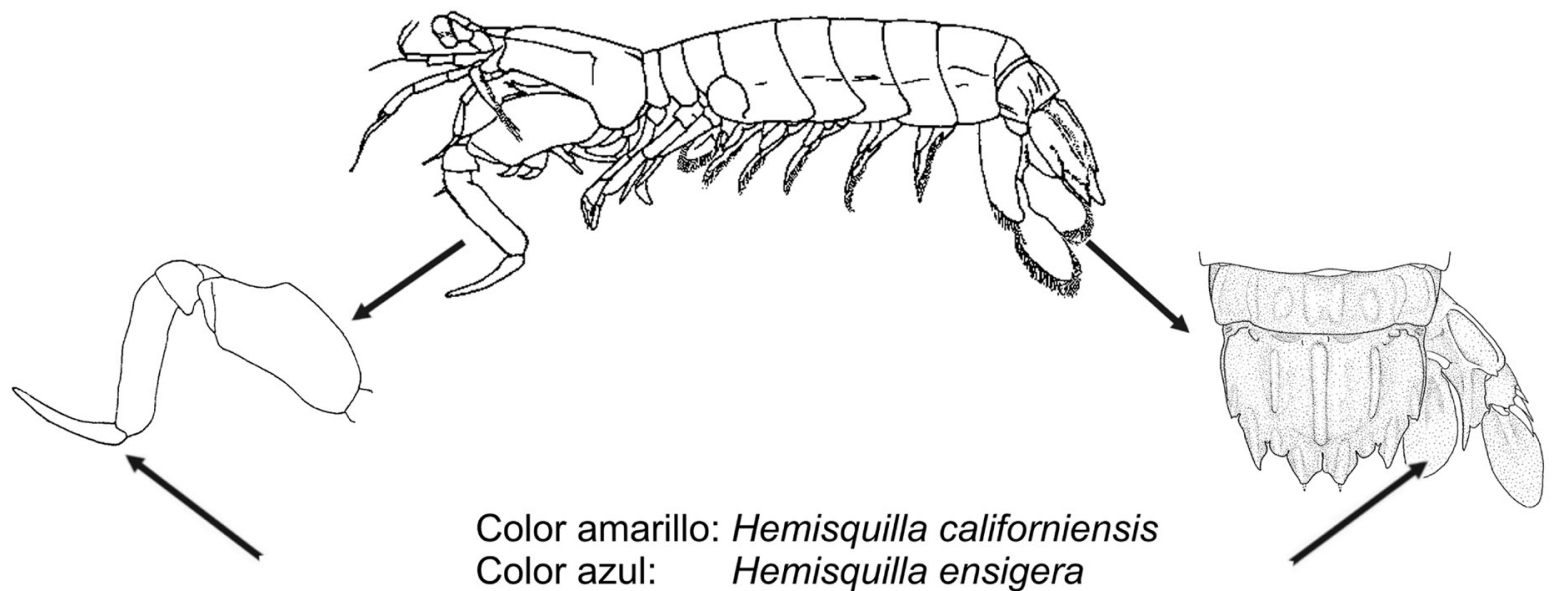

Familia Pseudosquillidae Manning, 1977

Los organismos de esta familia se caracterizan por ser de pequeños (21-50 mm) a medianos (51-100 mm). Tienen el cuerpo compacto, la placa rostral no armada o terminada en una espínula apical (Fig. 36A), la córnea es cilíndrica o aplanada y, si es bilobulada, tiene los lóbulos simétricos (Fig. 36B). Las articulaciones, tanto de la garra como del uropodito, terminales (Fig. 36C); el propodio y el dactilo de la garra son esbeltos, no hinchados en su base (Fig. 36D) y el propodio tiene 3 dientes móviles (Fig. 36E).

La familia Pseudosquillidae está representada en el Pacífico oriental por una sola especie: Pseudosquillisma adiastalta (Manning, 1964). Puede reconocerse por su tamaño mediano (51-100 mm), su córnea relativamente aplanada anteriormente, más ancha que la base y no claramente bilobulada (Fig. 36B), por presentar en el caparazón un par de manchas circulares en posición submedia (Fig. 36F) y el telson tiene una carina media y 4 carinas a cada lado (Fig. 36G) que son características del género Pseudosquillisma. En P. adiastalta, las manchas obscuras submedias del caparazón están parcialmente cubiertas por manchas blancas bien definidas que las rodean y también aparecen en el resto de la superficie dorsal del caparazón. 
Pseudosquillisma adiastalta (golfo de California - Ecuador; $78 \mathrm{~mm}$; 0-6 m; arena, coral, rocas).
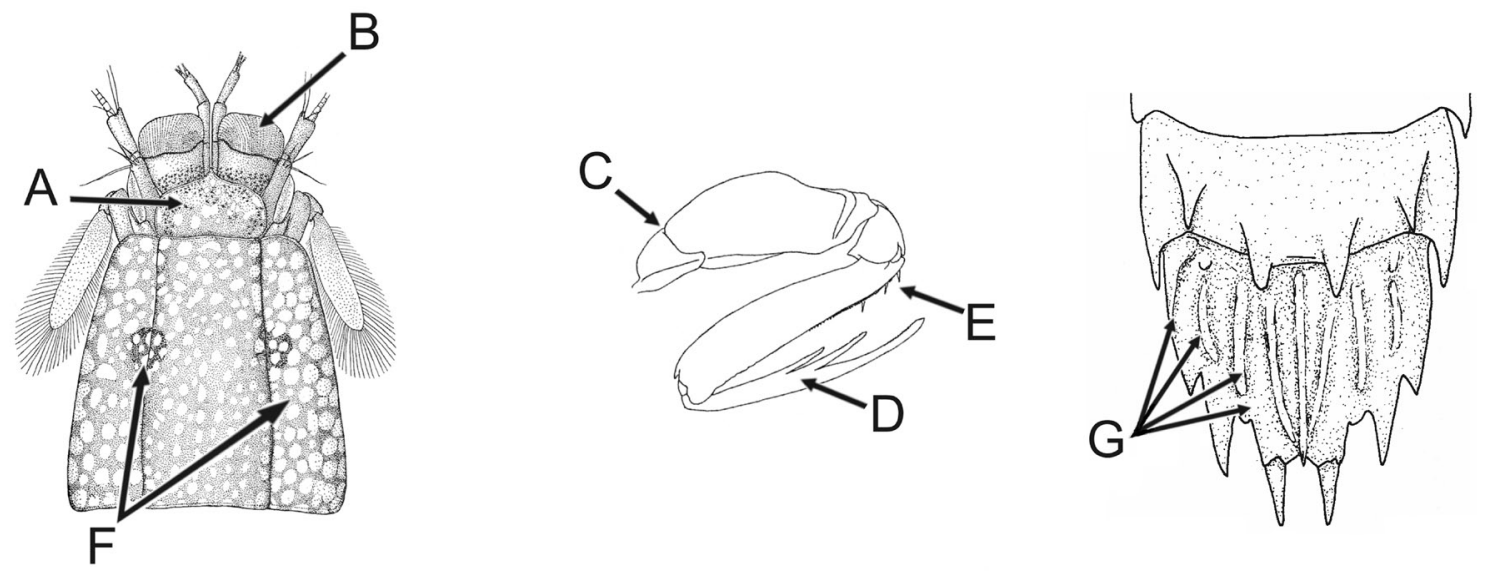

Familia Gonodactylidae Giesbrecht, 1910

La familia Gonodactylidae está compuesta por 9 géneros, de los cuales solamente Neogonodactylus ha sido recolectado en aguas de América. Son organismos de tamaño pequeño a mediano (hasta aprox. $50 \mathrm{~mm}$ ), de cuerpo robusto, con ojos redondeados no bilobulados y regularmente habitan fondos duros con roca, coral, gravas, algas o esponjas.

Las características que distinguen a la familia Gonodactylidae son los ojos globulares no bilobulados (Fig. 37A), la garra con la articulación subterminal entre el isquio y el mero, de forma que el mero se proyecta posteriormente mas allá de la articulación (Fig. 37B), el dactilo de la garra no tiene dientes internos, es engrosado en su base y con una proyección prominente redondeada en el margen externo (Fig. 37C), la articulación de los segmentos del uropodito es subterminal (Fig. 37D). En el género Neogonodactylus hay una carina intermedia accesoria en el dorso del telson (Fig. 37E).
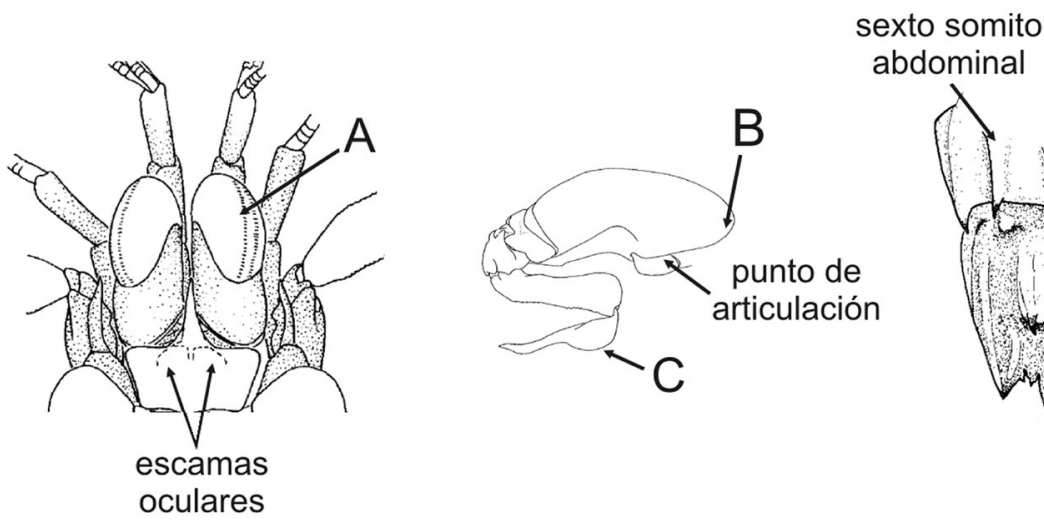
abdominal

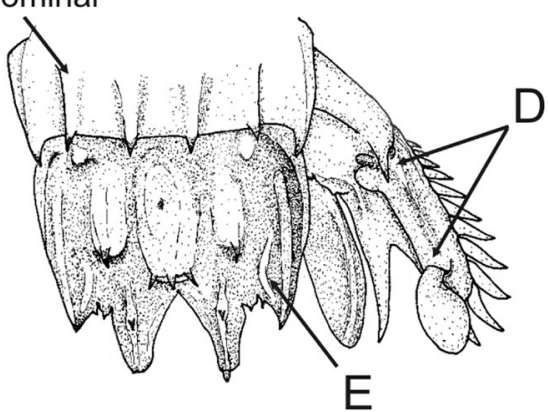

Las especies conocidas de Neogonodactylus del Pacífico y del Atlántico de América son muy parecidas entre sí; de hecho, su identificación está basada en el telson, su forma, sus dientes y dentículos, la disposición de las carinas y la disposición y cantidad de espinas dorsales. La forma de la placa rostral y las escamas oculares, ubicadas en el somito ocular, debajo de la placa rostral, también son importantes para la identificación, y en menor medida el contorno de las pleuras abdominales. No se conocen especies anfiamericanas. La mayoría de las especies presentan dimorfismo sexual en el que las carinas del telson de los machos suelen engrosarse y perder algunas de sus espinas, lo que dificulta la identificación de las especies en no pocos casos. Dado que la estructura del telson suele ser relevante y la nomenclatura de sus carinas es ligeramente distinta a la de otros grupos de estomatópodos, se presenta en la figura 38. 


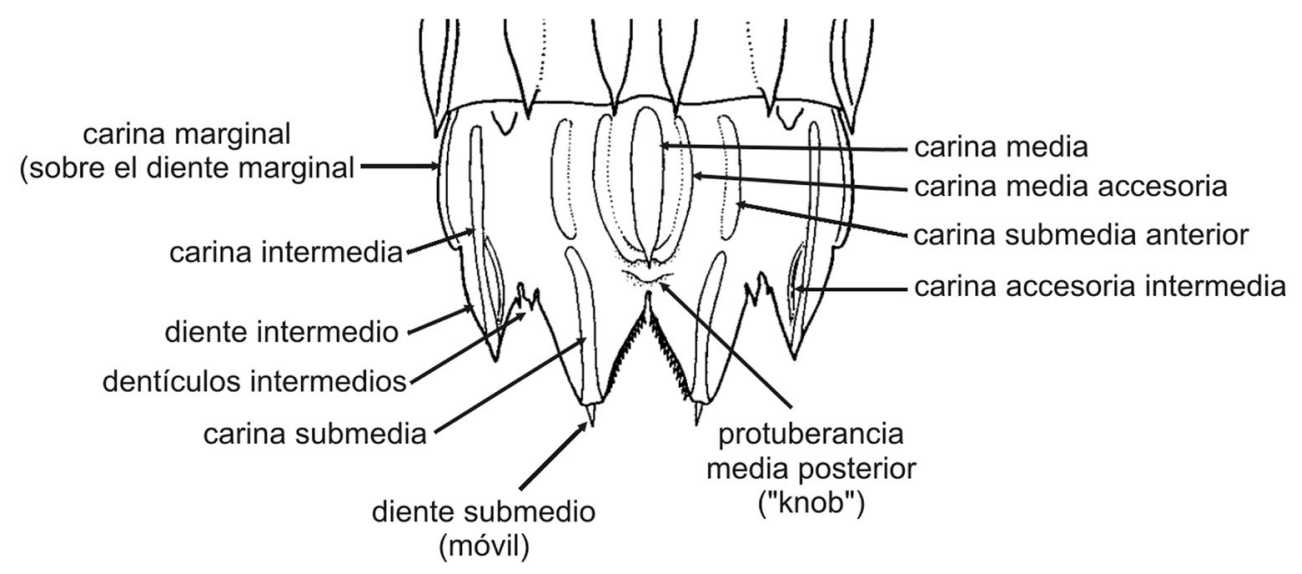

Figura 38. Nomenclatura de los dientes y las carinas del telson de los Gonodactylidae.

Especies de Gonodactylidae del Pacifico oriental.

Neogonodactylus albicinctus (Manning y Reaka, 1979);

Neogonodactylus bahiahondensis (Schmitt, 1940);

Neogonodactylus costaricensis (Manning y Reaka, 1979);

Neogonodactylus festae (Nobili, 1901);

Neogonodactylus lalibertadensis (Schmitt, 1940);

Neogonodactylus pumilus (Manning, 1970);

Neogonodactylus stanschi (Schmitt, 1940);

Neogonodactylus zacae (Manning, 1972).

\section{Clave para la identificación de las especies de Gonodactylidae (Neogonodactylus)}

1a. Telson sin espinas dorsales, pueden tener tubérculos (Fig. 39A). Los dientes intermedios en ocasiones parecen estar fusionados al telson y no se distinguen claramente de éste (Fig. 39B), excepto por su ápice, que se ubica en posición anterior o al nivel de los dentículos intermedios (telson denominado tipo Bredini) (Fig. 39C)

. Neogonodactylus zacae (golfo de California - Ecuador; $59 \mathrm{~mm}$; 0-64 m; lodo, arena, grava, rocas, coral, algas).

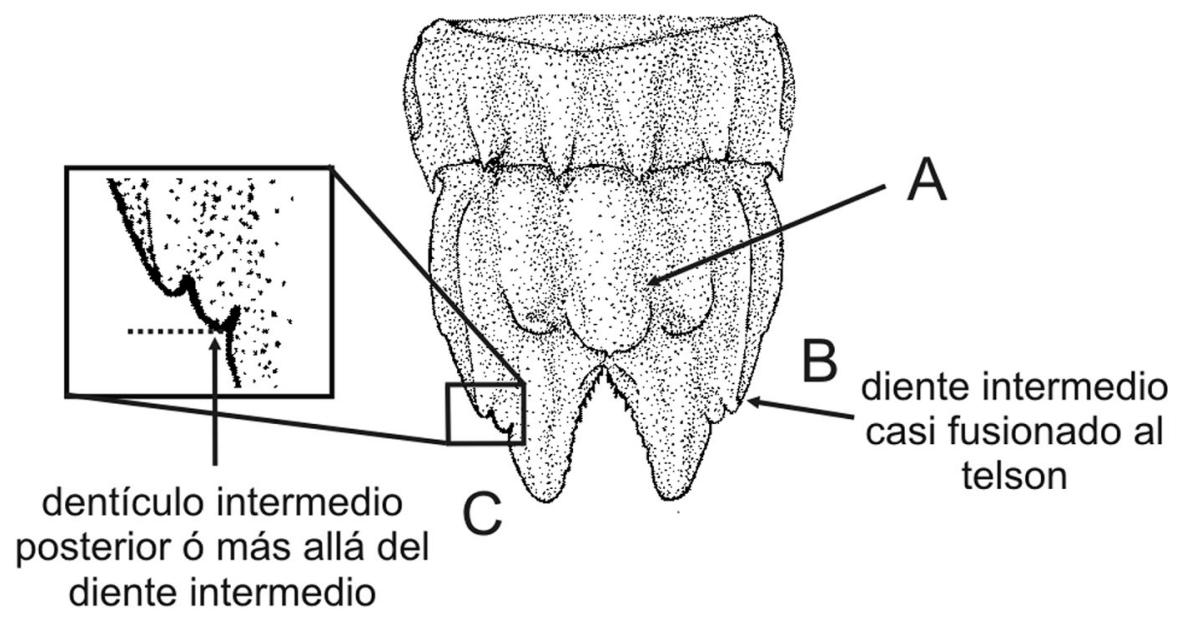


1b. Telson generalmente con espinas dorsales (Fig. 40A). Dientes intermedios claramente separados del cuerpo del telson (Fig. 40B) y situados en posición posterior con respecto a los dentículos intermedios, telson denominado como tipo "Oerstedii" (Fig. 40C)

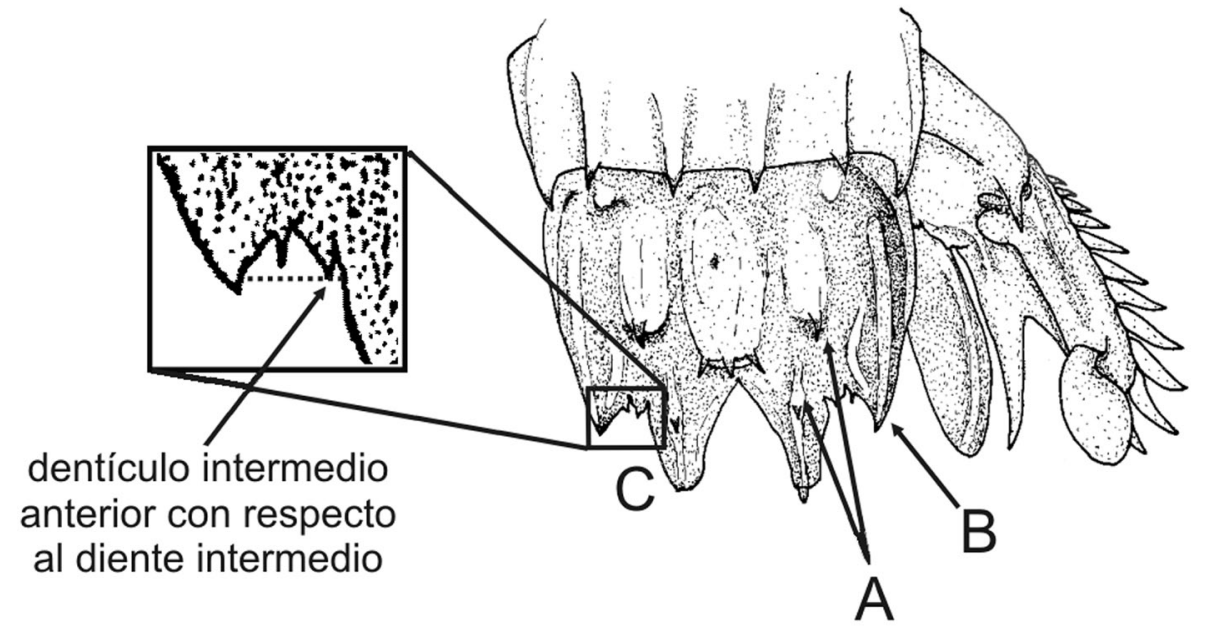

2a. Carina accesoria intermedia del telson sin espinas (Fig. 41) 3

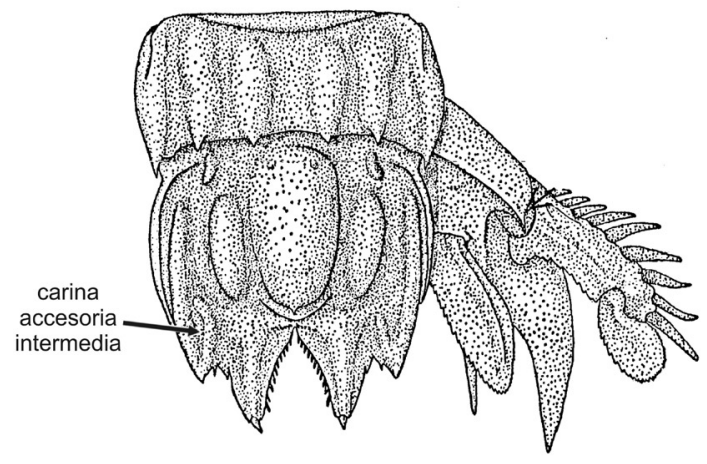

2b. Carina accesoria intermedia del telson con espinas (Fig. 42). 4

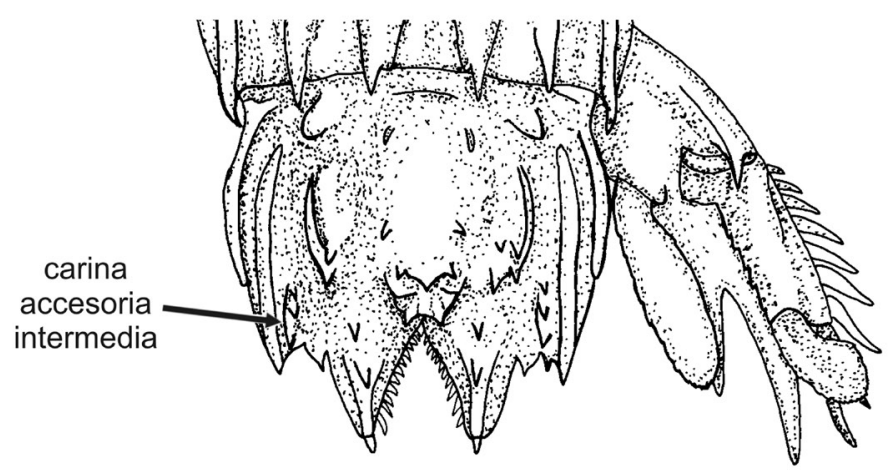


3a. Organismos muy pequeños en estado adulto (hasta $20 \mathrm{~mm}$ ). Telson sin tubérculos o espinas sobre las carinas dorsales, excepto en la carina media que termina en una espina fuerte (Fig. 43A), la carina media tiene forma globosa, especialmente en machos, arqueada dorsalmente. Protuberancia media posterior claramente visible (Fig. 43B)

Neogonodactylus pumilus (islas Galápagos - Colombia; $20 \mathrm{~mm} ; 5 \mathrm{~m}$; coral).

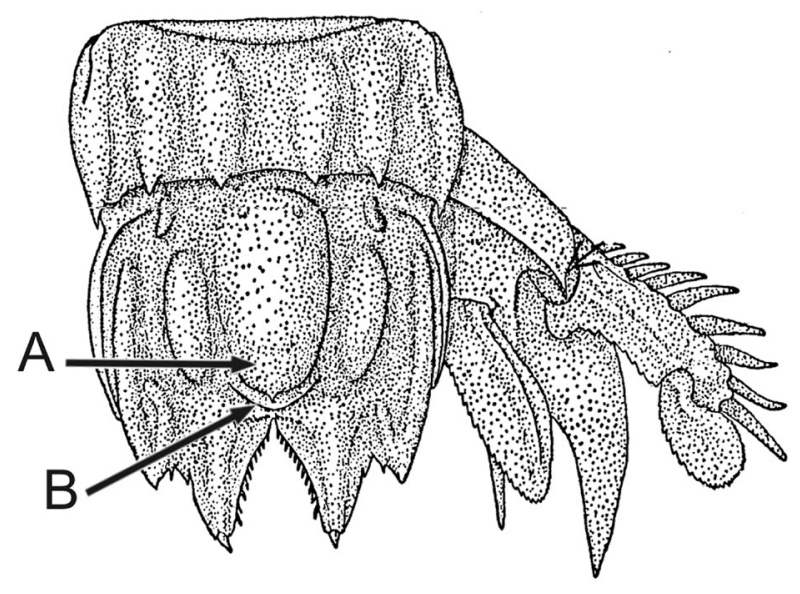

3b. Organismos pequeños a medianos en estado adulto (hasta $62 \mathrm{~mm}$ ). Carinas dorsales del telson generalmente con una espina terminal, excepto en la carina submedia, que puede tener una espina dorsal (Fig. 44A). Carina media generalmente esbelta y no muy arqueada, en los machos adultos las carinas dorsales suelen ser más gruesas y con menos espinas que en las hembras (Fig. 44B). Protuberancia media posterior poco visible y sin espinas (Fig. 44C)

..Neogonodactylus stanschi (golfo de California - Colombia; 62 mm; 0-17 m; grava, rocas, coral).
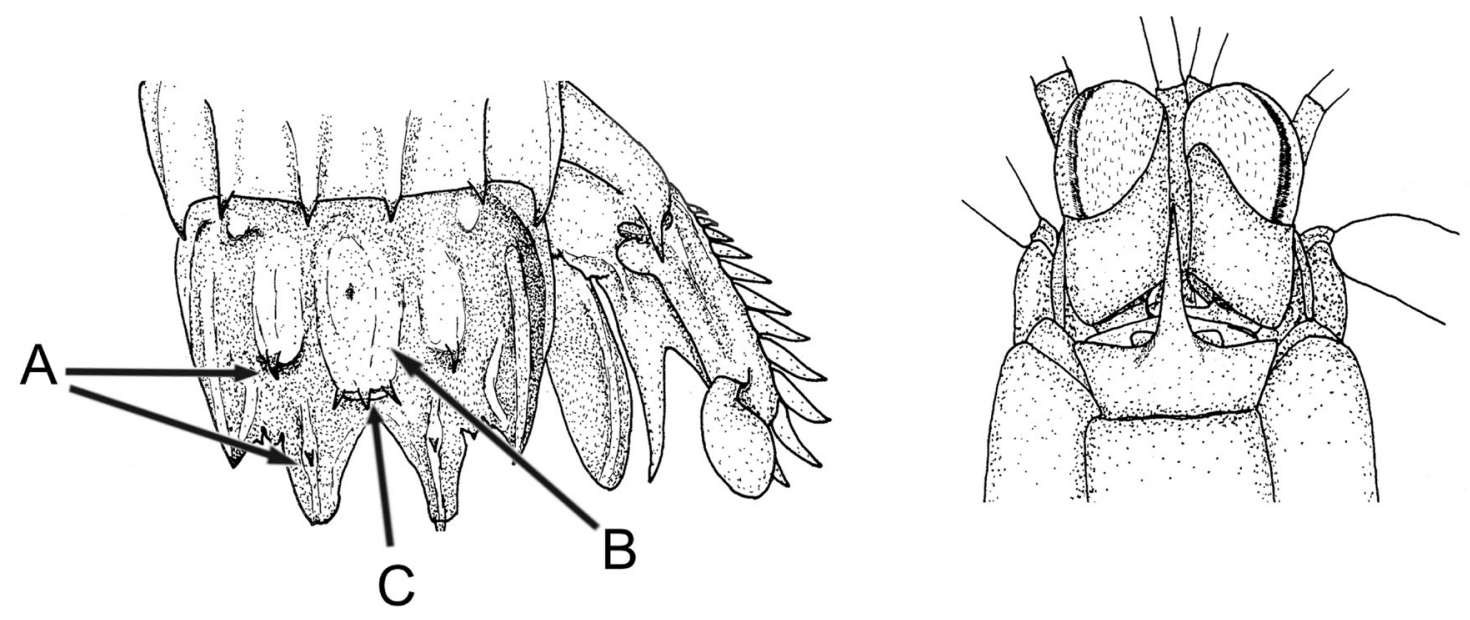

4a. Carina media accesoria del telson corta, de aproximadamente un cuarto de la longitud de la carina media y fusionada posteriormente a ésta para formar una estructura parecida a una ancla (Fig. 45A).Con un dentículo debajo del lóbulo del diente lateral (Fig. 45B). Ángulos anterolaterales de la placa rostral terminados en una punta aguda (Fig. 45C) y escamas 
oculares proyectadas hacia los lados (Fig. 45D)

..Neogonodactylus festae (El Salvador - Ecuador; 49 mm; arena, rocas, coral).
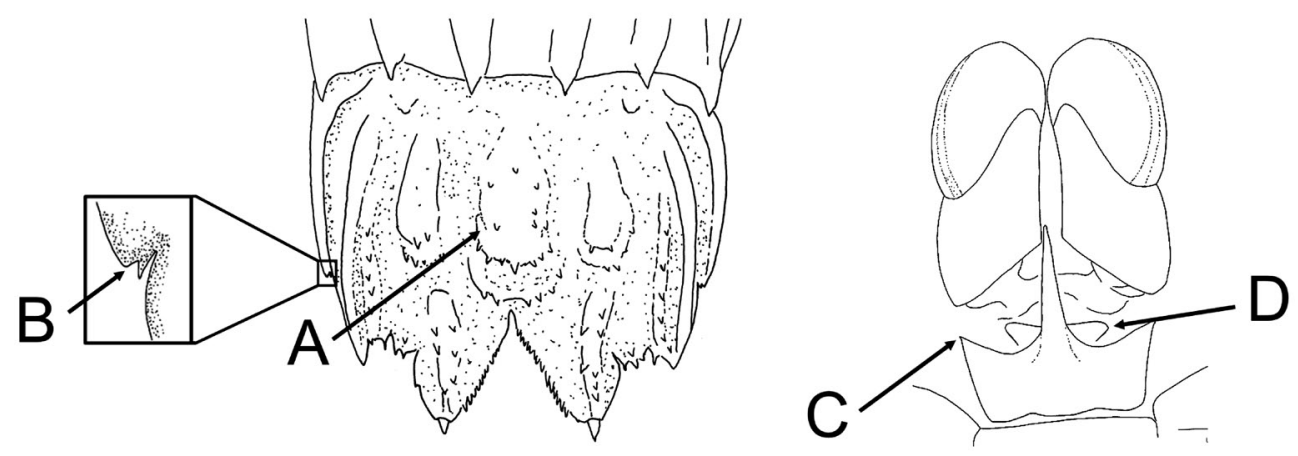

4b. Carina media accesoria del telson tan larga como la carina media, no fusionada posteriormente a ésta. En algunos ejemplares, especialmente en machos adultos estas carinas pueden aparecer engrosadas, pero no fusionadas posteriormente a la carina media (Fig. 46A). Sin dentículos debajo del lóbulo del diente lateral (Fig. 46B). Ángulos anterolaterales de la placa rostral y escamas oculares variables (Fig. 46C)
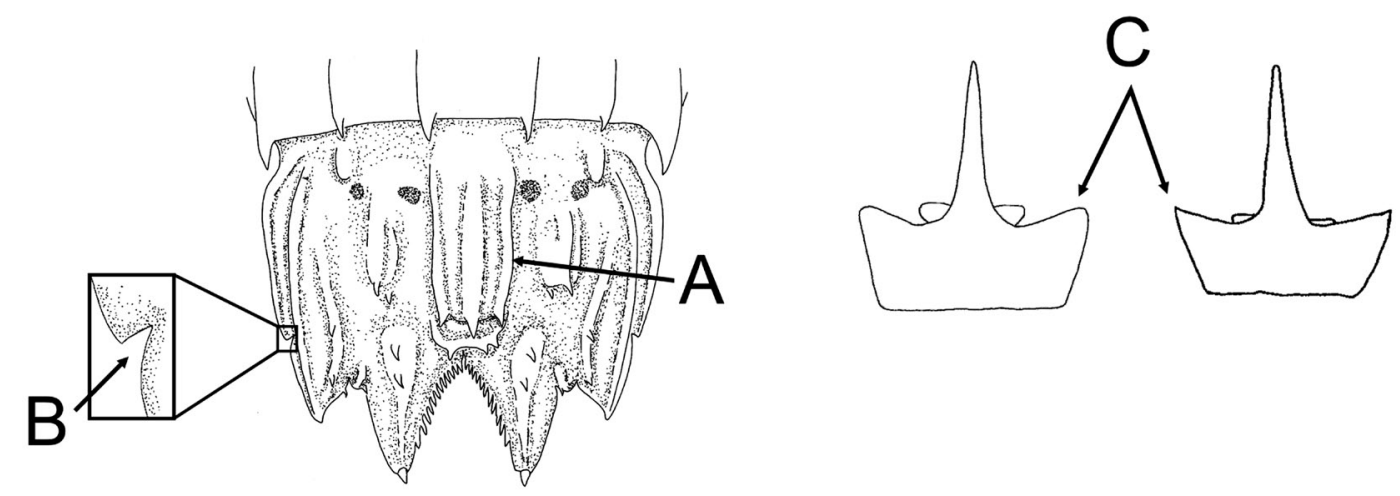

5a. Carina media accesoria del telson con 2-4 espinas a lo largo y terminada en una espina (Fig. 47A). Placa rostral con ángulos anterolaterales agudos pero obtusos (Fig. 47B). Escamas oculares proyectadas hacia los lados, ubicadas delante de la base de la placa rostral (Fig. 47C)

.Neogonodactylus lalibertadensis (golfo de California - Ecuador; $34 \mathrm{~mm}$; 2-9 m; arena, rocas, coral).
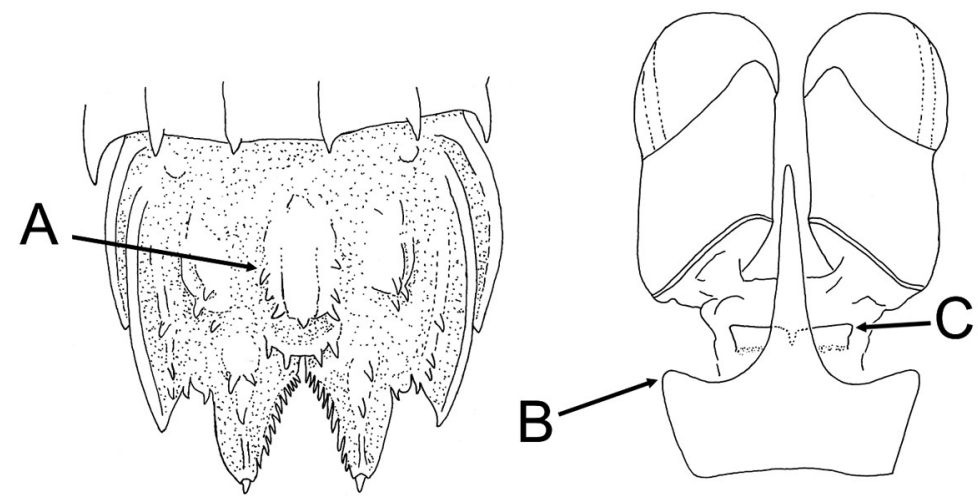
5b. Carina media accesoria del telson sin espinas a lo largo, ocasionalmente puede presentar 1 o 2 tubérculos, con una espina terminal (Fig. 48A). Placa rostral con ángulos anterolaterales muy agudos o espiniformes y escamas oculares variables (Fig. 48B)
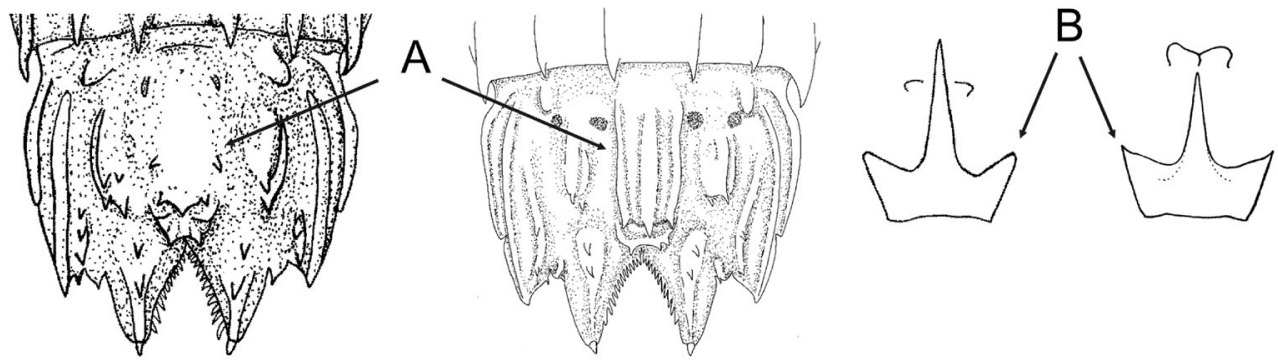

6a. Placa rostral con ángulos anterolaterales agudos pero no espiniformes y escamas oculares redondeadas, no alargadas, proyectadas lateralmente (Fig. 49A). La carina media accesoria del telson puede presentar hasta 2 tubérculos a lo largo (Fig. 49B). Protuberancia media posterior del telson con 2 espinas (Fig. 49C) Neogonodactylus albicinctus (Costa Rica-Colombia; $25 \mathrm{~mm}$; 9-17 m; arena, grava, rocas, coral).

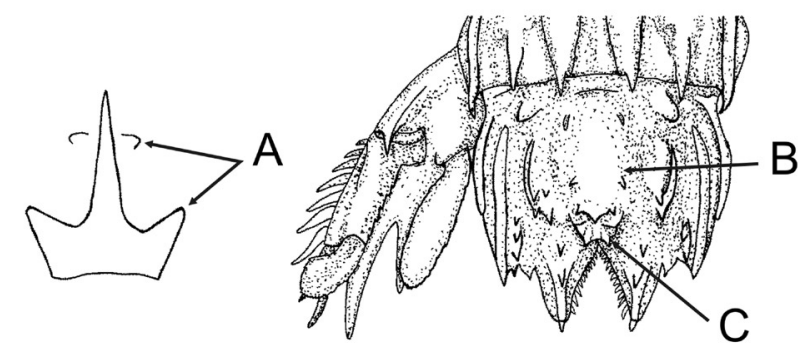

6b. Placa rostral con los ángulos anterolaterales agudos, espiniformes y escamas oculares no proyectadas lateralmente (Fig. 50A). Sin tubérculos a lo largo de la carina media accesoria del telson (Fig. 50B). Protuberancia media posterior del telson con 2-4 espinas

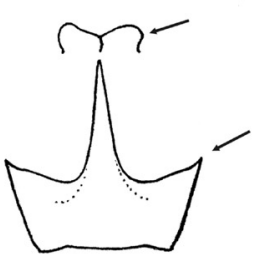

A

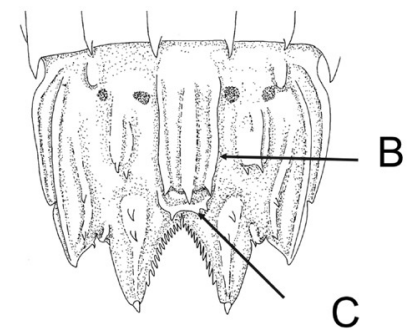

7a. Ángulos anterolaterales del rostro muy agudos, pero no espiniformes (Fig. 51A). Escamas oculares anchas, cuadradas o subrectangulares (Fig. 51B). Telson generalmente con 4 manchas anteriores dorsales (Fig. 51C). Protuberancia media 

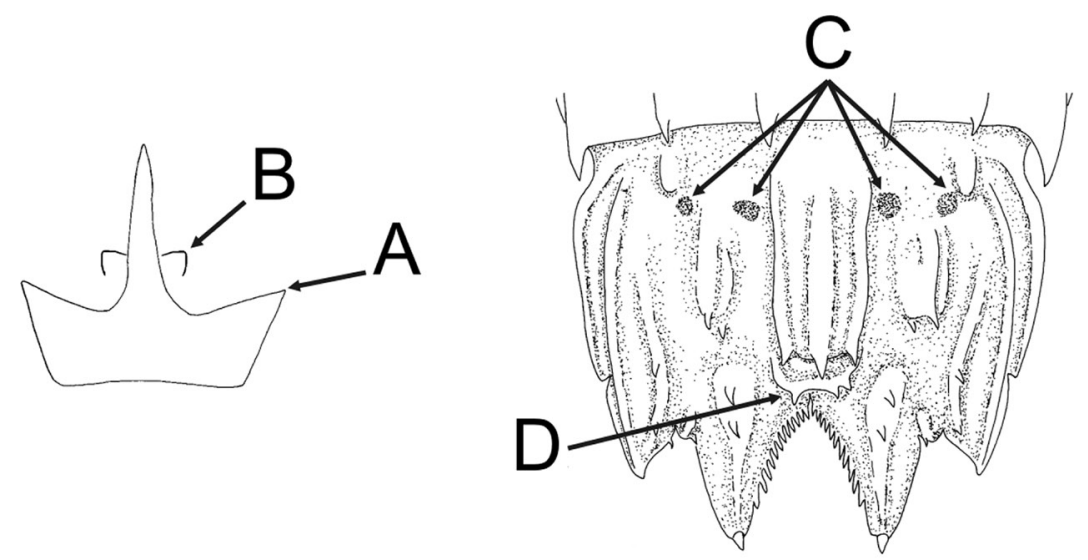

7b. Ángulos anterolaterales del rostro espiniformes (Fig. 52A). Escamas oculares redondeadas, dirigidas hacia adelante (Fig. 52B). Telson sin manchas anteriores (Fig. 52C). Protuberancia media posterior con 2 espinas pequeñas (Fig. 52D) Neogonodactylus bahiahondensis (Costa Rica - Ecuador; 49 mm; 0-20 m; lodo, arena, rocas, grava, coral).
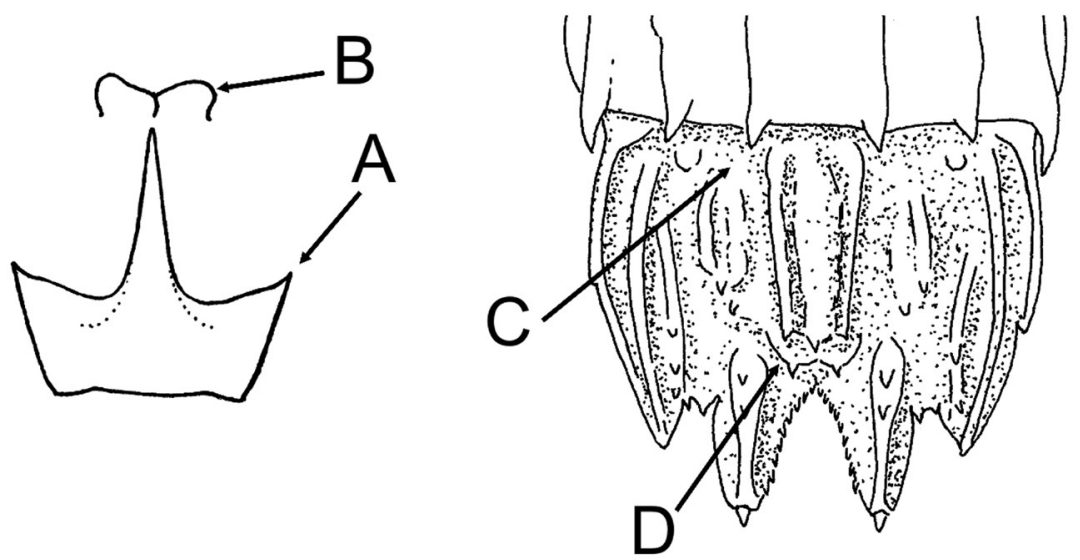

Familia Odontodactylidae Manning, 1980

La familia Odontodactylidae contiene únicamente el género Odontodactylus. Son organismos de tamaño mediano a grande $(50-200 \mathrm{~mm}$ ) y se caracterizan por presentar los ojos subglobulares (Fig. 53A), la articulación isquiomeral de la garra subterminal (Fig. 53B), el dactilo de la garra claramente hinchado en su base y con dientes cortos en su margen interno (Fig. 53C), la articulación de los segmentos del exopodio del uropodito terminal (Fig. 53D) y el margen del exopodio uropodal recto o ligeramente curvado, no fuertemente curvado anteriormente como en los Gonodactylidae (Fig. $53 \mathrm{E})$. 

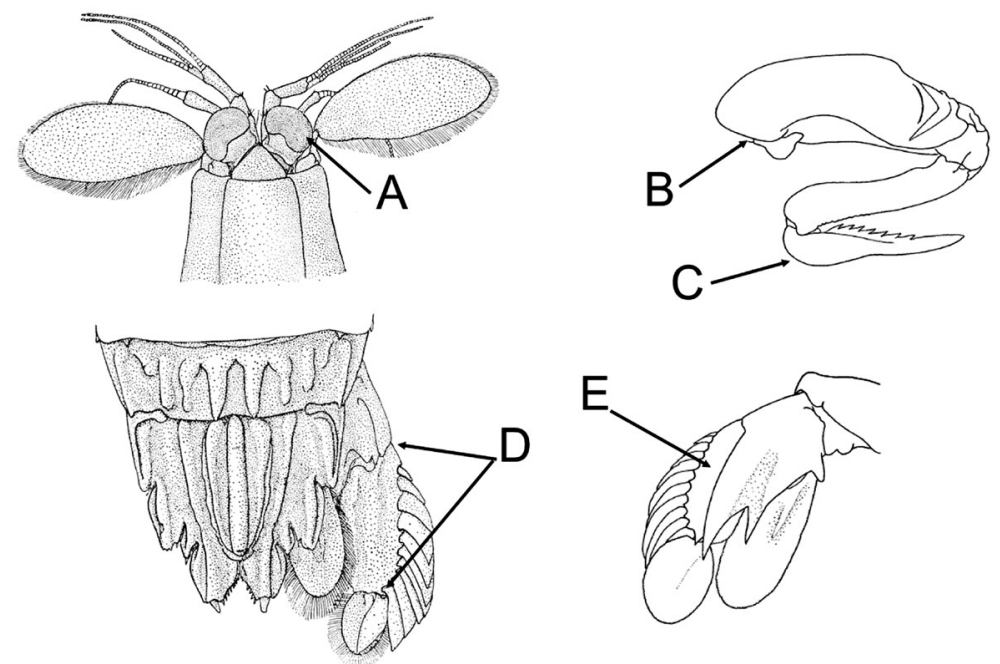

Dentro del género Odontodactylus se han descrito 8 especies, todas registradas en el Indo-Pacífico, el Pacífico central y en el Atlántico. Entre las especies reconocidas como del Indo-Pacífico o de las islas oceánicas del Pacífico central se tiene el registro de una postlarva de O. hawaiiensis Manning, 1967 en las islas Sala y Gómez, Chile (Retamal, 2002).

Odontodactylus hawaiiensis y O. japonicus (de Haan, 1844) se distinguen de otras especies del género por presentar las escamas oculares unidas (Fig. 54A) en combinación con un par de carinas medias accesorias a cada lado de la carina media del telson (Fig. 54B) y una garra con más de 5 dientecillos en el margen interno del dactilo (Fig. 54C). Odontodactylus hawaiiensis se distingue de O. japonicus por carecer de carina longitudinal entre el margen anterior del telson y el dentículo submedio (Fig. 54D). Odontodactylus hawaiiensis (Hawaii, islas Sala y Gómez, Chile; 107 mm; 109-276 m; sustrato duro?).

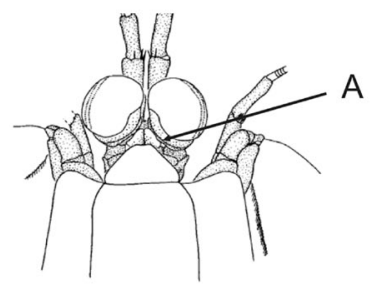

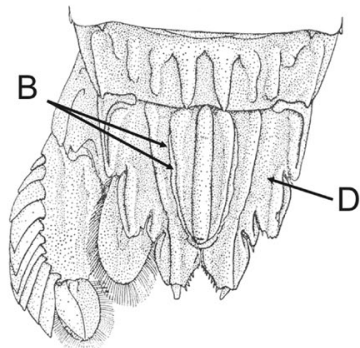

O. hawaiiensis

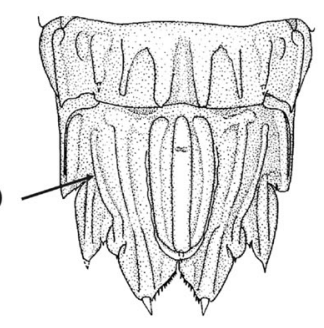

O. japonicus

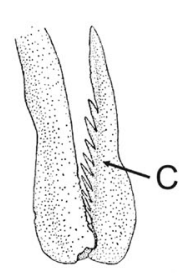

Superfamilia Lysiosquilloidea Giesbrecht, 1910

La superfamilia Lysiosquilloidea incluye organismos con tallas desde muy pequeñas $(<20 \mathrm{~mm})$ o pequeñas $(21-50$ $\mathrm{mm}$ ) (Nannosquillidae), medianas (51-100 mm) (Coronididae y Tetrasquillidae) y grandes o muy grandes $(>101 \mathrm{~mm})$ (Lysiosquillidae).

Las especies de Lysiosquilloidea presentan el proceso dorsal del somito antenal espiniforme o aplanado dorsoventralmente, pero nunca comprimido anteriormente o redondeado lateralmente (Fig. 55A), maxilípedos 3 y 4 con el propodio subcuadrado o francamente más ancho que largo, generalmente con ornamentaciones ventrales en forma de costillas o glóbulos (Fig. 55B), el telson sin carina dorsal, aunque en algunas especies, como en Lysiosquillidae, puede presentar una prominencia media no afilada (Fig. 55C) y la prolongación basal del uropodito con hasta 2 espinas primarias (Fig. 55D). 

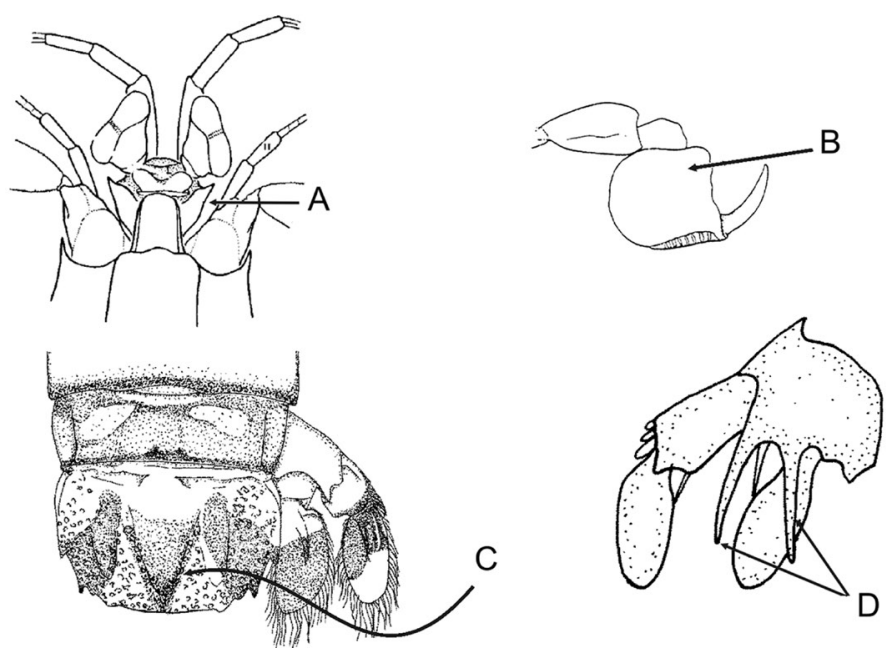

La superfamilia Lysiosquilloidea está compuesta por 4 familias: Coronididae, Lysiosquillidae, Nannosquillidae y Tetrasquillidae, todas ellas representadas en el Pacífico americano. La identificación de las especies de este grupo en el Pacífico oriental suele ser simple, con excepción de la familia Nannosquillidae, en particular el género Nannosquilla, cuyas especies son pequeñas, con un cierto grado de endemismo y variables intraespecíficamente.

Clave para la identificación de las familias de Lysiosquilloidea

1a. Organismos pequeños $(<50 \mathrm{~mm})$. Telson cubierto dorsalmente con espinas, tubérculos aplanados o espínulas estrechamente agrupadas (Fig. 56A). Dactilo de la garra robusto, hinchado en su base y con 4 dientes (Fig. 56B). Las especies con el dactilo no hinchado presentan el sexto somito abdominal y el telson totalmente cubiertos por espínulas erectas

Coronididae
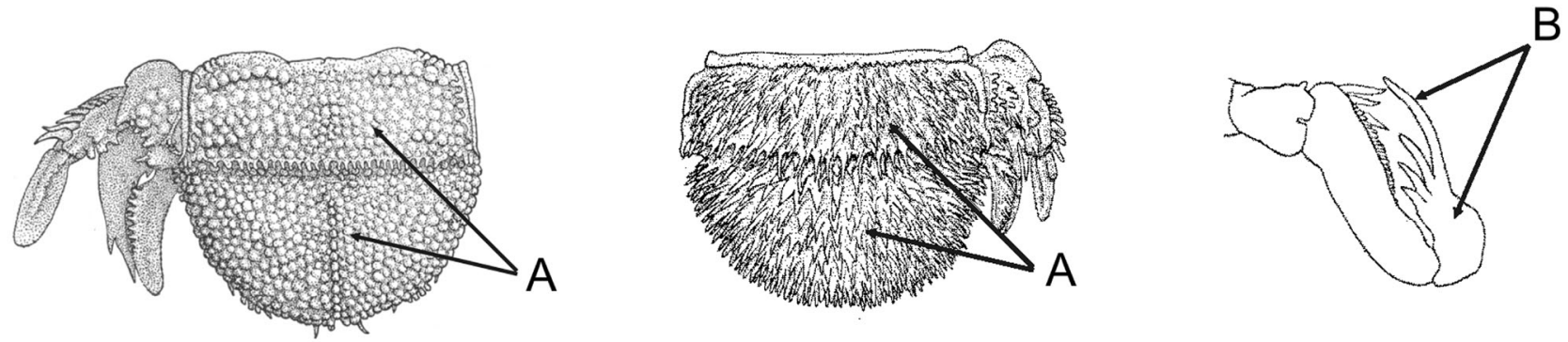

1b. Organismos de talla pequeña hasta muy grande $(>200 \mathrm{~mm})$. Telson liso o con carinas dorsales pero no enteramente cubierto con espinas o tubérculos (Fig. 57A). Dactilo de la garra no hinchado en su porción basal y con más de 4 dientes en el margen interno (Fig. 57B)
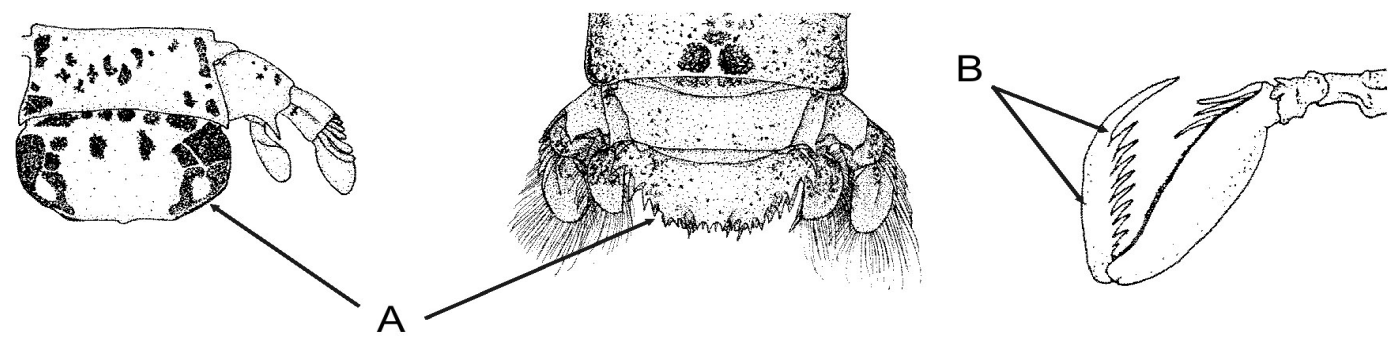
2a. Organismos pequeños ( $<20-50 \mathrm{~mm})$. Córnea subglobular (Fig. 58A). Margen dorsal del endopodito uropodal con un fuerte doblez proximal (Fig. 58B) ..Nannosquillide
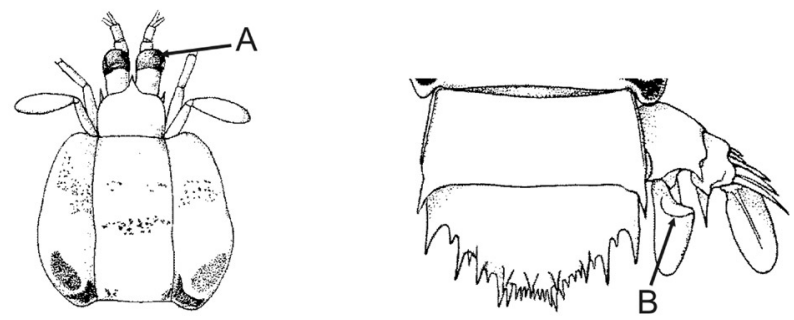

2b. Organismos de pequeños a muy grandes (>200 mm). Córnea de los ojos bilobulada (Fig. 59A). Margen dorsal del endopodito uropodal sin doblez proximal bien marcado o poco pronunciado (Fig. 59B)
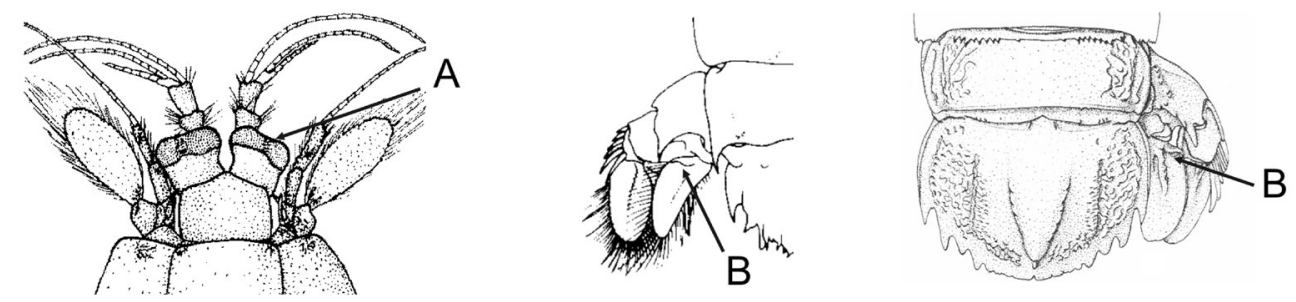

3a. Cuerpo débilmente articulado, no compacto (Fig. 60A). Telson con los dientes fusionados al margen, cuanto más aparecen como pequeñas proyecciones marginales (Fig. 60B)

.Lysiosquillidae
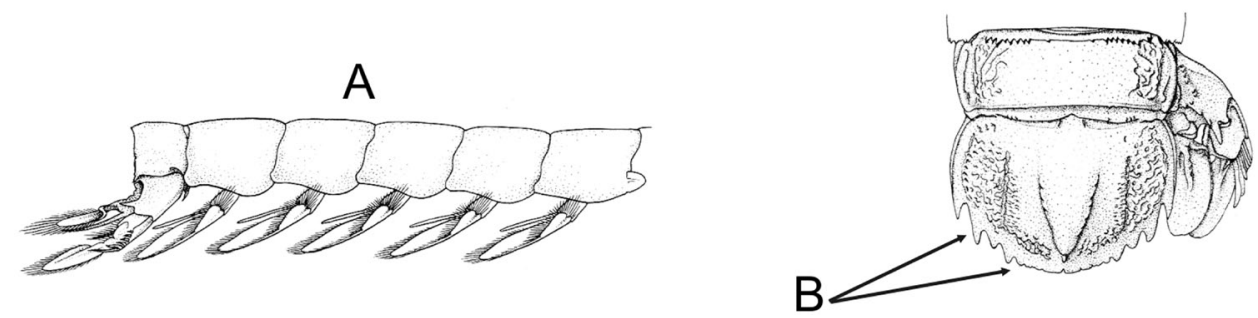

3b. Cuerpo compacto (Fig. 61A). Telson con dientes y dentículos no fusionados, claramente marcados y esbeltos (Fig. 61B). ...Tetrasquillidae
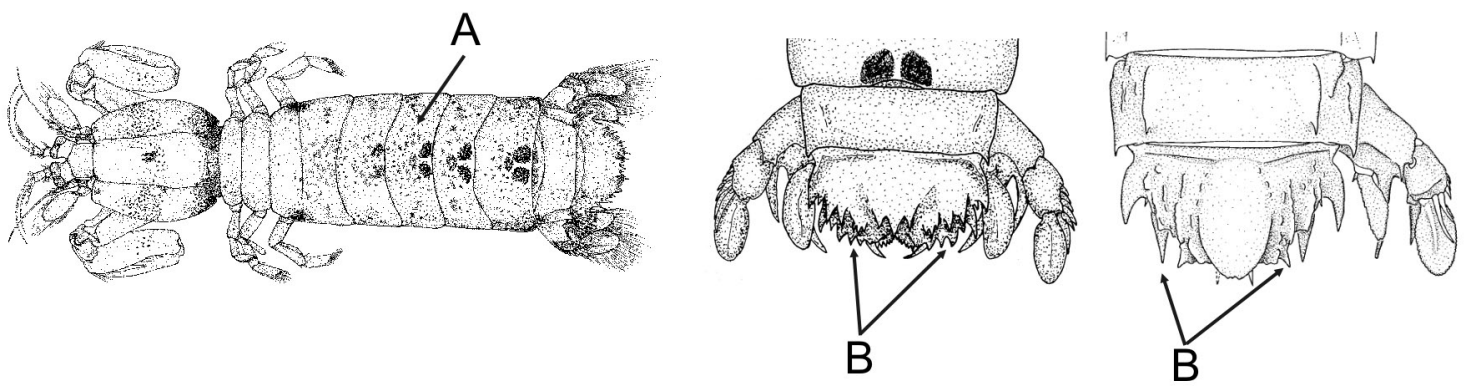
Familia Coronididae Manning, 1980

La familia Coronididae está compuesta por organismos pequeños a medianos $(<50-100 \mathrm{~mm})$, de articulación abdominal compacta y que se caracterizan por la forma particular del sexto somito abdominal y del telson, ambos cubiertos dorsalmente con espinas, tubérculos aplanados o espínulas estrechamente agrupadas (Fig. 62A), y por el dactilo de la garra robusto, hinchado en su base y con 4-5 dientes; 4 en los 2 géneros presentes en aguas de América (Fig. 62B).
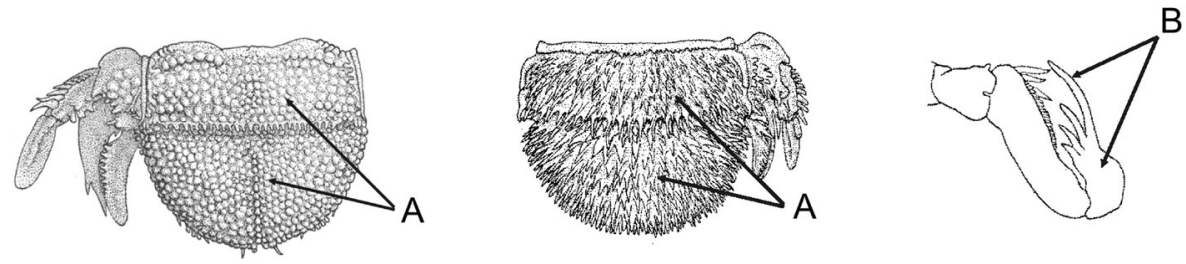

Especies de Coronididae del Pacifico oriental.

Coronida glasselli Manning, 1976;

Coronida schmitti Manning, 1976;

Neocoronida cocosiana (Manning, 1972).

Clave para la identificación de las especies de Coronididae

1a. Telson y sexto somito abdominal con proyecciones suaves o estrelladas, sin espinas (Fig. 63A). Proyecciones marginales del telson no agudas (Fig. 63B) (Neocoronida)

Neocoronida cocosiana (isla del Coco, Costa Rica; $20 \mathrm{~mm}$; sustrato duro?).

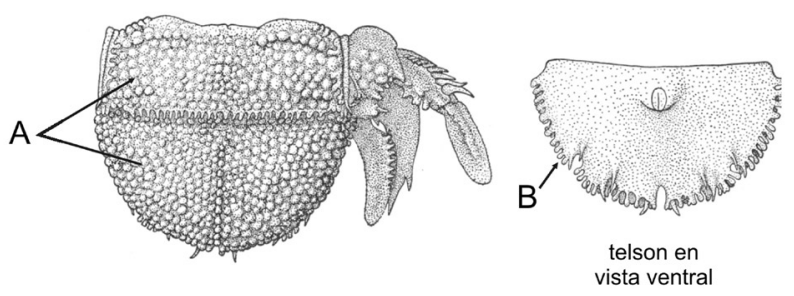

1b. Sexto somito abdominal y telson espinados (Fig. 64A). Proyecciones marginales del telson agudas (Fig. 64B) (Coronida)
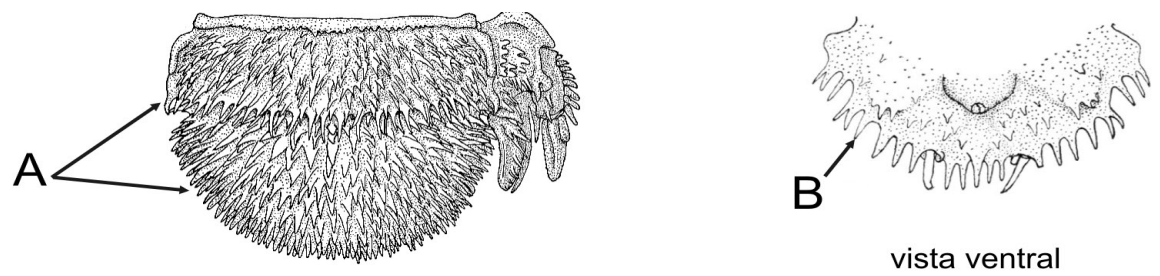

2a. Margen anterior del sexto somito abdominal con espinas o proyecciones submedias (Fig. 65A). Sexto somito abdominal y telson con espinas dorsales largas (Fig. 65B). Porción basal del exopodio uropodal con menos de 10 espinas (Fig. 65C) 
Coronida glasselli (isla Gorgona, Colombia; 36 mm; 10-13 m; arena, grava, coral).

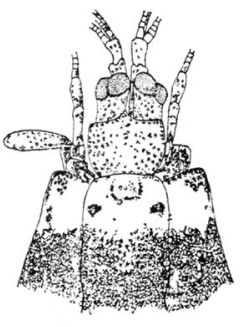

porción anterior

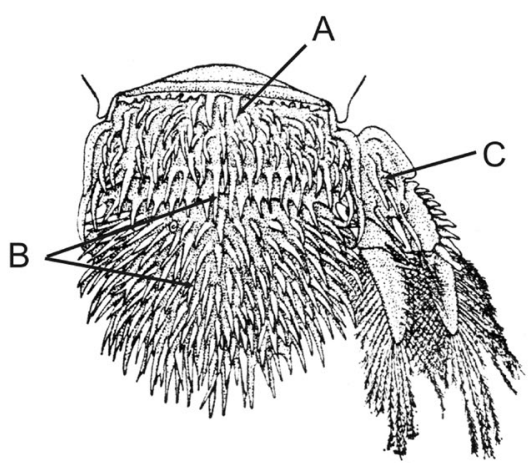

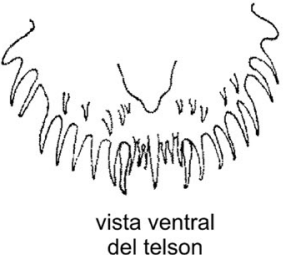

2b. Margen anterior del sexto somito abdominal sin espinas o proyecciones submedias bien definidas (Fig. 66A). Sexto somito abdominal y telson con espinas dorsales relativamente cortas (Fig. 66B). Porción basal del exopodio uropodal con 15-25 espinas (Fig. 66C) ........Coronida schmitti (golfo de California - Ecuador; 48 mm; 14-128 m; grava, rocas, coral).

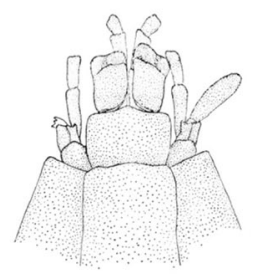

porción anterior
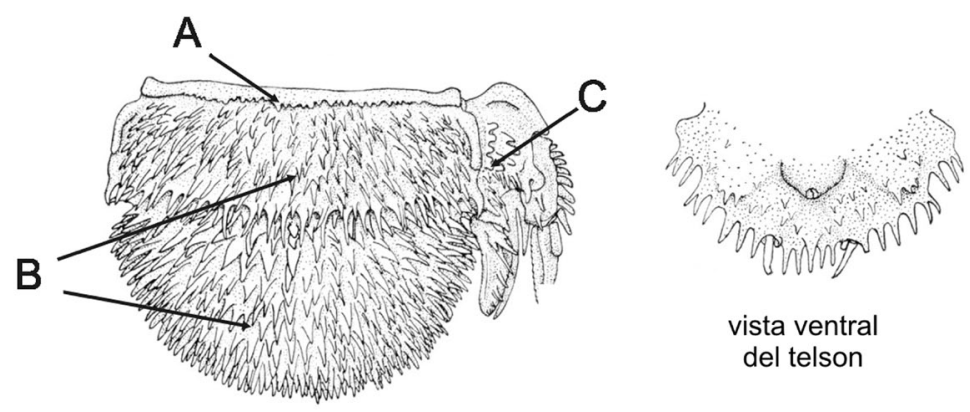
del telson vista ventral

Familia Nannosquillidae Manning, 1980

Las especies de Nannosquillidae son de talla pequeña $(<20-50 \mathrm{~mm})$ y ocasionalmente un poco más grandes (hasta $60 \mathrm{~mm}$ ). Presentan ojos con la córnea globular (Fig. 67A), la garra con 4 espinas móviles en el propodio y el dactilo no hinchado en su base (Fig. 67B), de articulación abdominal no compacta (Fig. 67C), con los pereiópodos 1 y 2 con endopodito subcircular y el tercero ovalado (Fig. 67D), telson con dientes primarios y dentículos esbeltos (Fig. 67E) y el margen proximal dorsal del endopodito del uropodito con un pliegue bien marcado (Fig. 67F).
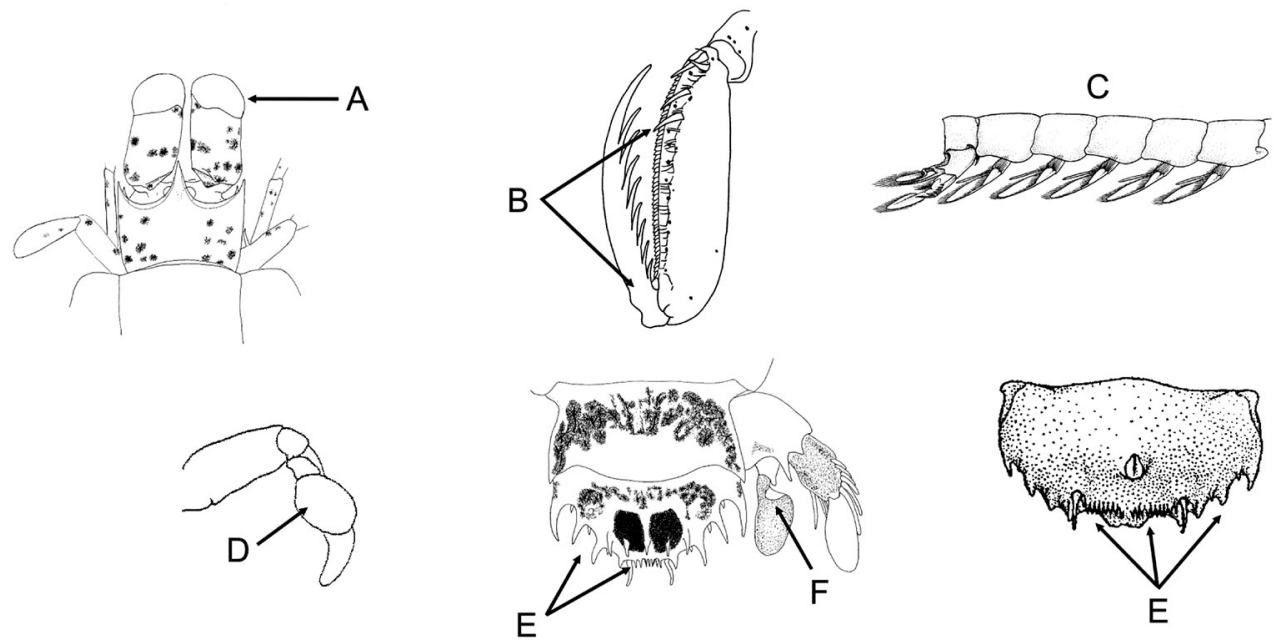
Especies de Nannosquillidae del Pacifico oriental.

Alachosquilla digueti (Coutiere, 1905);

Bigelowina biminiensis (Bigelow, 1893);

Nannosquilla anomala Manning, 1967;

Nannosquilla californiensis (Manning, 1961);

Nannosquilla canica Manning y Reaka, 1979;

Nannosquilla chilensis (Dahl, 1954);

Nannosquilla decemspinosa (Rathbun, 1910);

Nannosquilla galapagensis Manning, 1972;

Nannosquilla raymanningi Salgado-Barragán y Hendrickx, 1997;

Nannosquilla similis Manning, 1972.

Clave para la identificación de las especies de Nannosquillidae

1a. Rostro con 1-3 espinas proyectadas hacia adelante (Fig. 68A). Telson con 5 espinas dorsales agudas, subiguales, colocadas por arriba del margen posterior (Fig. 68B) 2
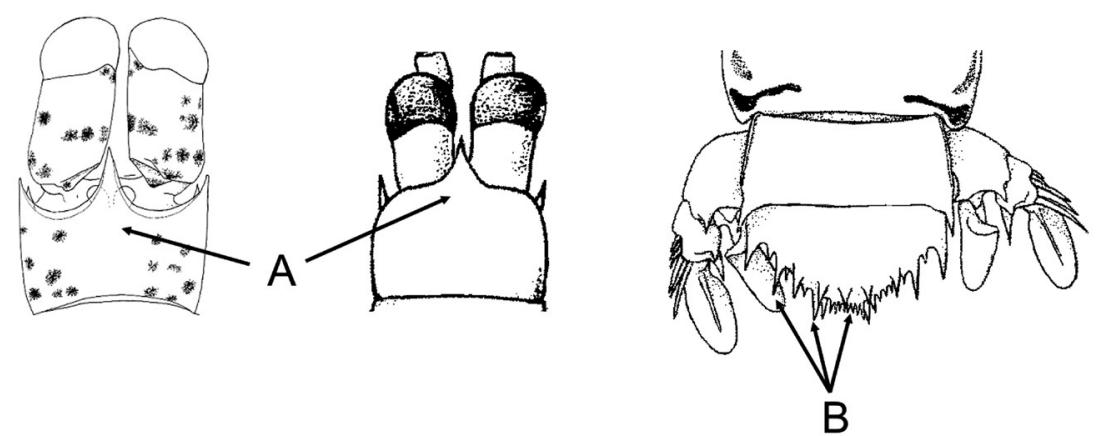

1b. Rostro cuadrado o subrectangular, sin espinas proyectadas hacia adelante (Fig. 69A). Dorso del telson sin espinas dorsales dirigidas hacia atrás, pero con una proyección anterior al margen distal a manera de falso margen o alero, que puede tener proyecciones distales agudas, sin espinas (Fig. 69B) (Nannosquilla)

. .3
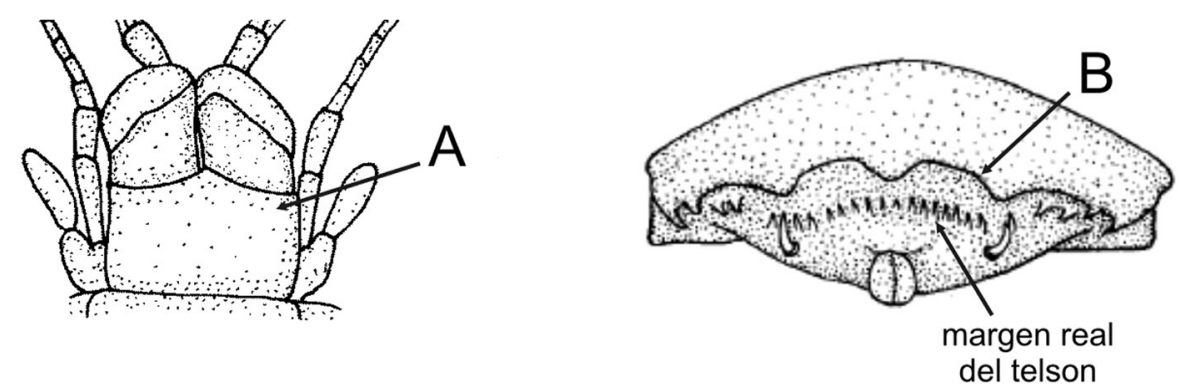

2a. Placa rostral con 3 proyecciones anteriores agudas (Fig. 70A). Margen del telson con 4 dientes fijos primarios (Fig. 
70B) (Alachosquilla) Alachosquilla digueti (golfo de California- Panamá; $30 \mathrm{~mm}$; 0-54 m; arena, rocas, comensal de Balanoglossus sp.).
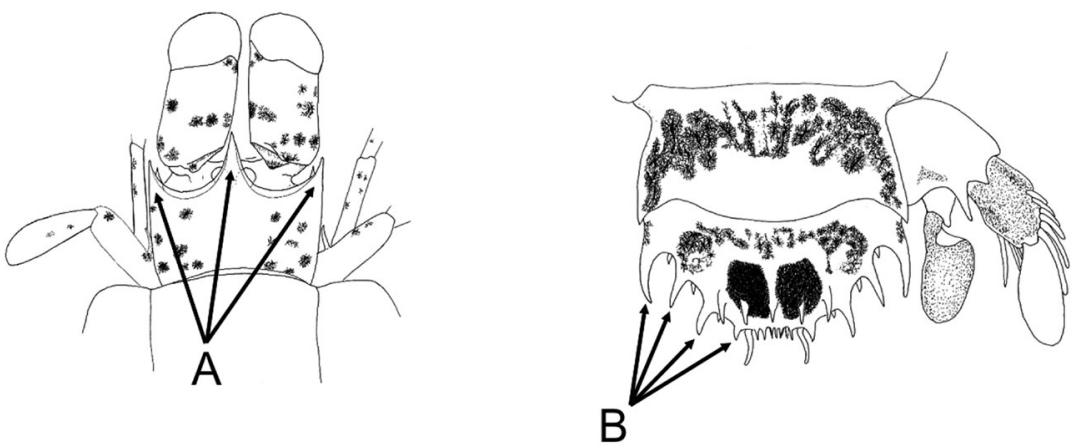

2b. Rostro con sólo una espina central anterior (Fig. 71A). Margen del telson con 2 pares de dientes primarios fijos (Fig. 71B) (Bigelowina) Bigelowina biminiensis (Costa Rica - Colombia; $62 \mathrm{~mm}$; 0-54 m; arena, grava, rocas, coral).
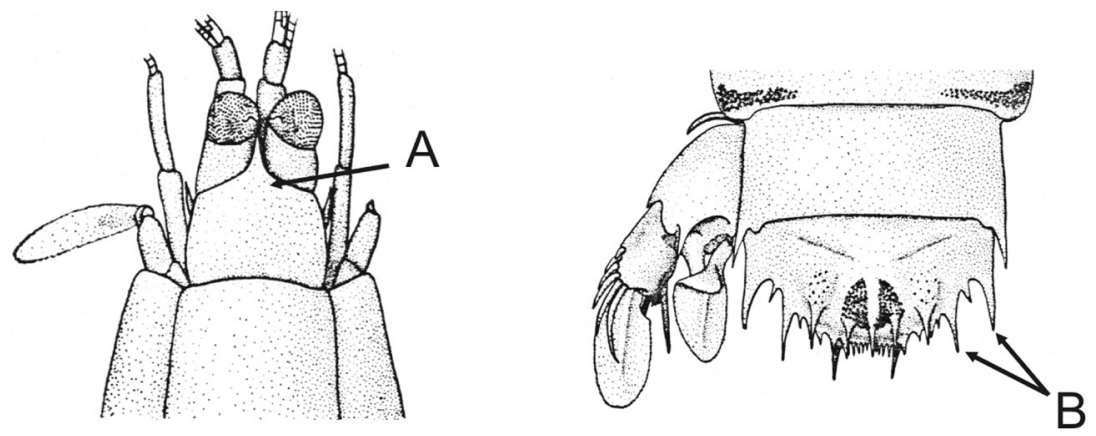

3a. Sexto somito abdominal con ángulos posterolaterales terminados en una espina aguda y alargada (Fig. 72A). Falso alero del telson con 8 o más proyecciones marginales (Fig. 72B)

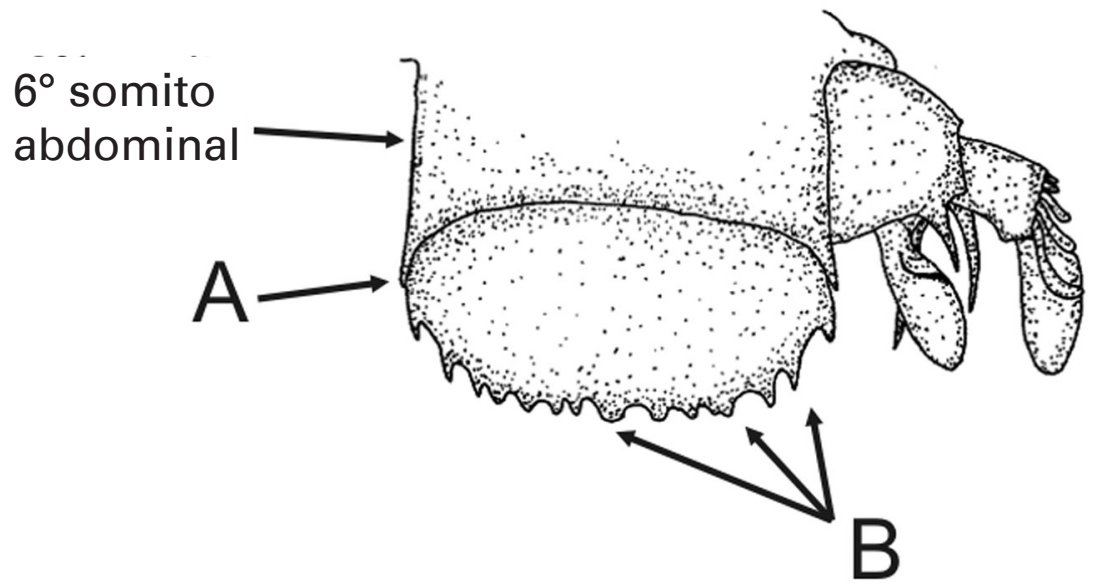


3b. Sexto somito abdominal con ángulos posterolaterales rectos o agudos, pero no terminados en una espina larga, a lo más en forma de ángulo agudo (Fig. 73A). Falso alero del telson sin proyecciones marginales; si están presentes, éstas son menos de 8 (Fig. 73B)
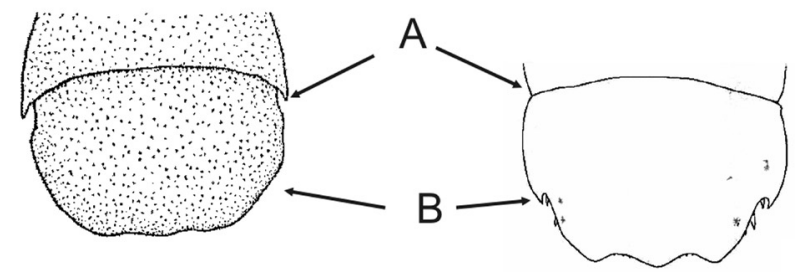

4a. Placa rostral subcuadrada o subpentagonal (Fig. 74A). Falso alero del telson con 8 proyecciones laterales, las submedias en forma de espina (Fig. 74B), con 14-20 dentículos submedios y 8 laterales (Fig. 74C). Espina interna de la prolongación basal del uropodito más larga que la externa (Fig. 74D)

Nannosquilla anomala (isla San Clemente, California; $41 \mathrm{~mm}$; 4-21 m; arena, grava).
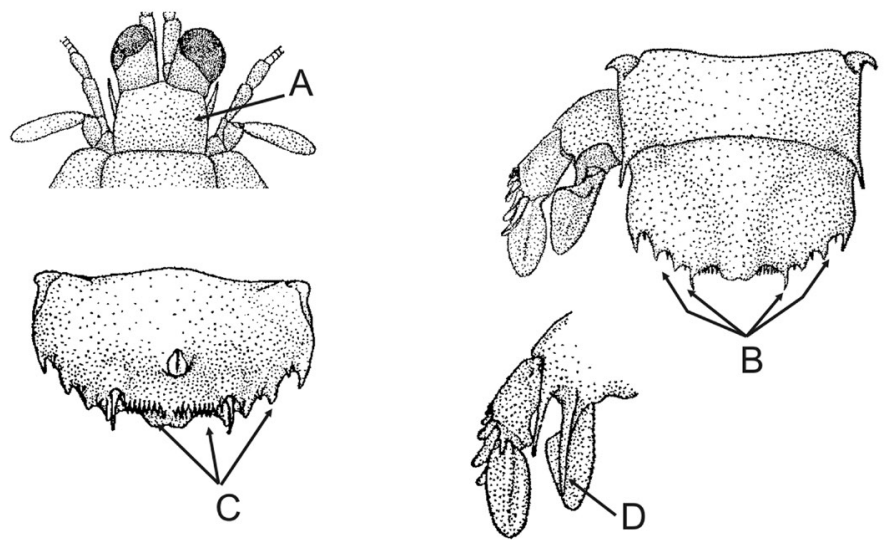

4b. Rostro rectangular (Fig. 75A). Falso alero del telson con 12-13 proyecciones laterales (Fig. 75B), con 4-16 dentículos submedios y laterales (Fig. 75C). Espinas interna y externa de la prolongación basal del uropodito subiguales (Fig. 75D) Nannosquilla californiensis (golfo de California - Colombia; 23 mm; 9-48 m; arena, grava, coral, algas).
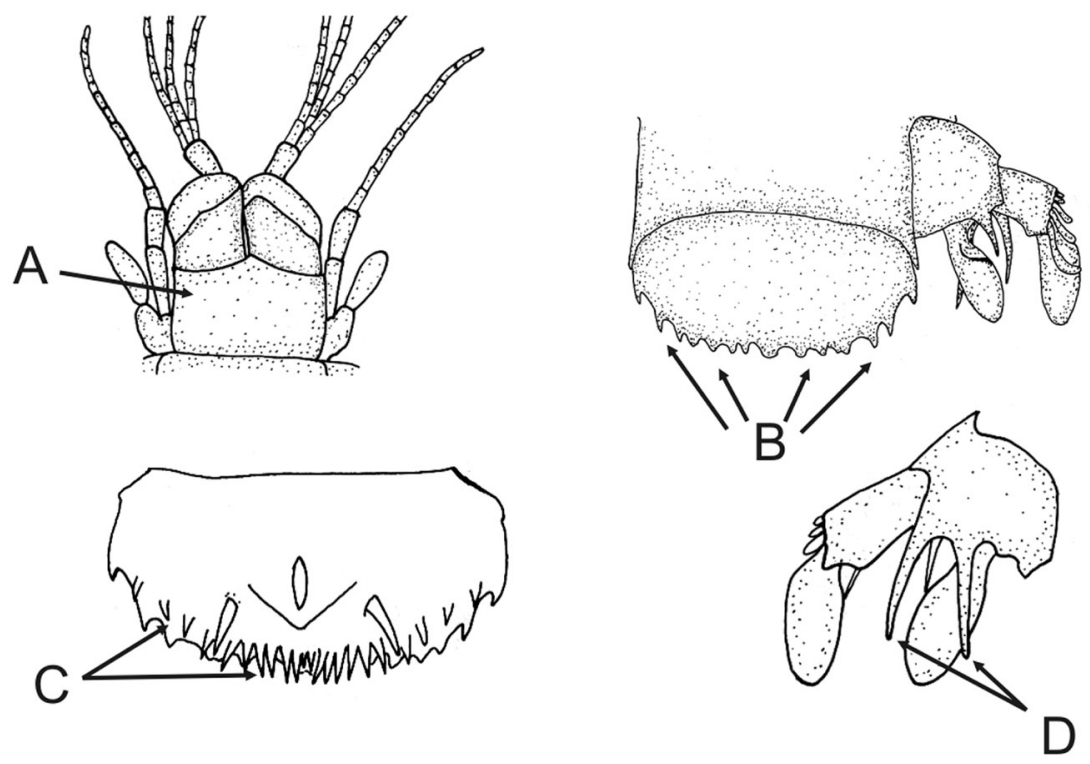
5a. Placa rostral subpentagonal, con márgenes anteriores obtusos (Fig. 76A). Espina interna de la prolongación basal del uropodito notablemente más corta que la externa (Fig. 76B). Margen verdadero del telson con 18-22 dentículos submedios (Fig. 76C) y 7 laterales (Fig. 76D) .....Nannosquilla raymanningi (isla Partida, golfo de California; 48 mm; 14 m; arena).
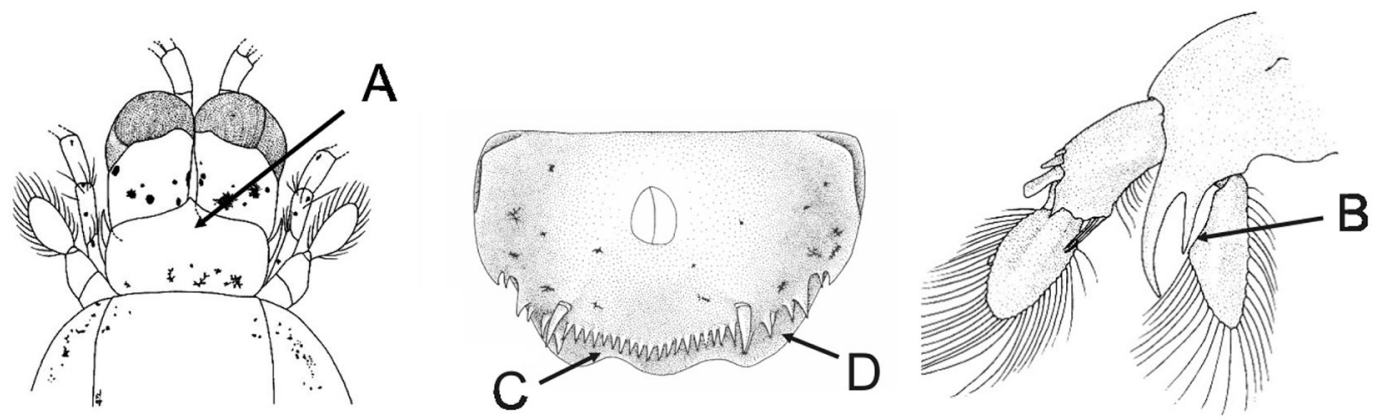

5b. Placa rostral cuadrada o rectangular (Fig. 77A). Espina interna de la prolongación basal del uropodito subigual o más larga que la externa (Fig. 77B). Telson con número de dentículos variable (Fig. 77C)
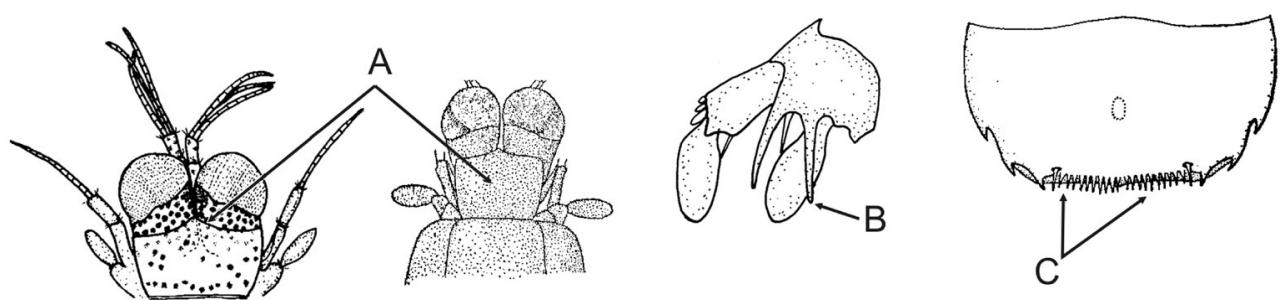

6a. Placa rostral rectangular, el doble de ancho que largo (Fig. 78A). Dactilo de la garra con 12-17 dientes, generalmente 17 (Fig. 78B) 7
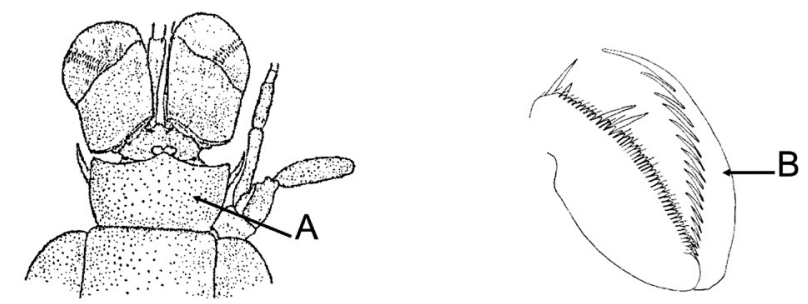

6b. Placa rostral pentagonal, cuadrada o subrectangular, pero no mucho más ancha que larga (Fig. 79A). Dactilo de la garra con menos de 15 dientes (Fig. 79B)
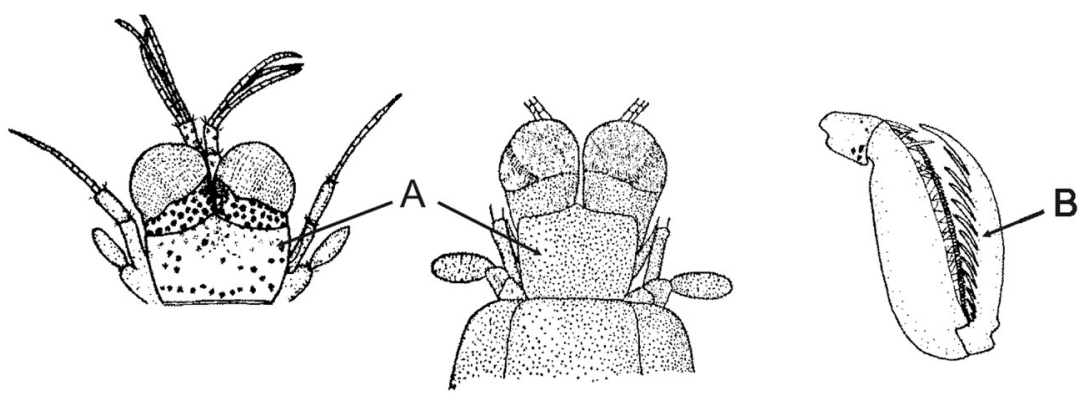
7a. Ángulos anterolaterales de la placa rostral agudos (Fig. 80A). Sexto somito abdominal con los márgenes posterolaterales terminados en ángulo agudo, pero no alargados (Fig. 80B). Prolongación basal del uropodito con la espina interna notablemente más larga que la externa (Fig. 80C) .Nannosquilla similis (islas Galápagos; $25 \mathrm{~mm} ; 2 \mathrm{~m}$ ).
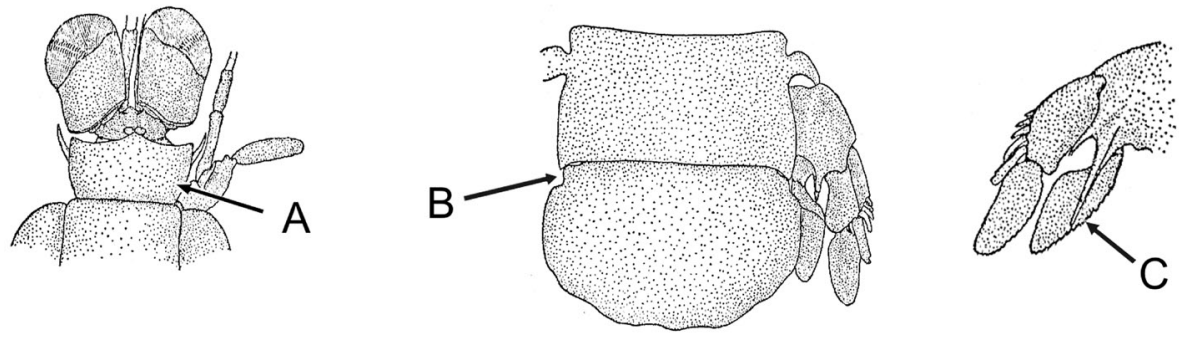

7a. Ángulos anterolaterales de la placa rostral redondeados (Fig. 81A). Sexto somito abdominal con los márgenes posterolaterales terminados en ángulo, espina o en una proyección alargada (Fig. 81B). Prolongación basal del uropodito con la espina interna de longitud similar a la externa (Fig. 81C)

.Nannosquilla chilensis (Isla Tenglo, Chile; $28 \mathrm{~mm}$; intermareal; arena).
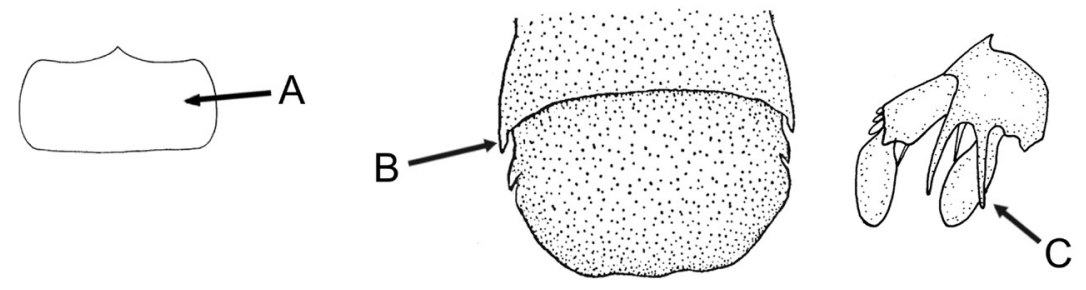

8a. Segmento basal de cada pereiópodo con una espina posterior (Fig. 82A). Placa rostral pentagonal (Fig. 82B)

..Nannosquilla canica (golfo de California - Colombia; $19 \mathrm{~mm}$; 5-33 m; arena).
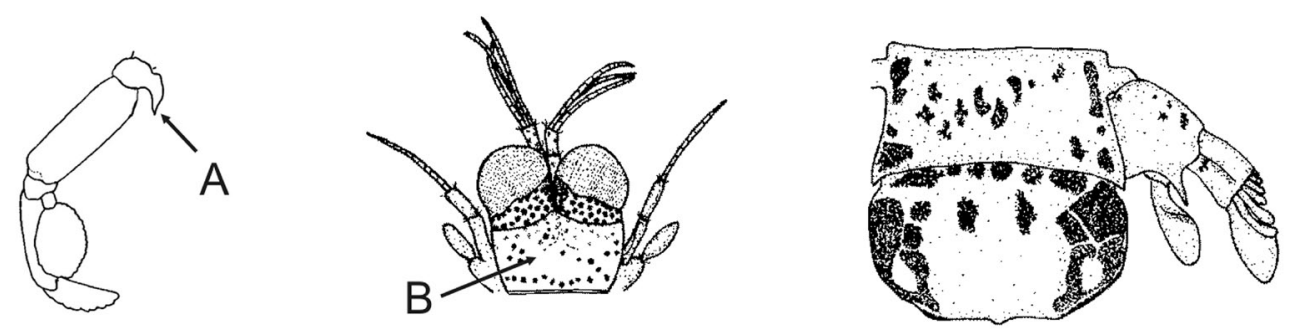

8b. Segmento basal de cada pereiópodo sin espinas posteriores (Fig. 83A). Placa rostral cuadrada o rectangular (Fig. 83B).
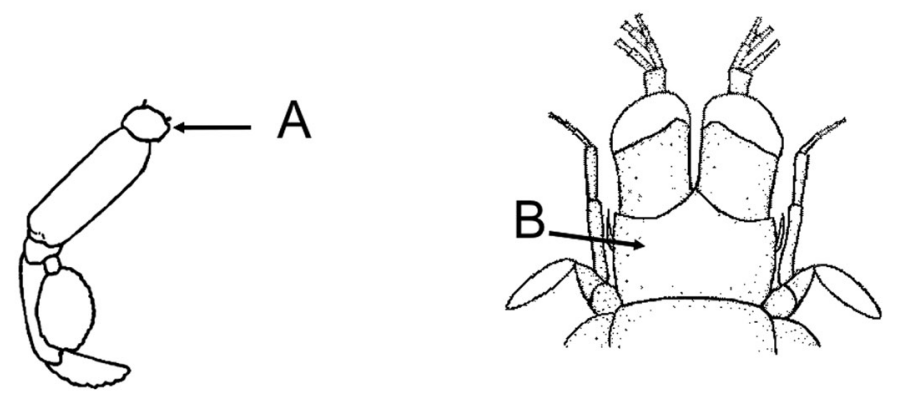
9a. Placa rostral rectangular con márgenes anterolaterales agudos, aunque no terminados en espina (Fig. 84A). Dactilo de la garra con 11 dientes (Fig. 84B). Armadura del telson con 3 pares de dientes fijos visibles dorsalmente (Fig. 84C) .Nannosquilla decemspinosa (El Salvador - Perú; $25 \mathrm{~mm}$; intermareal; lodo, arena).
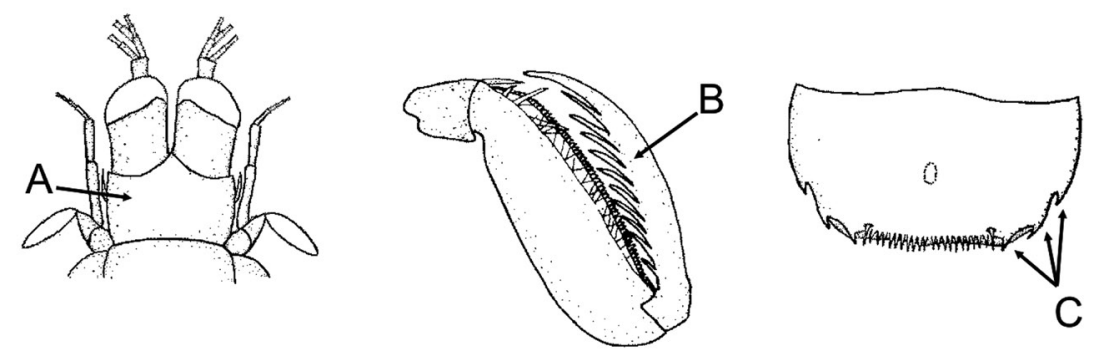

9b. Placa rostral subcuadrada con ángulos anterolaterales obtusos, no armados (Fig. 85A). Dactilo de la garra con 1315 dientes dientes (Fig. 85B). Armadura del telson con 4-5 pares de dientes cortos, no visibles dorsalmente (Fig. 85C) Nannosquilla galapagensis (Islas Galápagos; $23 \mathrm{~mm} ; 25 \mathrm{~m}$; arena).
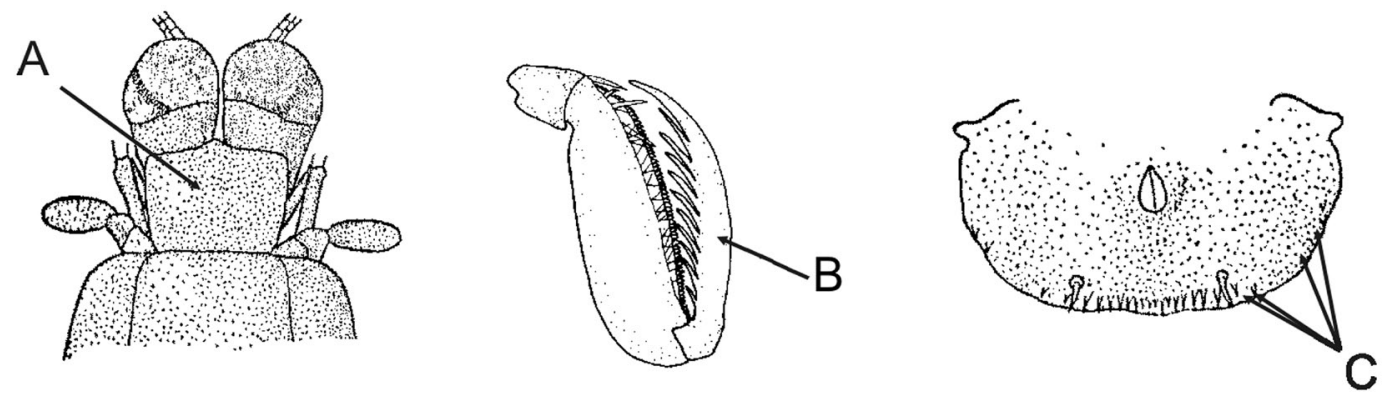

Familia Lysiosquillidae Giesbrecht, 1910

Las 2 especies de la familia Lysiosquillidae conocidas para el Pacífico americano son de talla grande (100 - >200 mm). Se caracterizan por tener la córnea bilobulada, oblicua con respecto al pedúnculo (Fig. 86A), una garra con el propodio con 4 espinas móviles proximales y el dactilo no hinchado en su base, generalmente con más de 10 dientes (Fig. 86B), el cuerpo deprimido y el abdomen no compacto (Fig. 86C), los pereiópodos 1- 3 con el endopodito alargado (Fig. 86D), el margen proximal del endopodito uropodal sin pliegue dorsal notablemente marcado (Fig. 86E) y el telson con los dientes primarios fusionados al margen, o con apariencia de pequeñas proyecciones (Fig. 86F). Las 2 especies presentan bandas obscuras en las partes anterior y posterior dorsales de los segmentos torácicos y abdominales (Fig. 86G).
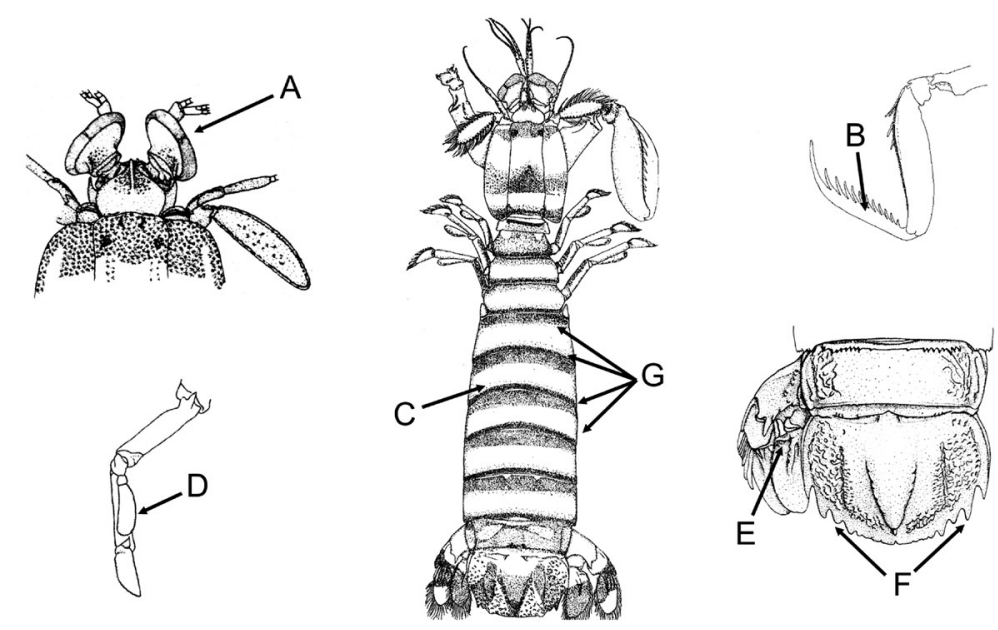
Especies de Lysiosquillidae del Pacifico oriental.

Lysiosquilla manningi Boyko, 2000 (= L. desaussurei (Stimpson, 1857));

Lysiosquilla panamica Manning, 1971.

Clave para la identificación de especies de Lysiosquillidae

1a. Sexto somito abdominal y margen anterior del telson con numerosas espínulas o dentículos dorso-marginales (Fig. 87A). Margen distal del telson redondeado, con proyecciones que en ocasiones pueden dar apariencia de dentículos (Fig. 87B). Dactilo de la garra generalmente con 11-12 dientes (Fig. 87C)

Lysiosquilla manningi (golfo de California - Perú; $210 \mathrm{~mm}$; 20-48 m; lodo, arena).
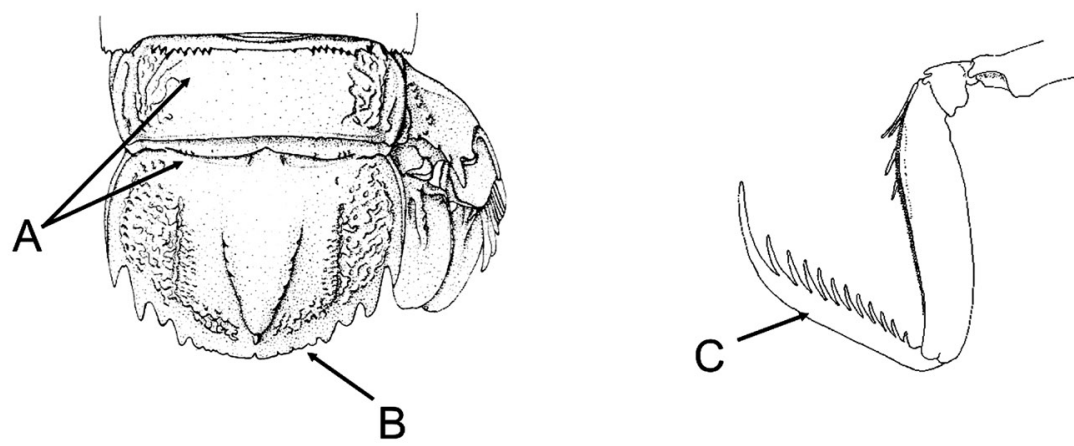

1b. Sexto somito abdominal y telson sin espínulas o dentículos, puede presentar un aspecto irregular o erosionado dorsalmente (Fig. 88A). Margen distal del telson semi-recto con muy pocas proyecciones (Fig. 88B). Dactilo de la garra generalmente con 11 dientes (Fig. 88C) ........Lysiosquilla panamica (Jalisco, México - Ecuador; 205 mm; 3-90 m; lodo).
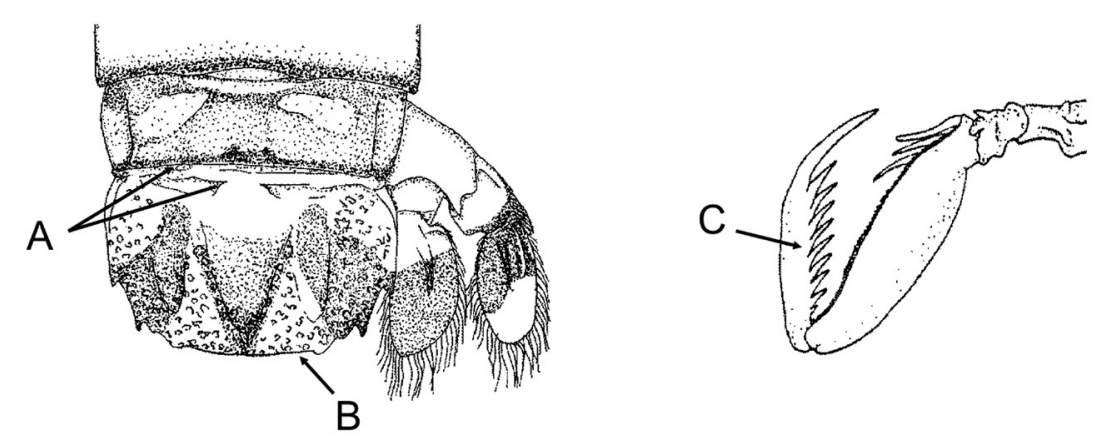

Familia Tetrasquillidae Manning y Camp, 1993

La familia Tetrasquillidae contiene especies de pequeñas a medianas (21-100 mm). Se distinguen del resto de las especies de Lysiosquilloidea por presentar una combinación de las siguientes características: córnea bilobulada (Fig. 89A); propodio de la garra con 3-4 dientes móviles proximales (Fig. 89B) y dactilo no hinchado en su base, con 4 o más dientes (Fig. 89C); articulación abdominal compacta (Fig. 89D); telson con dientes y dentículos no fusionados, claramente marcados y esbeltos (Fig. 89E). 

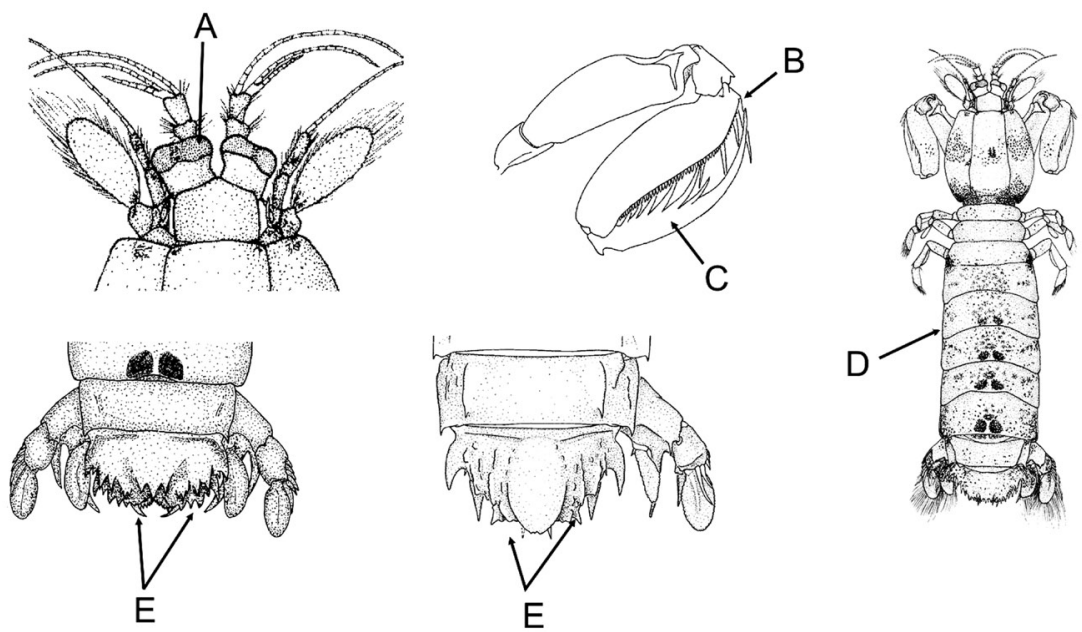

Especies de Tetrasquillidae del Pacifico oriental. Heterosquilloides insignis (Manning, 1963);

Heterosquilla polydactyla (von Martens, 1881); Tetrasquilla mccullochae (Schmitt, 1940).

Clave para la identificación de las especies de Tetrasquillidae

1a. Córnea subglobular o ensanchada, pero no claramente bilobulada (Fig. 90A). Prolongación basal del uropodito con la espina externa notablemente más larga que la interna (Fig. 90B) (Heterosquilla). Rostro más largo que ancho (Fig. 90C). Dactilo de la garra con 17 a 20 dientes (Fig. 90D)

Heterosquilla polydactyla (Perú - Chile, Tierra del Fuego; 95 mm; 10-50 m; lodo, arena).
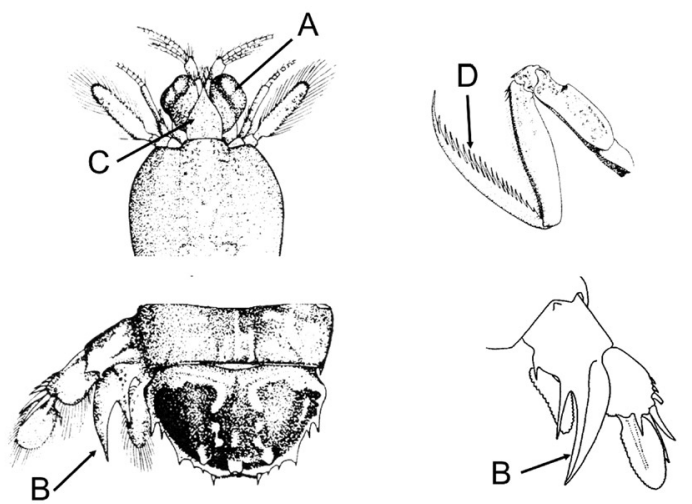

1b. Córnea claramente bilobulada (Fig. 91A). Prolongación basal del uropodito con la espina interna tan larga o más larga que la externa (Fig. 91B)
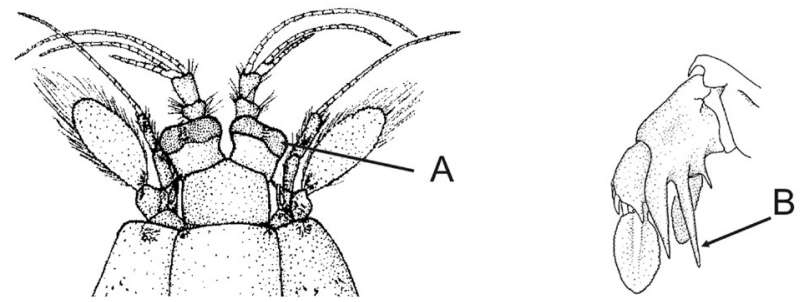
2a. Protopodito antenal sin papilas en su cara interna (Fig. 92A). Prolongación basal del uropodito con una espina ventral anterior a la articulación del endopodito (Fig. 92B) (Heterosquilloides). Garra con 7-8 dientes (Fig. 92C). Telson con 2 espinas marginales primarias a cada lado (Fig. 92D)
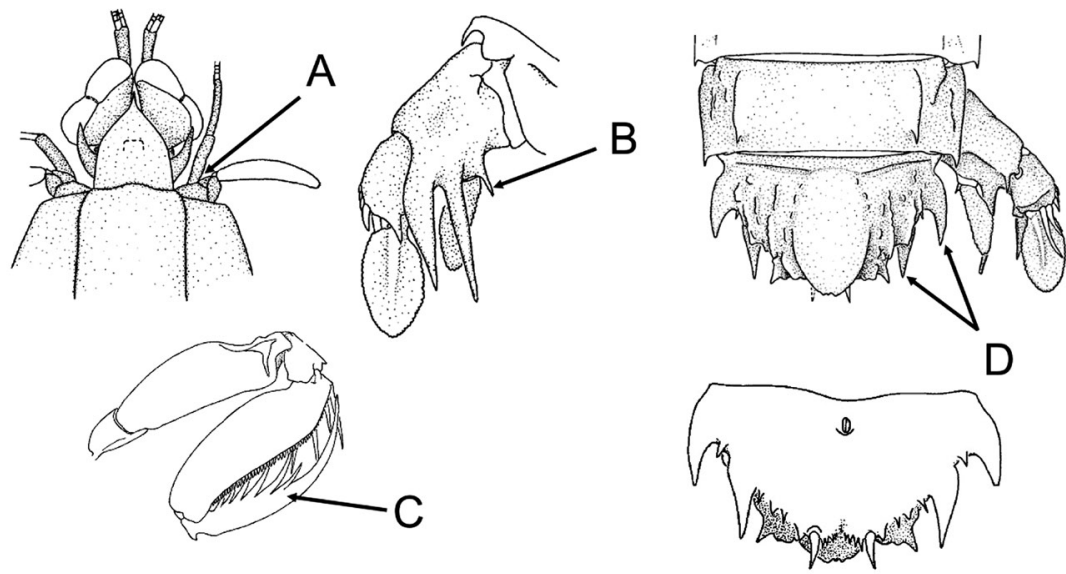

2b. Protopodito antenal con 2 papilas ventrales y 2 en la cara interna (Fig. 93A). Prolongación basal del uropodito sin espina ventral anterior a la articulación del endopodito (Fig. 93B) (Tetrasquilla). Dactilo de la garra con 4 dientes (Fig. 93C). Telson con 4 espinas marginales primarias a cada lado (Fig. 93D)

.....Tetrasquilla mccullochae (golfo de California a Ecuador: circumtropical; 50 mm; 0-54 m; arena, grava, rocas, coral).
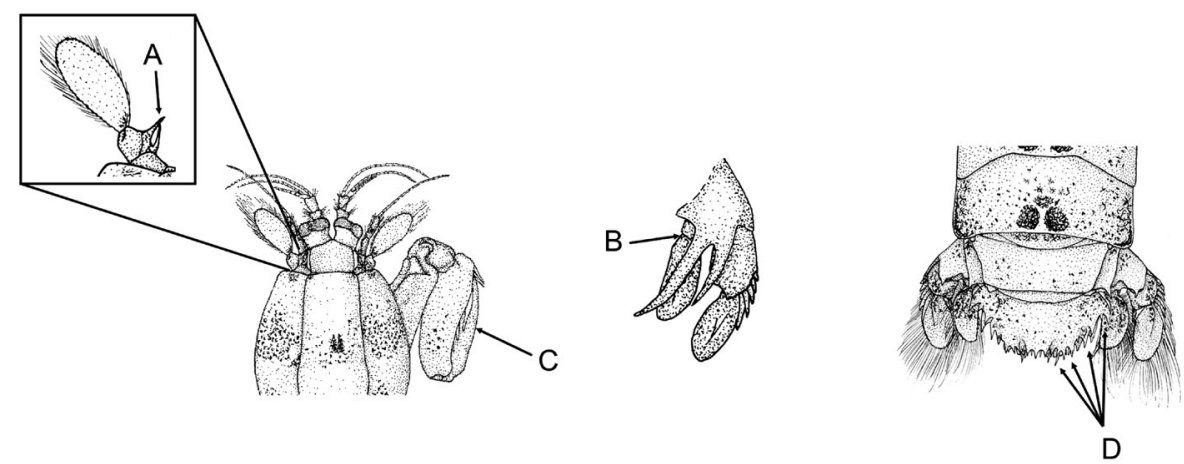

Superfamilia Squilloidea Latreille, 1802

Los miembros de la superfamilia Squilloidea se caracterizan por tener 2 hileras de omatidias hexagonales en la banda media de la córnea (Fig. 94A), el tercero y cuarto maxilípedos con el propodio ovalado y no ornamentado distalmente (Fig. 94B), la garra con articulación terminal (Fig. 94C), con 3 dientes móviles en la parte proximal del propodio (Fig. 94D), el dactilo con 4 o más dientes (Fig. 94E), el telson con una carina media (Fig. 94F) y 4 o más dentículos intermedios (Fig. 94G), el protopodito uropodal por lo general con 2 o más espinas primarias, ocasionalmente con una (Fig. 94H) y la articulación de los segmentos del exopodio siempre de tipo terminal (Fig. 94I). 

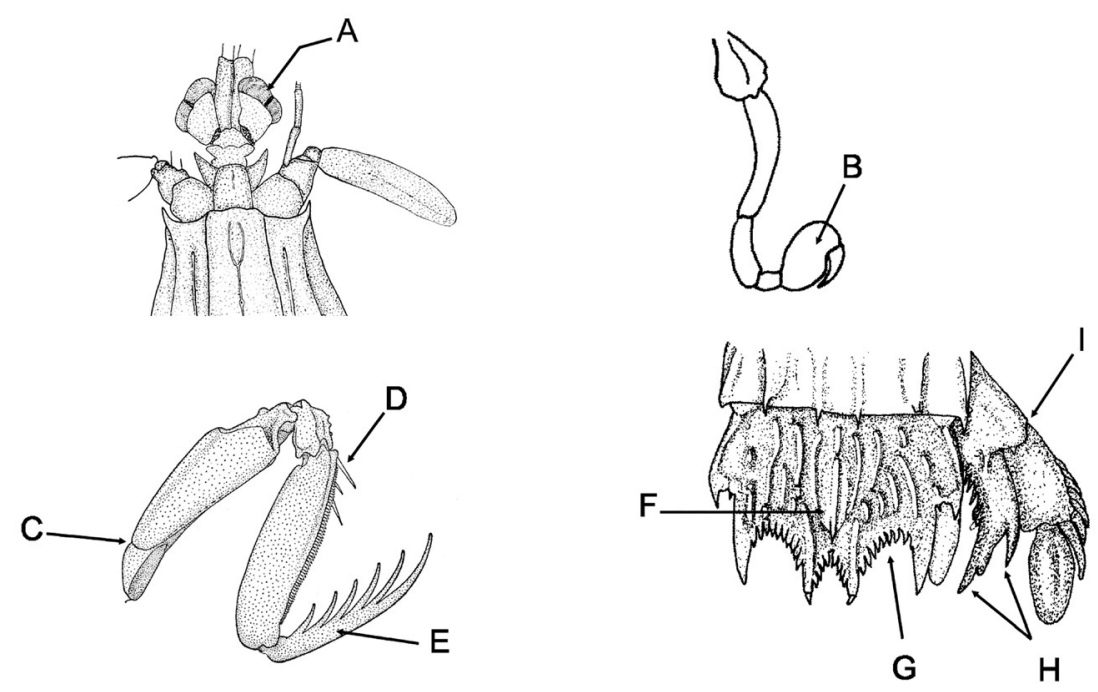

La superfamilia Squilloidea está formada por una sola familia, Squillidae, que contiene el mayor número de géneros y especies en el mundo. La talla de las especies varía desde muy pequeñas $(<20 \mathrm{~mm})$ hasta muy grandes $(>200 \mathrm{~mm})$. En el Pacífico oriental se conocen 7 géneros y 17 especies.

Especies de Squillidae del Pacifico oriental. Cloridopsis dubia (H. Milne Edwards, 1837);

Crenatosquilla oculinova (Glassell, 1942);

Meiosquilla dawsoni Manning, 1970;

Meiosquilla swetti (Schmitt, 1940);

Pontiosquilla maniana (Bigelow, 1931);

Pterygosquilla armata armata (H. Milne Edwards, 1837);

Pterygosquilla gracilipes (Miers, 1881);

Schmittius peruvianus Manning, 1972;

Schmittius politus (Bigelow, 1891);

Squilla aculeata aculeata Bigelow, 1893;

Squilla biformis Bigelow, 1891;

Squilla bigelowi Schmitt, 1940;

Squilla hancocki Schmitt, 1940;

Squilla mantoidea Bigelow, 1893;

Squilla panamensis Bigelow, 1891;

Squilla parva Bigelow, 1891;

Squilla tiburonensis Schmitt, 1940.

Clave para la identificación de los géneros y especies de Squillidae

1a. Ápices de los dientes submedios del telson móviles, ocasionalmente perdidos en los adultos, pero en su lugar queda 
una pequeña marca (Fig. 95)
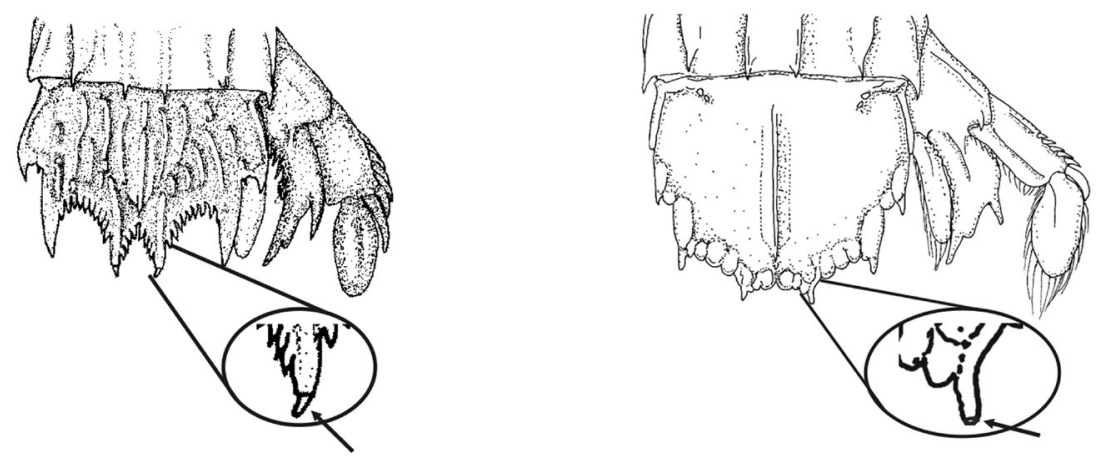

1b. Ápices de los dientes submedios del telson fijos (Squilla) (Fig. 96)

.10

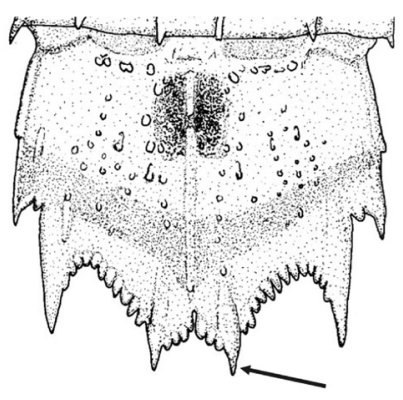

2a. Ángulos anterolaterales del caparazón terminados en espina (Fig. 97) .3

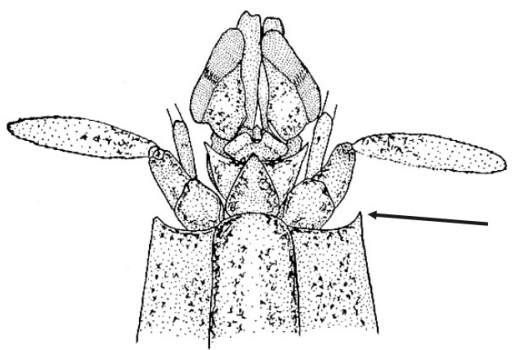

2b. Ángulos anterolaterales del caparazón obtusos, no terminados en espina (Fig. 98)

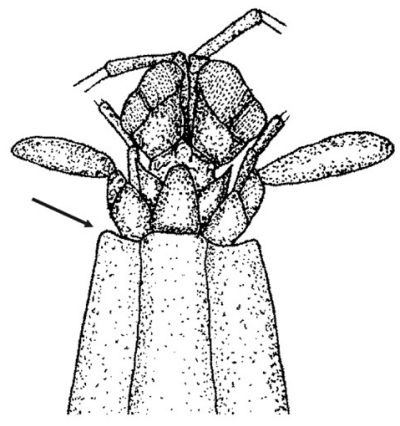


3a. Escamas oculares en forma de espina y dirigidas hacia delante (Fig. 99), distribución en aguas templadas del hemisferio sur (Pterygosquilla)

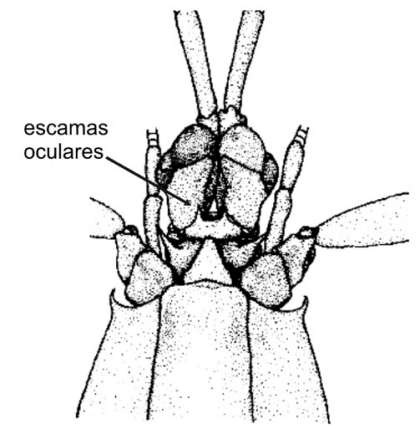

3b. Escamas oculares de forma variable, pero no en forma de espina (Fig. 100), distribución al menos hasta la franja subtropical 5

4a. Córnea en forma de "T", bilobulada y claramente más ancha que el pedúnculo ocular (Fig. 101A). Base de la placa rostral más ancha que el extremo distal (Fig. 101B). Carinas submedias presentes en todos los somitos abdominales (Fig. 101C). Telson con o sin 1 dentículo submedio (Fig. 101D) Pterygosquilla armata armata (Valparaíso, Chile - Argentina; 168 mm; 10-400 m; limo, arena).
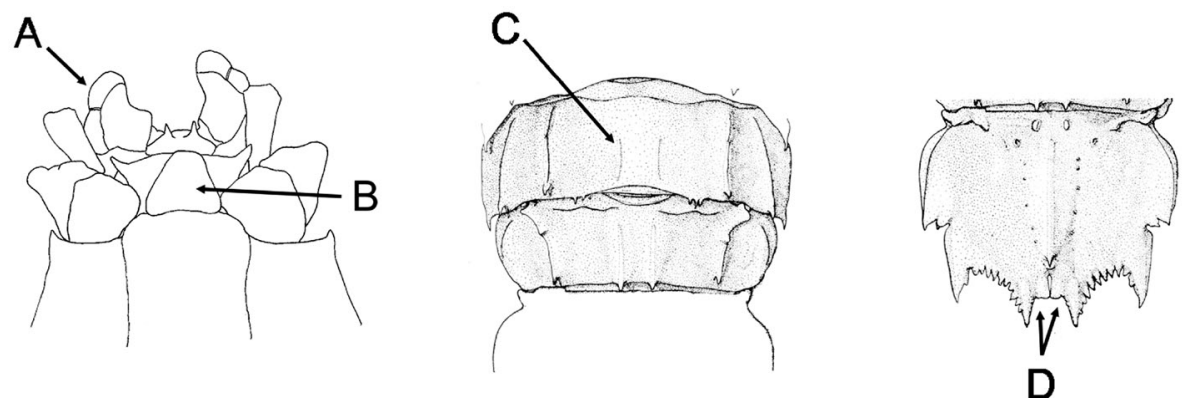

4b. Córnea globular, no claramente bilobulada y no mucho más ancha que el pedúnculo ocular (Fig. 102A). Placa rostral subrectangular (Fig. 102B). Carinas submedias presentes sólo en el sexto somito abdominal (Fig. 102C). Telson con más 

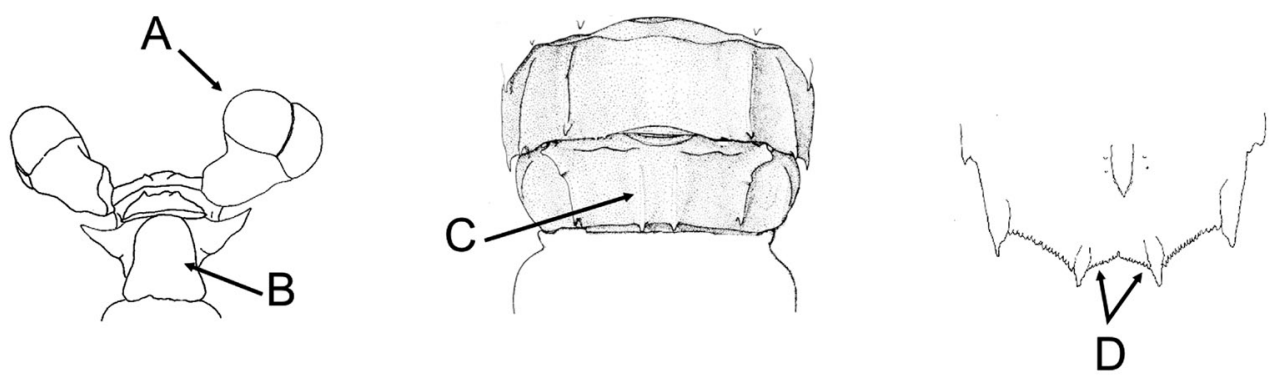

5a. Pedúnculo ocular no dilatado en su base (Fig. 103A). Dactilo de la garra con 4 dientes (Fig. 103B). Pereiópodos 1-4 con epipoditos (Fig. 103C). Dientes marginales del telson esbeltos, agudos y alargados (Fig. 103D) (Schmittius)
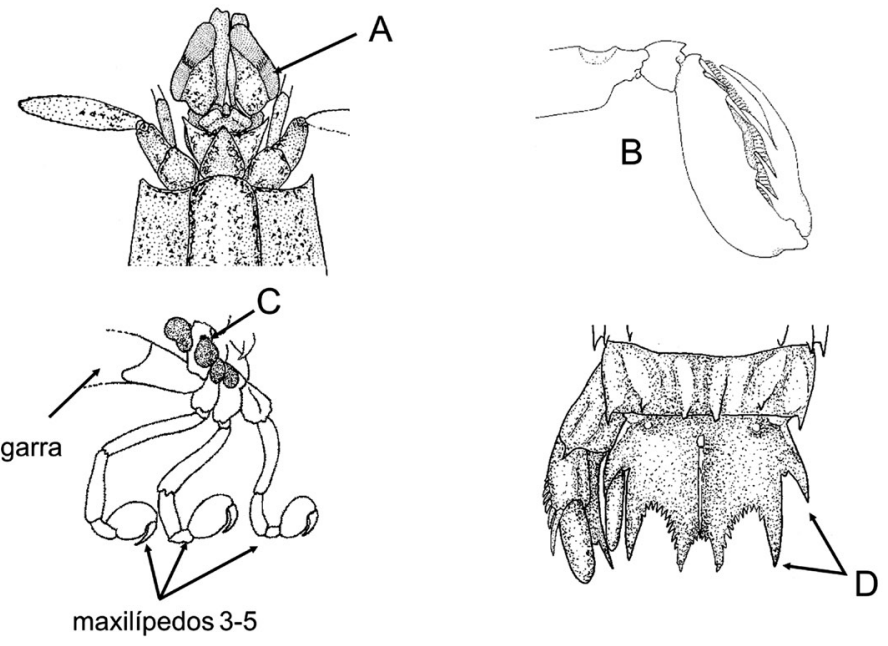

5b. Pedúnculo ocular dilatado en su base (Fig. 104A). Dactilo de la garra con 5-6 dientes (Fig. 104B). Base de los 3 primeros maxilípedos, incluida la garra, con epipoditos en su margen externo (Fig. 104C). Dientes marginales del telson cortos y engrosados en su base (Fig. 104D)

Cloridopsis dubia (golfo de California - Perú: anfiamericana; $168 \mathrm{~mm}$; 0-73 mm; lodo, sistemas lagunares).
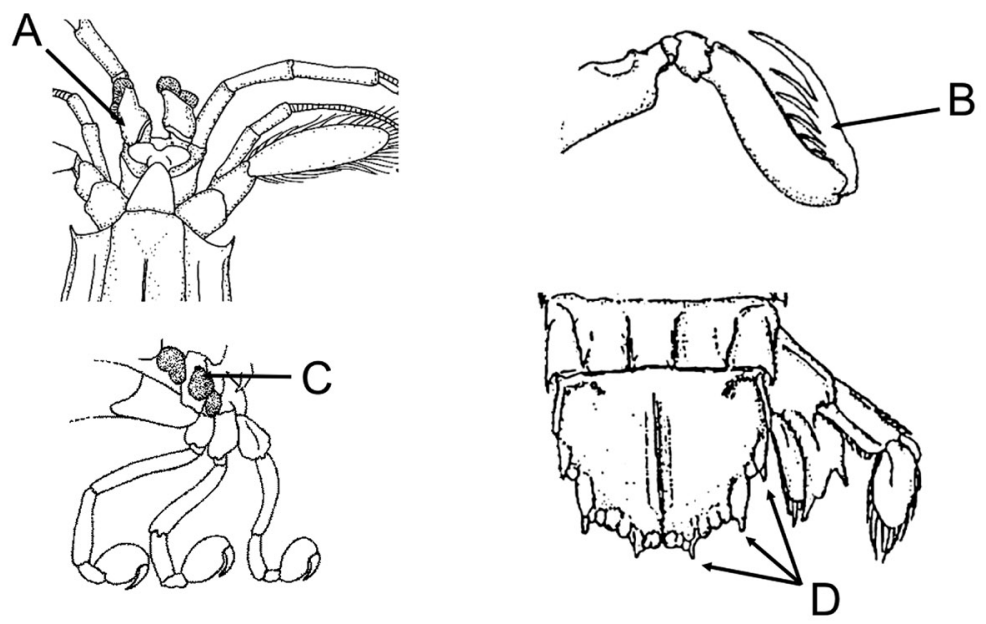
6a. Placa rostral aguzada anteriormente pero no terminada en espina (Fig. 105A). Proceso lateral del quinto somito torácico con la punta aguda (Fig. 105B). Espina interna de la prolongación basal del uropodito delgada, con una protuberancia pequeña (Fig. 105C) Schmittius peruvianus (Perú; 60 mm; 125-350 m; fondos blandos).
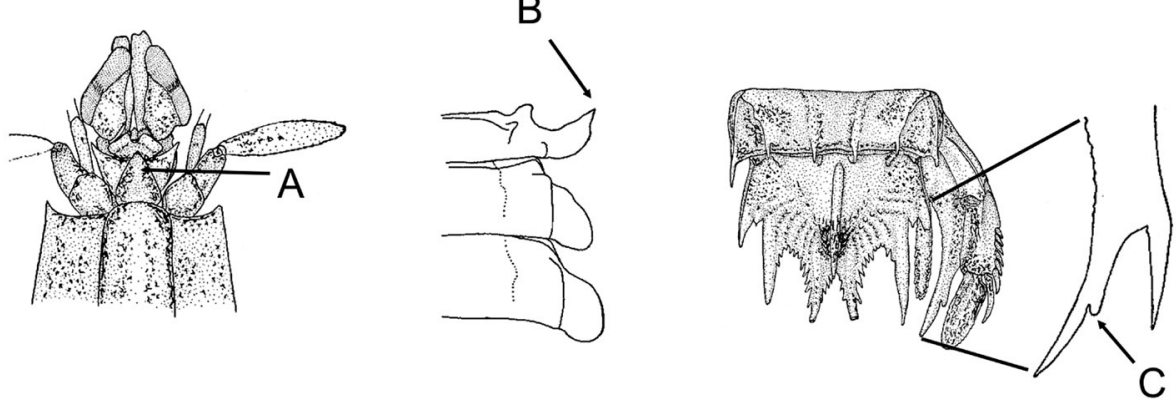

6b. Placa rostral triangular, no aguzada anteriormente (Fig. 106A). Proceso lateral del quinto somito torácico obtuso (Fig. 106B). Espina interna de la prolongación basal del uropodito con una protuberancia grande (Fig. 106C)

Schmittius politus (California - golfo de California; $63 \mathrm{~mm}$; 12-245 m; fondos blandos).
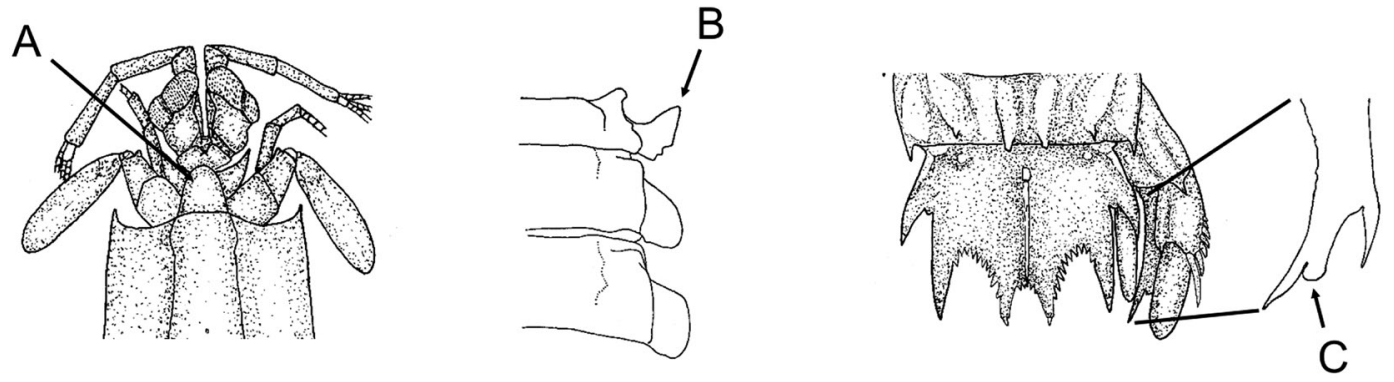

7a. Ojos pequeños, córnea ligeramente más ancha que el pedúnculo (Fig. 107A). Dactilo de la garra con 5 dientes (Fig. 107B). Con espinas en el dorso del telson además de la terminal en la carina media (Pontiosquilla)

Pontiosquilla mauiana (golfo de

California - golfo de Tehuantepec, México e Indo-Pacífico; 27 mm; 29-79 mm; arena, grava, coral).

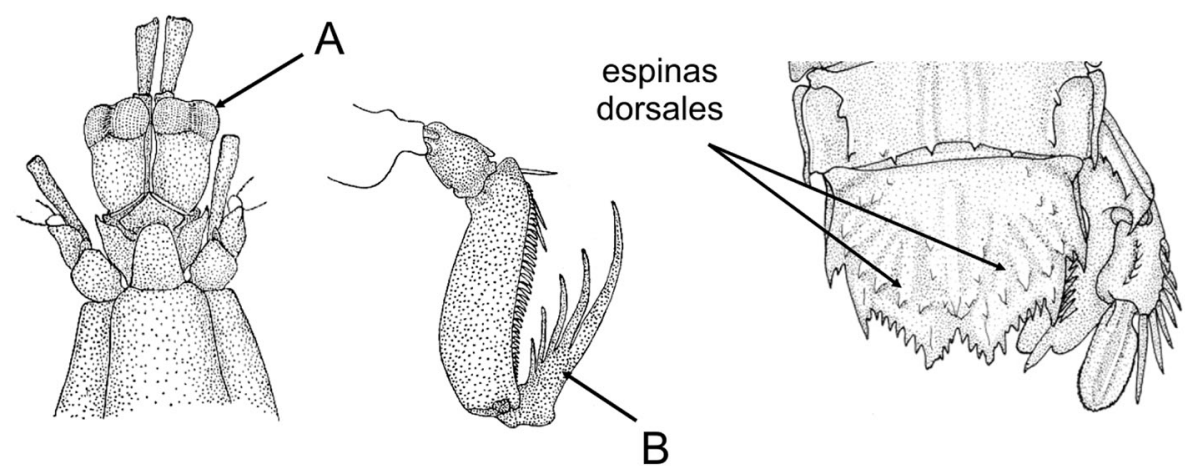


7b. Ojos grandes o medianos, córnea claramente más ancha que el pedúnculo (Fig. 108A). Dactilo de la garra con 4 dientes (Fig. 108B). Telson sin espinas dorsales, excepto la terminal de la carina media (Fig. 108C)
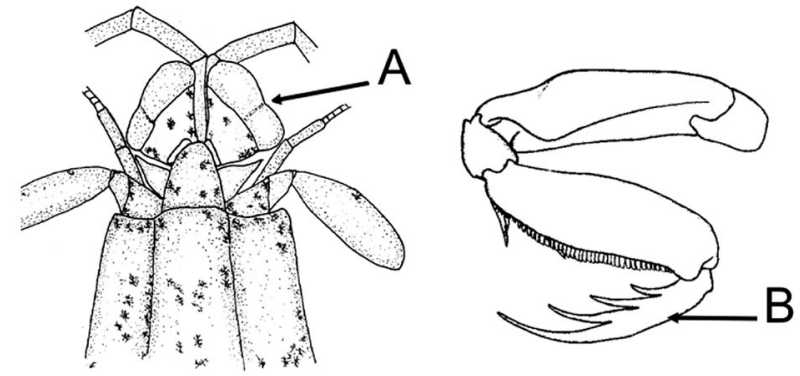

C

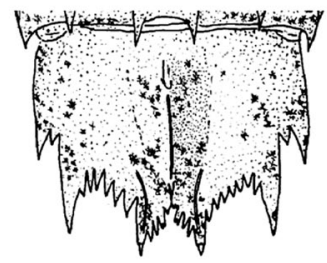

8a. Córnea del ojo con ondulaciones anteriores (Fig. 109A). Antenas y anténulas con tubérculos o espinas a lo largo de sus segmentos (Fig. 109B). Telson con un par de carinas laterales a la carina media que se prolongan hasta los dientes submedios (Fig. 109C) (Crenatosquilla)

.Crenatosquilla oculinova (golfo de California - Ecuador; 36 mm; 0-61 m; lodo, arena, grava).
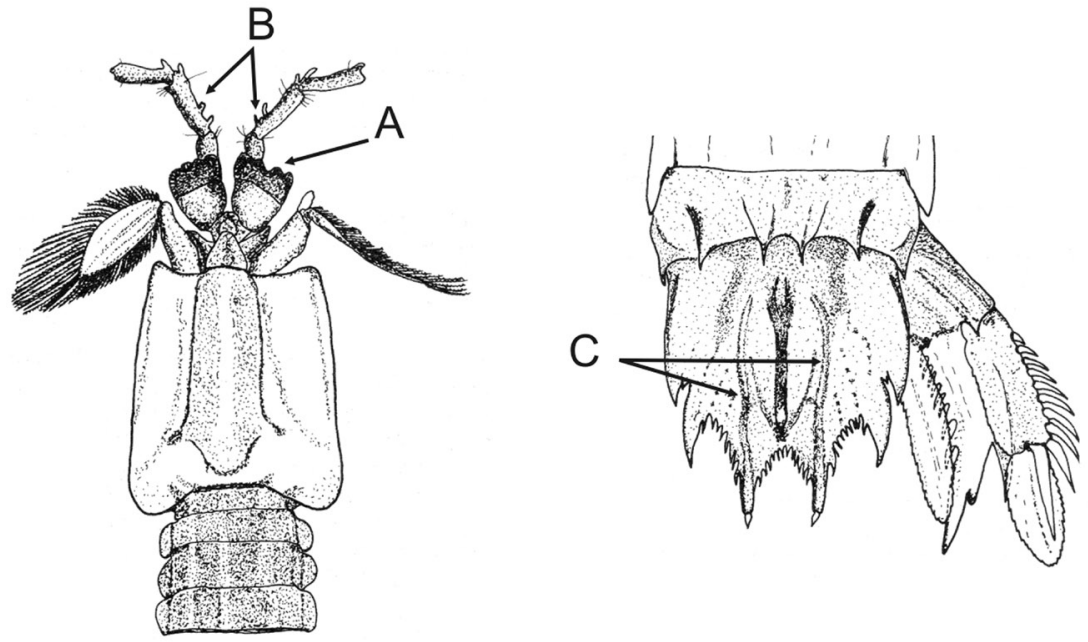

8b. Córnea bilobulada y con el margen anterior recto, liso (Fig. 110A). Anténulas y antenas sin espinas ni tubérculos en su margen (Fig. 110B). Telson sin carinas laterales a la media o con varios pares (Fig. 110C) (Meiosquilla)
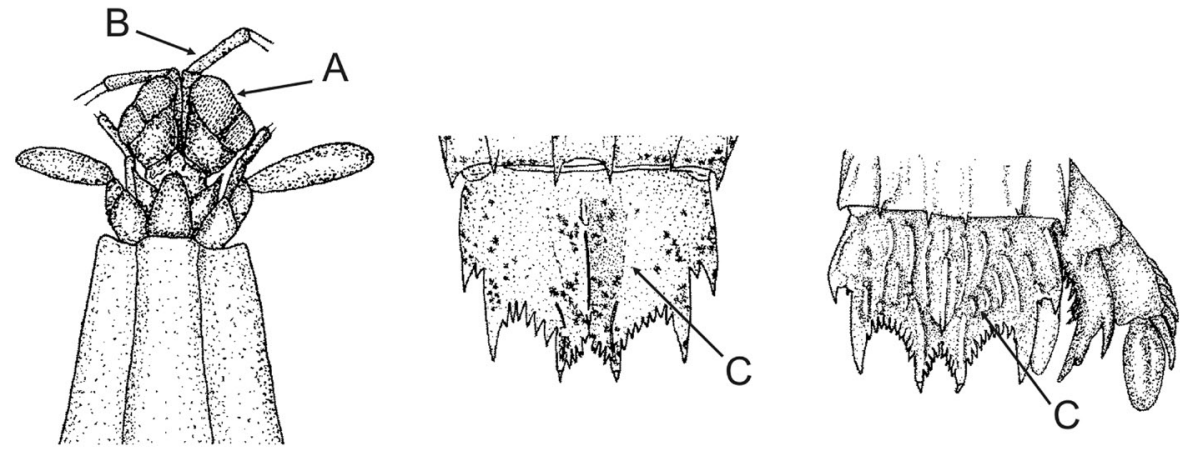
9a. Superficie dorsal del telson con varios pares de carinas laterales a la carina media (Fig. 111) .Meiosquilla swetti (golfo de California - Colombia; $42 \mathrm{~mm}$; 1-45 m; arena, grava, coral).

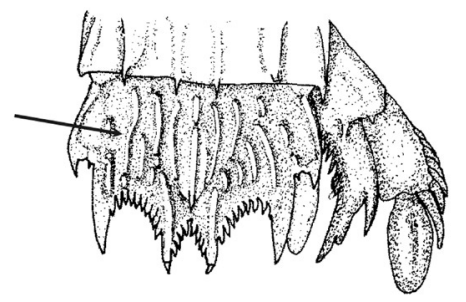

9b. Superficie dorsal del telson sin carinas laterales a la carina media (Fig. 112)

..Meiosquilla dawsoni (golfo de California - Colombia; $47 \mathrm{~mm}$; 0-30 m; lodo, arena, grava).

10a. Isquio de la garra con una espina ventral (Fig. 113A). Epipoditos presentes sólo en los 4 primeros maxilípedos (Fig. 113B). Ápice de los dientes submedios del telson generalmente curvado hacia el interior (Fig. 113C)

Squilla aculeata aculeata (golfo de California - Iquique, Chile; $197 \mathrm{~mm}$; 0-73 m; lodo, bahías y lagunas).
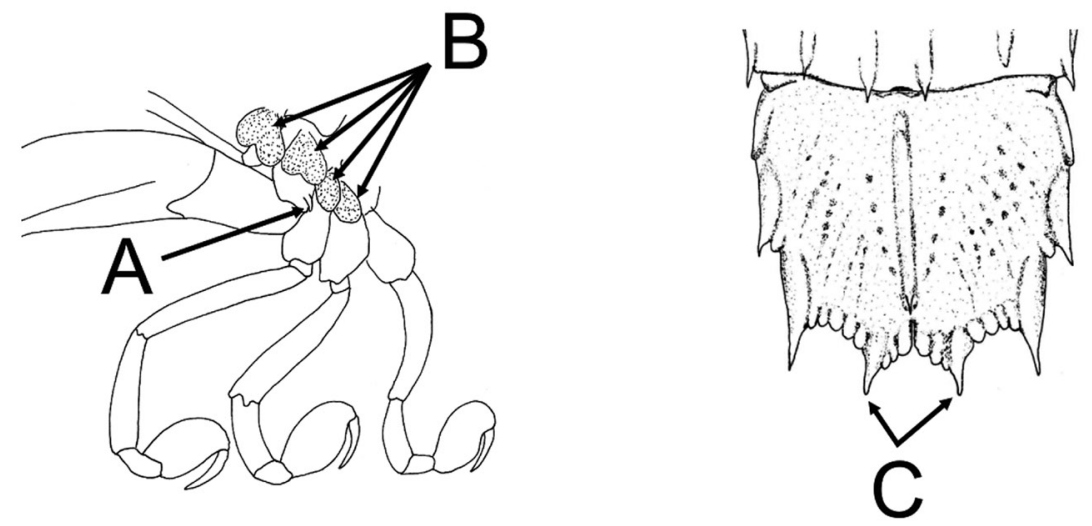

10b. Isquio de la garra sin espina ventral (Fig. 114A). Epipoditos en los 5 maxilípedos (Fig. 114B). Ápices de los dientes 

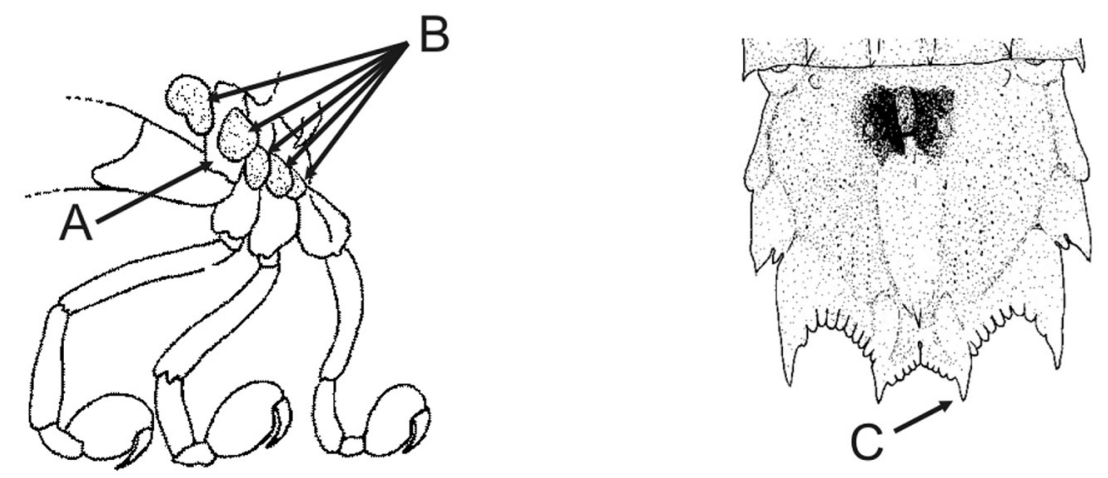

11a. Lóbulo prelateral del telson presente y terminado en espina (Fig. 115A). Machos adultos con carinas marginales del telson claramente engrosadas (Fig. 115B)

Squilla bigelowi (golfo de California, registros dudosos en Costa Rica y Perú; 140 mm; 6-150 m; lodo, arena).
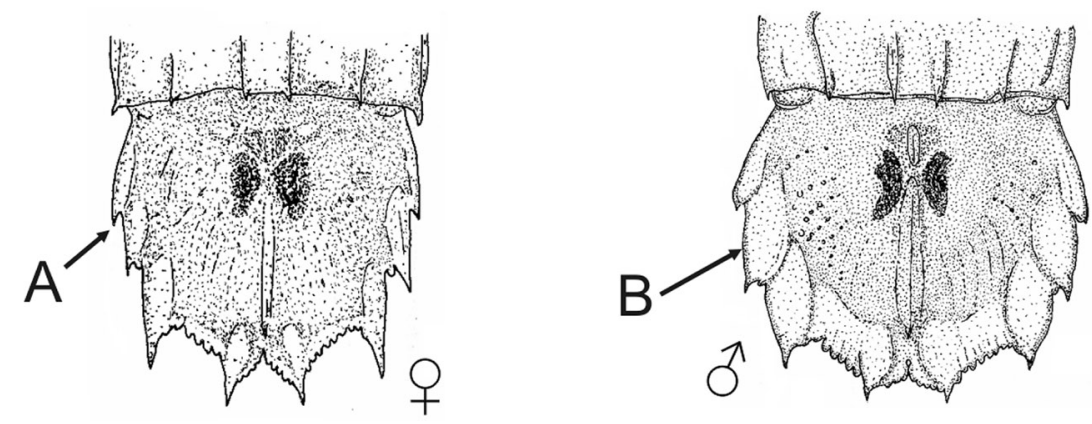

11b. Lóbulo prelateral del telson ausente o presente pero nunca terminado en espina (Fig. 116A). Los machos adultos pueden tener engrosadas, o no, las carinas marginales del telson (Fig. 116B)

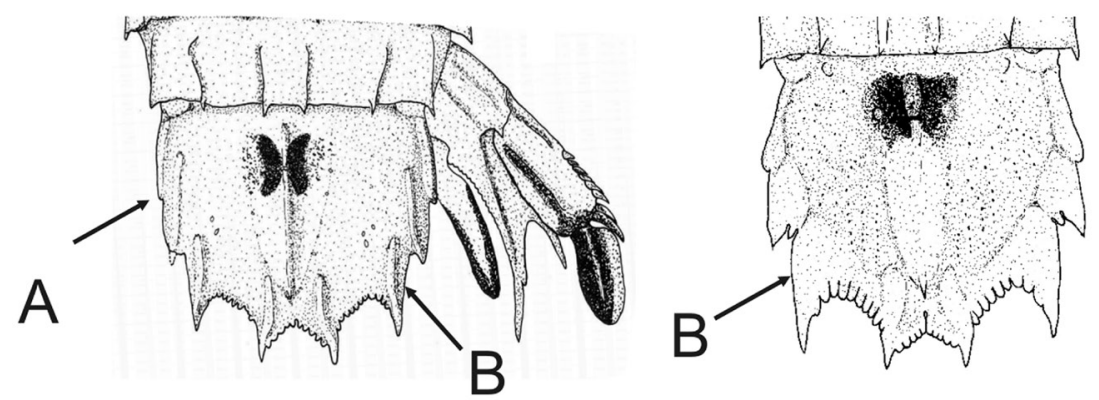

12a. Telson con carina post-anal, ventral, terminada en espina (Fig. 117A). Los machos adultos presentan las carinas marginales del telson fuertemente engrosadas, al grado de que en ocasiones aparecen como fusionadas entre sí (Fig. 
117B) Squilla biformis (golfo de California - Perú; 208 mm; 28-518 m; lodo, arena).
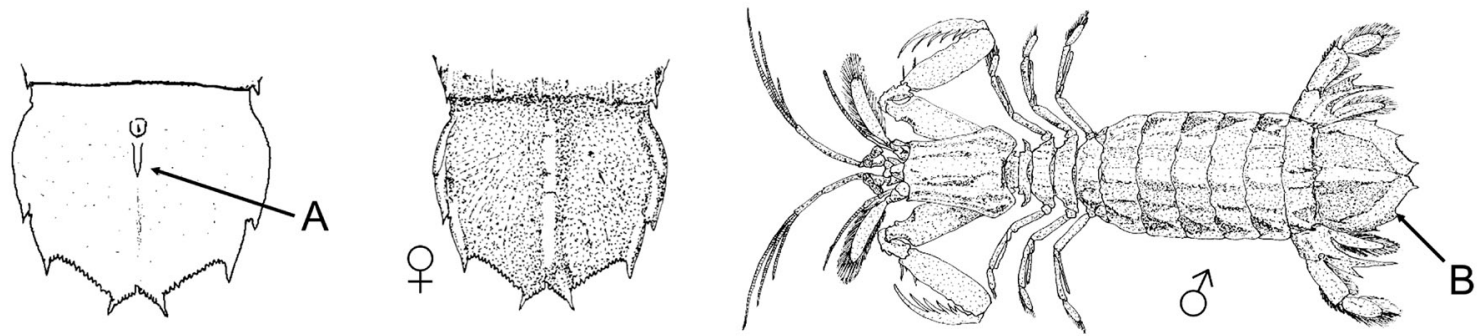

12b. Telson con o sin carina post-anal, cuando está presente nunca termina en espina (Fig. 118). Con o sin dimorfismo sexual, pero las carinas marginales en machos adultos no aparecen como fusionadas

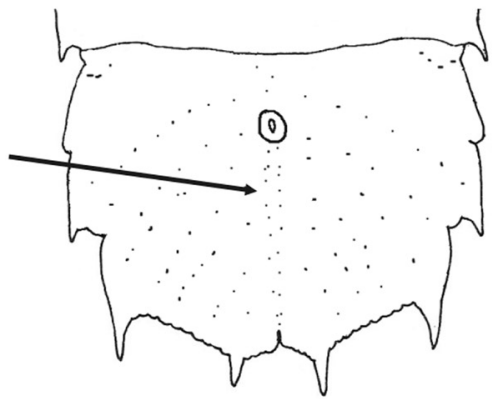

13a. Sólo el sexto somito abdominal presenta carinas submedias terminadas en espina (Fig. 119)

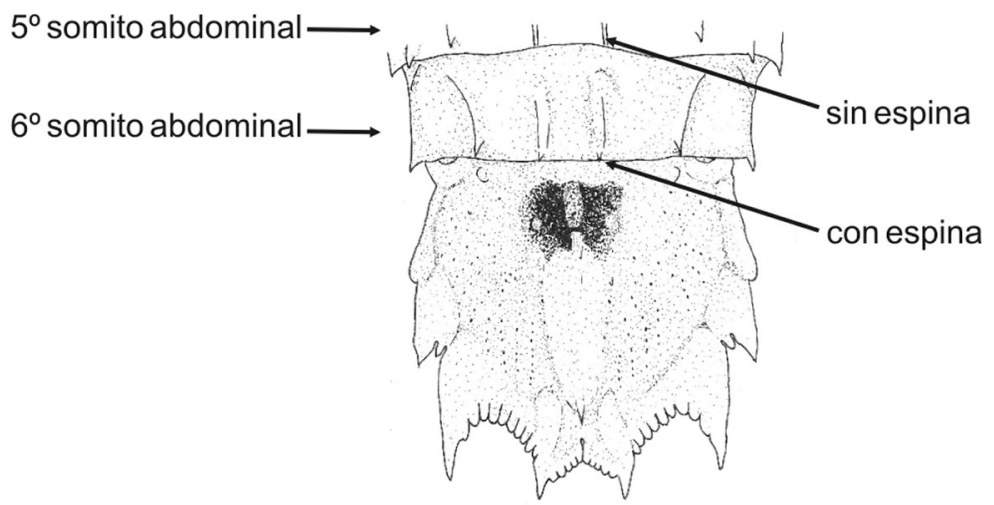

13b. Al menos los somitos abdominales 5 y 6 presentan carinas submedias terminadas en 1 espina (Fig. 120)

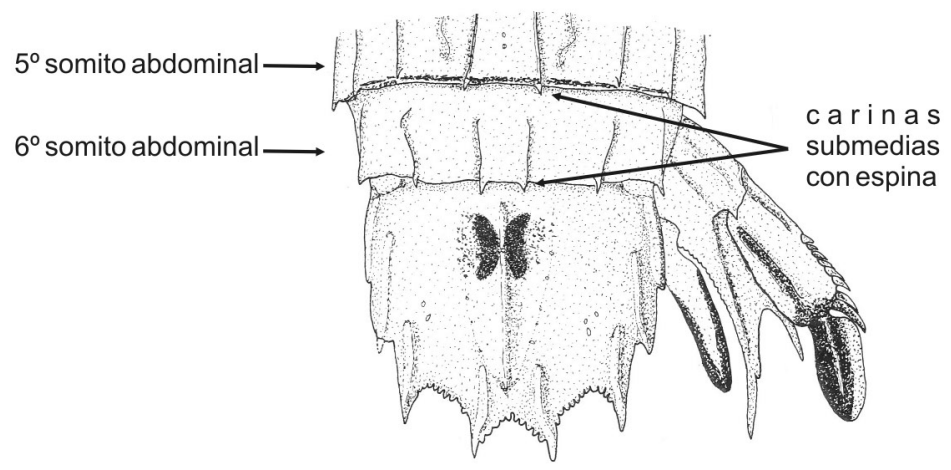


14a. Carina media del caparazón, anterior al surco cervical, con una bifurcación bien marcada (Fig. 121A). Placa rostral con una carina media (Fig. 121B), ocasionalmente las carinas submedias del quinto somito abdominal pueden terminar en espina Squilla mantoidea (golfo de California - Perú; 222 mm; 4-60 m; lodo, arena).
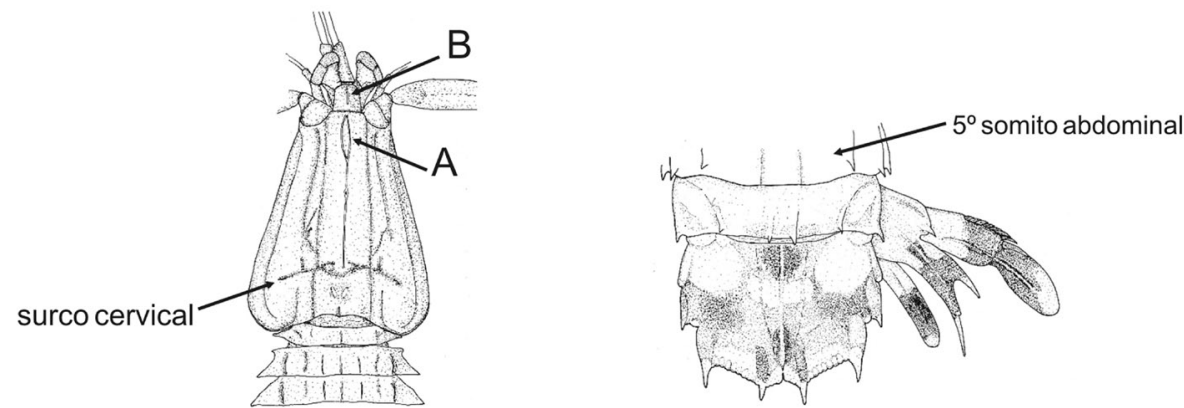

14b. Carina media del caparazón, anterior al surco cervical sin bifurcación (Fig. 122A). Placa rostral sin carina media (Fig. 122B) .15

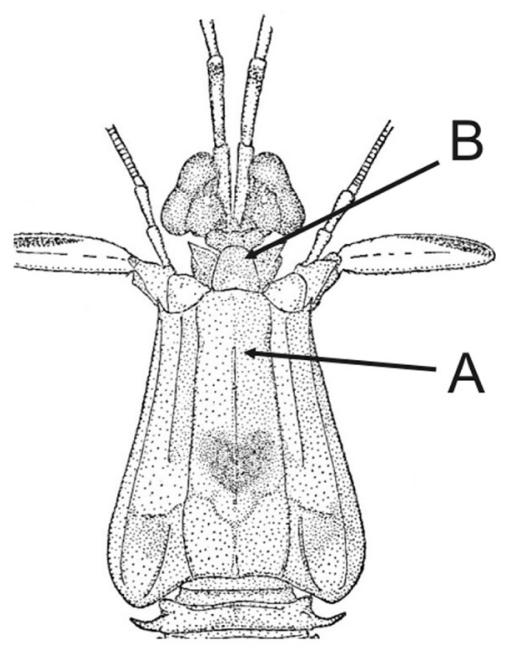

15a. Carina intermedia del caparazón alcanzando el margen anterior del mismo (Fig. 123A). Proceso lateral del quinto somito torácico levemente curvado hacia delante (Fig. 123B). Superficie dorsal del telson con tubérculos a cada lado de la carina media (Fig. 123C) Squilla hancocki (golfo de California - Perú; 105 mm; 20-220 m; lodo).
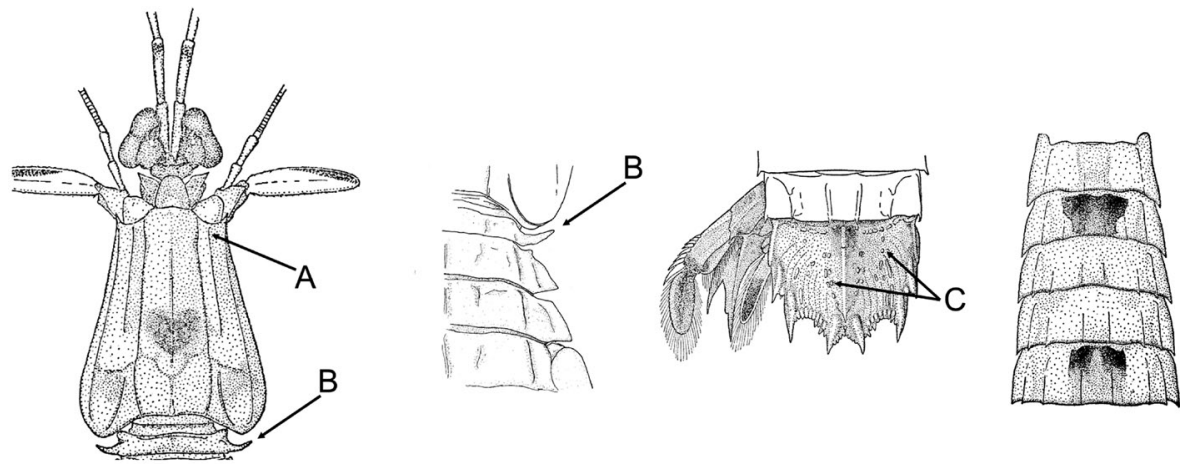
15b. Carina intermedia del caparazón sin alcanzar el margen anterior (Fig. 124A). Proceso lateral del quinto somito torácico fuertemente curvado hacia delante (Fig. 124B). Superficie dorsal del telson sin tubérculos (Fig. 124C), coloración dorsal similar a la de $S$. hancocki Squilla tiburonensis (golfo de California; $109 \mathrm{~mm}$; 15-122 m; arena).
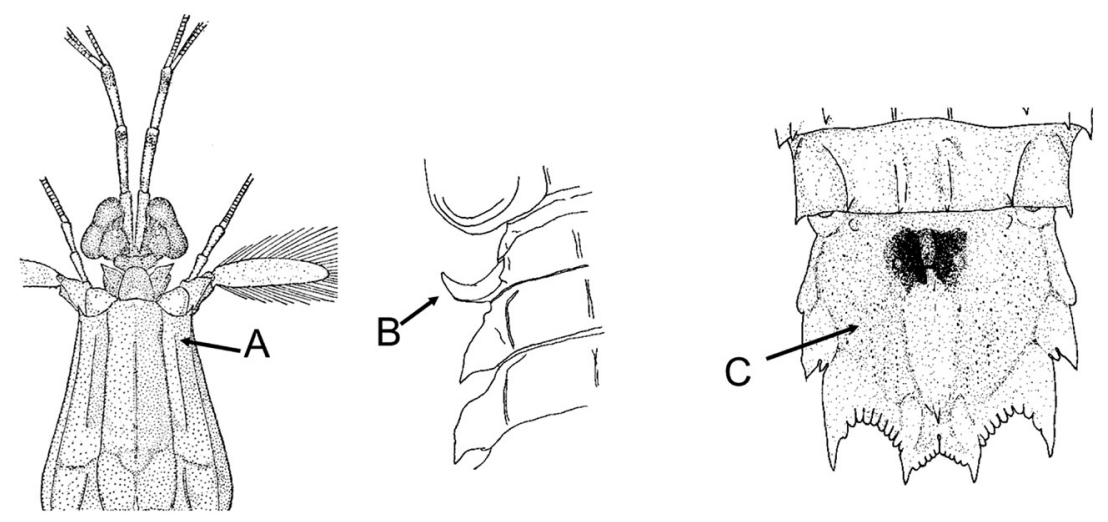

16a. Carina media del caparazón, anterior al surco cervical, sin bifurcación (Fig. 125)

...Squilla parva (golfo de California - Perú; 77 mm; 7-46 m; arena fina).
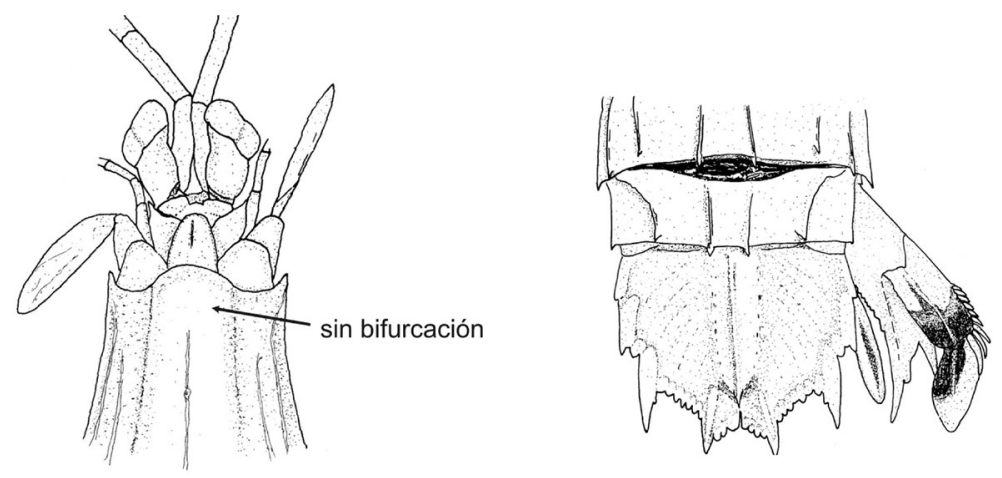

17a. Carinas submedias de los somitos abdominales 4-6 terminadas en una espina posterior (Fig. 126) Squilla panamensis (golfo de California - Perú; 128 mm; 18-102 m; lodo, arena).
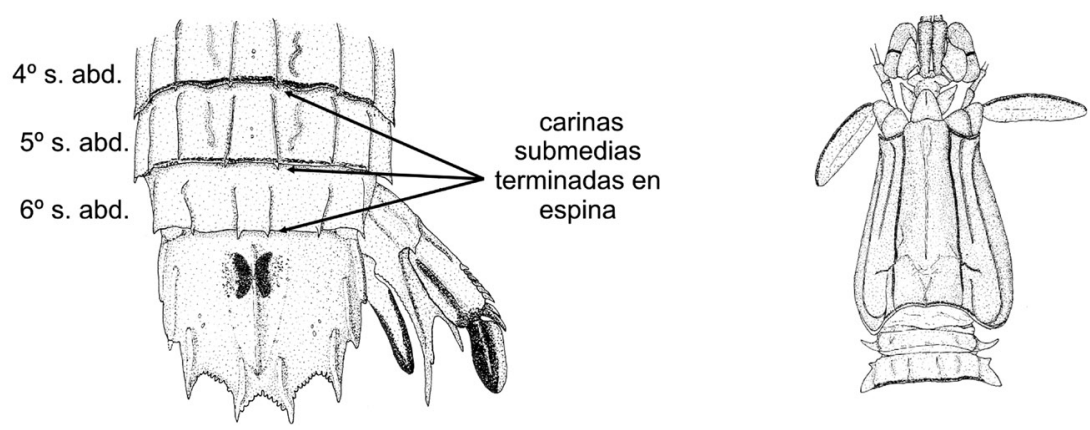
17b. Solamente las carinas submedias del sexto somito abdominal terminadas en una espina posterior (Fig. 127), en 10$15 \%$ de los organismos las carinas submedias del somito abdominal 5 pueden terminar en una espina posterior
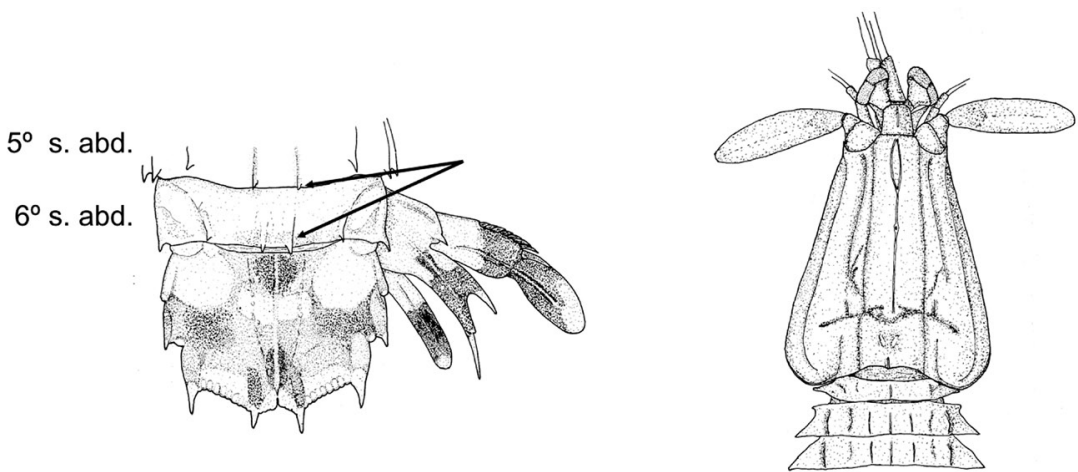

\section{Agradecimientos}

A Judith Arciniega Flores, Universidad de Guadalajara, e Isabel Muñoz García, Universidad de Sinaloa, por sus comentarios al manuscrito. A Fernando Álvarez (IBUNAM) y un revisor anónimo, por sus observaciones y comentarios al manuscrito, y a Rita Vargas (Universidad de Costa Rica), por la revisión del trabajo y por haber proporcionado ejemplares de estomatópodos para su identificación.

\section{Literatura citada}

Ahyong, S. T. y C. Harling. 2000. The phylogeny of the stomatopod Crustacea. Australian Journal of Zoology 48:607-642.

Bigelow, R. P. 1894. Scientific results of explorations by the U.S. Fish Commission Steamer "Albatross" XXXII. Report on the Crustacea of the order Stomatopoda collected by the steamer "Albatross" between 1885 and 1891, and on other specimens in the United States National Museum. Proceedings of the United States National Museum 17:489-550.

Caldwell, R. L. y H. Dingle.1976. Stomatopods. Scientific American 23:80-89.

Guzmán, G. 2002. Crustáceos chilenos. Orden Stomatopoda. Guías de identificación y biodiversidad fauna chilena. Apuntes de Zoología, Universidad Arturo Prat, Iquique [Chile]. p. 1-5.

Hendrickx, M. E. y J. Salgado-Barragán. 1991. Los estomatópodos (Crustacea: Hoplocarida) del Pacífico mexicano. Publicaciones Especiales 10, Instituto de Ciencias del Mar y Limnología, UNAM, México, D.F. 200 p.
Hendrickx, M. E. y J. Salgado-Barragán. 2002. Stomatopoda. In Biodiversidad, taxonomia y biogeografia de artrópodos de México: hacia una síntesis de su conocimiento, vol. III, J. J. Morrone Lupi, J. E. Llorente Bousquets y H. Ponce (eds.). Universidad Nacional Autónoma de México, México, D.F. p. 373-400.

Manning, R. B. 1969. Stomatopod Crustacea of the western Atlantic. Studies in tropical oceanography 8 . University of Miami Press, Coral Gables, Florida. 380 p.

Manning, R. B. 1995. Stomatopod Crustacea of Vietnam: The legacy of Raoul Serène.Crustacean Research, The Carcinological Society of Japan, Tokyo. Special Number 4. 339 p.

Murillo-Bohórquez, C. y R. Álvarez-León. 2004. Nuevos registros y consideraciones biogeográficas de los estomatópodos (Hoplocarida: Stomatopoda) del Pacífico colombiano y comparación con las especies del Caribe colombiano. In Contribuiciones al estudio de los crustáceos del Pacífico este 3, M. E. Hendrickx (ed.). Instituto de Ciencias del Mar y Limnología, UNAM, México, D.F. 15 p.

Reaka, M. L. y R. B. Manning 1980. The distributional ecology and zoogeographical relationships of stomatopod Crustacea from Pacific Costa Rica. Smithsonian Contributions to the Marine Sciences 7:1-29.

Retamal, M. A. 2002. Odontodactylus hawaiiensis Manning, 1967 (Stomatopoda, Gonodactylidae) in Chilean waters. Gayana 66:73-75.

Schmitt, W. L. 1940. The stomatopods of the west coast of America. Based on collections made by Allan Hancock Expeditions, 1933-38. Allan Hancock Pacific Expeditions 5:129-255.

Vargas, R. 2009. Stomatopods. In Marine biodiversity of Costa Rica, Central America, I. S. Wehrtmann y J. Cortés (eds.). Springer, Berlin. p. 193-197.

Zariquiey-Álvarez, R. 1968. Crustáceos decápodos ibéricos. Investigación Pesquera 32:1-510. 